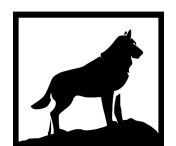

Michigan Technological

18 8 5 University
Michigan Technological University Digital Commons @ Michigan Tech

\title{
MODELS OF FOREST INVENTORY FOR ISTANBUL FOREST USING AIRBORNE LiDAR AND SPACEBORNE IMAGERY
}

Mustafa Kagan Ozkal

Michigan Technological University, mkozkal@mtu.edu

Copyright 2017 Mustafa Kagan Ozkal

Recommended Citation

Ozkal, Mustafa Kagan, "MODELS OF FOREST INVENTORY FOR ISTANBUL FOREST USING AIRBORNE LiDAR AND SPACEBORNE IMAGERY", Open Access Master's Thesis, Michigan Technological University, 2017.

https://doi.org/10.37099/mtu.dc.etdr/371

Follow this and additional works at: https://digitalcommons.mtu.edu/etdr

Part of the Forest Management Commons, and the Other Forestry and Forest Sciences Commons 


\title{
MODELS OF FOREST INVENTORY FOR ISTANBUL FOREST USING AIRBORNE LiDAR AND SPACEBORNE IMAGERY
}

By

Mustafa Kağan Özkal

\begin{abstract}
A THESIS
Submitted in partial fulfillment of the requirements for the degree of MASTER OF SCIENCE

In Forestry
\end{abstract}

MICHIGAN TECHNOLOGICAL UNIVERSITY

2017

(C) 2017 Mustafa Kağan Özkal 
This thesis has been approved in partial fulfillment of the requirements for the Degree of MASTER OF SCIENCE in Forestry.

School of Forest Resources and Environmental Science

Thesis Advisor: Dr. Robert E. Froese

Committee Member: Dr. Nan Pond

Committee Member: $\quad$ Dr. Curtis Edson

School Dean: Dr. Terry Sharik 


\section{Dedication}

“Verily with hardship comes ease.” ASH-SHARH [94:6]

To Turkish people who supported me with their taxes and Mustafa Kemal Atatürk 


\section{Table of Contents}

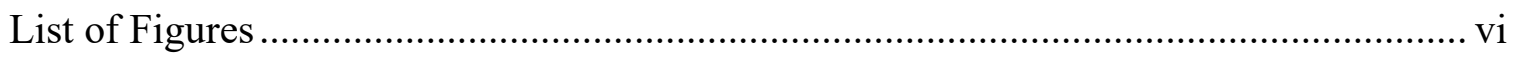

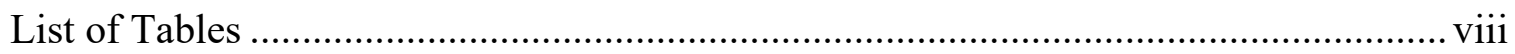

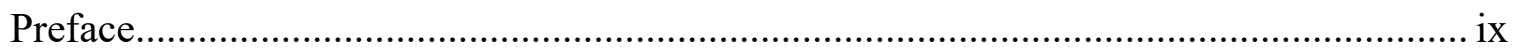

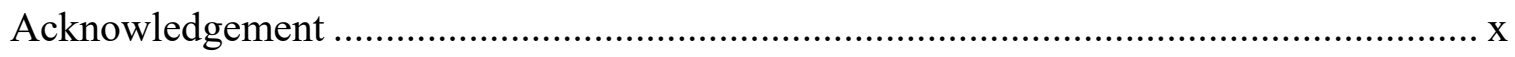

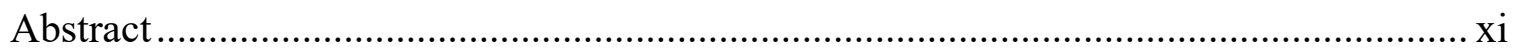

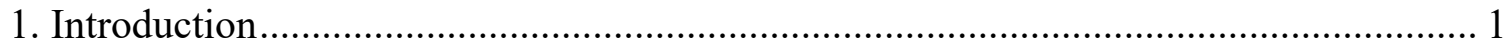

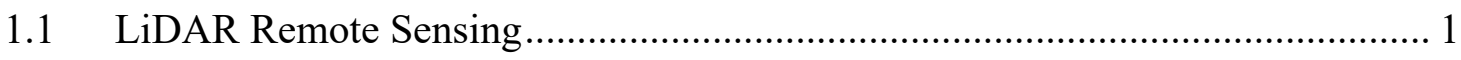

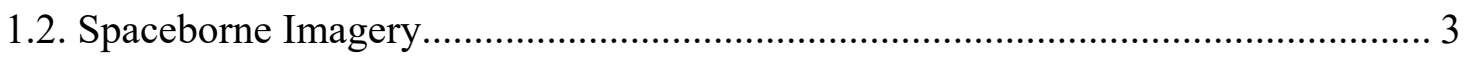

1.3. Statistical methods for inventory modelling ......................................................... 5

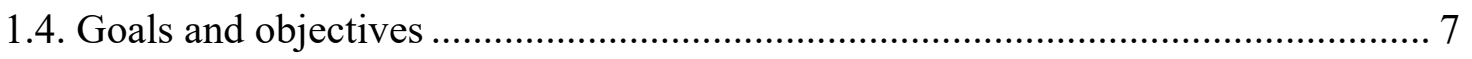

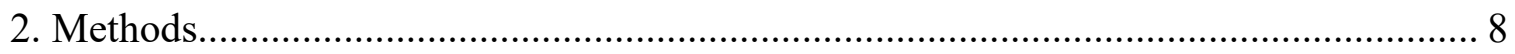

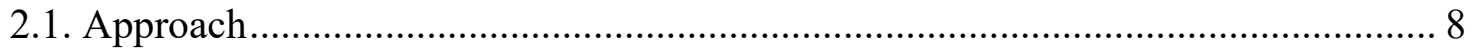

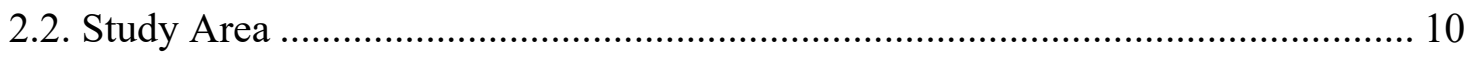

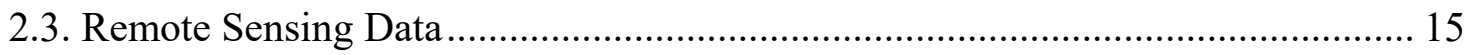

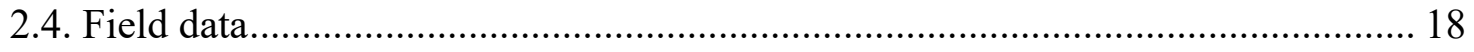

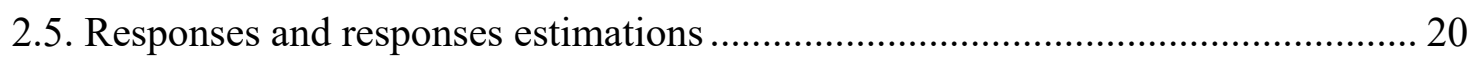

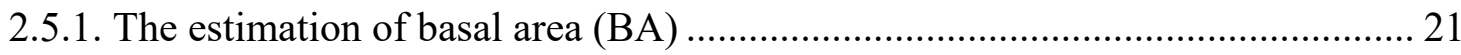

2.5.2. Estimating number of trees ......................................................................... 22

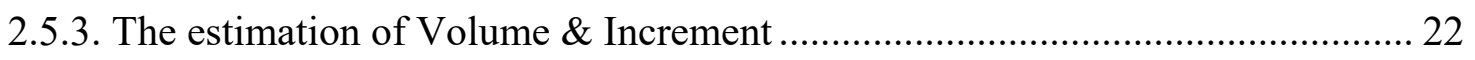

2.5.4. The estimation of Biomass and Carbon Sequestration ....................................... 24

2.5.5. The Abbreviations of Responses ................................................................... 26

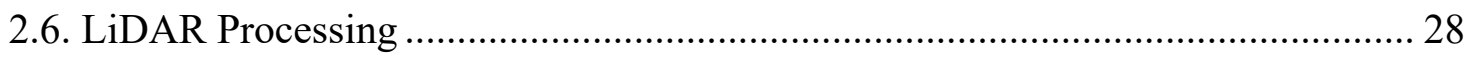

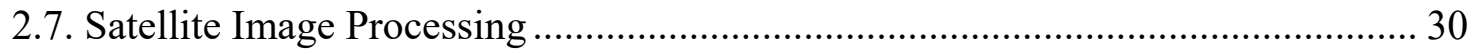

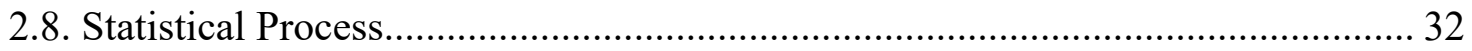

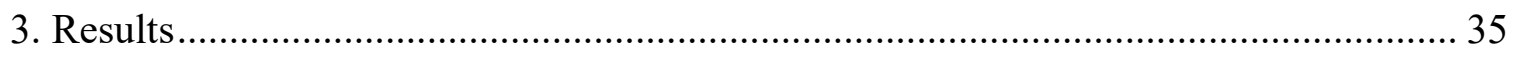

3.1 Models using all remote sensing instruments for oak.......................................... 37

3.2. Models using all remote sensing instruments for maritime pine ........................... 39

3.3. Models Using LiDAR for maritime pine ……….................................................. 41 


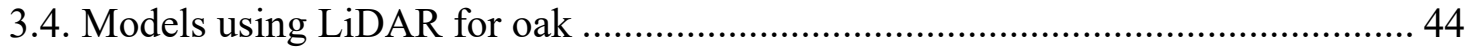

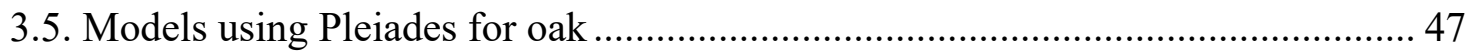

3.6. Models using Pleiades for maritime pine........................................................ 50

3.7. Models using Göktürk-2 for maritime pine ................................................... 53

3.8. Models using Göktürk-2 for oak...................................................................... 56

3.9 Comparisons of predictor sources and modelling methods ............................... 59

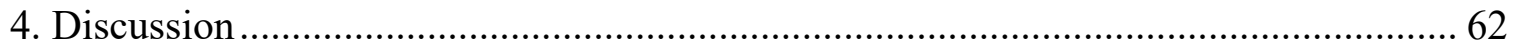

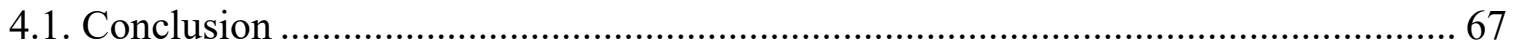

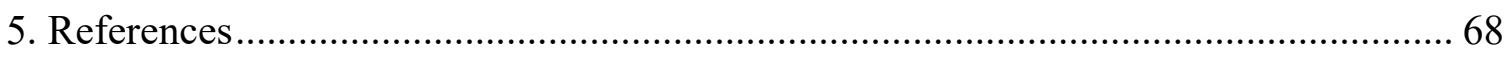

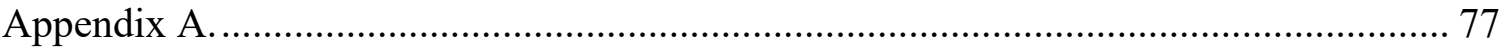




\section{List of Figures}

Figure 1. Process of LiDAR data and satellite images ................................................... 9

Figure 2. Location of the Istanbul Forest, within the city limits of Istanbul, Turkey ....... 11

Figure 3. Average temperature and rainfall for Istanbul (1950-2015)............................ 13

Figure 4. Insect and woodpecker damaged in the field ............................................... 14

Figure 5. Typical crown closure for coniferous (left) and deciduous (right) cover types. 15

Figure 6. Typical ground cover for coniferous (left) and deciduous (right) cover types.. 15

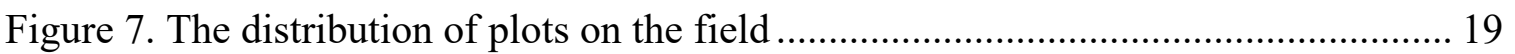

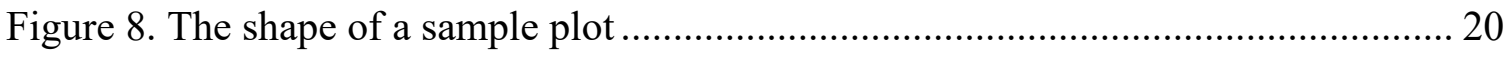

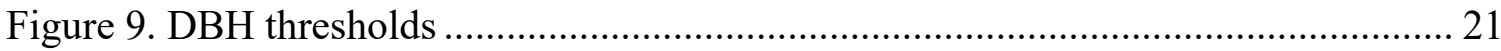

Figure 10. Volume (left) and diameter increment (right) for maritime pine ................... 24

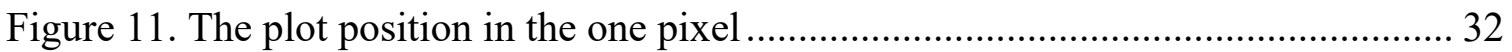

Figure 12. The best 30 predictors derived from RF for the tree count of oak for $\geq 8 \mathrm{~cm}$

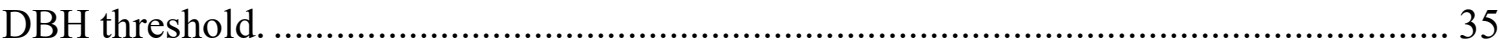

Figure 13. Regression diagnostics for the model of tree count using all instruments for $\geq 8$

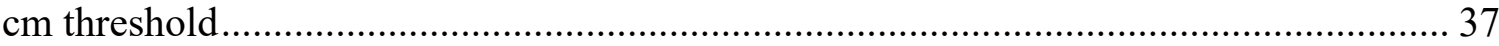

Figure 14. Regression diagnostics for model of tree count using all instruments for all

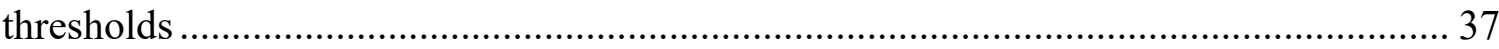

Figure 15. Tree count for $\geq 8 \mathrm{~cm}$ DBH thresholds oak species based on the plot size derived from regression analysis. .......................................................................... 38

Figure 16. Sum DBH for $\geq 8 \mathrm{~cm}$ DBH thresholds Maritime Pine based on the plot size

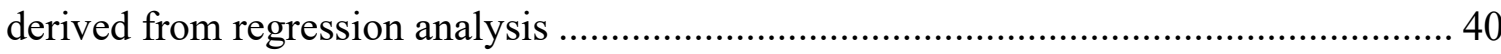

Figure 17. The average underground biomass of Maritime Pine using LiDAR for $\geq 8 \mathrm{~cm}$

DBH threshold derived from regression analysis .................................................... 42

Figure 18. The average under biomass pha for $\geq 8 \mathrm{~cm}$ DBH threshold of Maritime Pine using LiDAR derived from RF- $k \mathrm{NN}$ analysis

Figure 19. Average soil carbon sequestration for $\geq 10 \mathrm{~cm}$ DBH threshold derived from regression analysis ....

Figure 20. The average carbon amount in the soil for $\geq 10 \mathrm{~cm}$ DBH thresholds derived

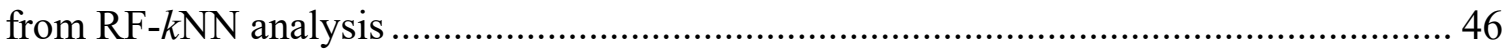

Figure 21.Sum volume based on the plot level derived from regression.......................... 48

Figure 22. Average volume based on the plot level derived from RF- $k$ NN .................... 49

Figure 23.The average carbon amount per hectare for all DBH thresholds derived from

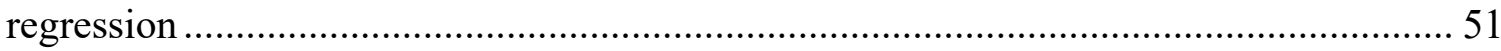

Figure 24. The average carbon amount per hectare for all DBH thresholds derived from $\mathrm{RF}-k \mathrm{NN}$. 
Figure 25. The average general biomass per hectare for all DBH thresholds of maritime pine derived from regression

Figure 26. The average general biomass per hectare for all DBH thresholds of maritime

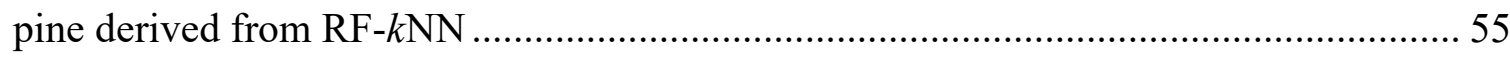

Figure 27. Increment per hectare of oak using regression ........................................ 57

Figure 28. Increment per hectare for $\geq 8 \mathrm{~cm}$ DBH threshold of oak using RF- $k$ NN ........ 58 


\section{List of Tables}

Table 1. General information about remote sensing data .......................................... 16

Table 2. Information about RIEGL Q680i airborne scanning system ........................... 16

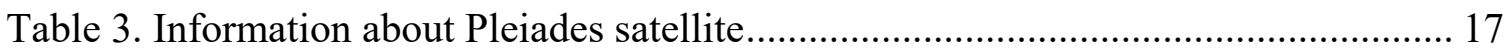

Table 4. Information about Göktürk-2 ................................................................ 18

Table 5. Volume and Increment Tables for two species............................................. 23

Table 6. Summary of the response variables and the abbreviations used........................ 26

Table 7. LiDAR metrics that were calculated for the models...................................... 28

Table 8. Top three predictors chosen for regression analysis for some responses .......... 34

Table 9. Plot-level summary statistics for two attributes for oak and maritime pine cover

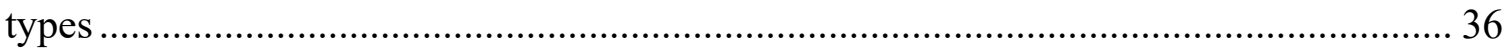

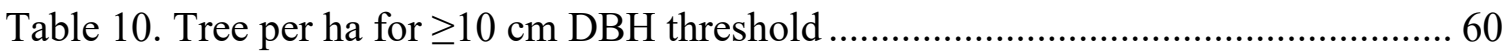

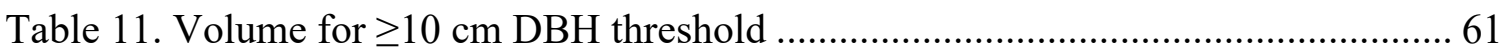

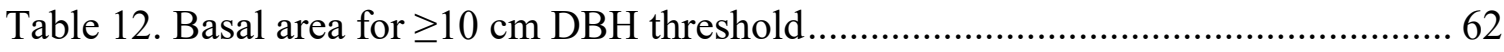

Table 13. Forest inventory using all remote sensing instruments for oak species........... 77

Table 14. Forest Inventory using all remote sensing instrument for maritime species .... 82

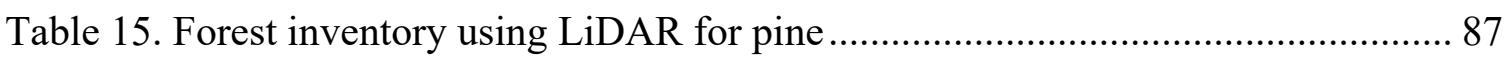

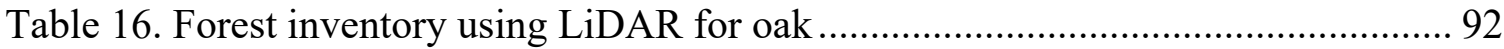

Table 17. Forest inventory using Pleiades for oak ................................................... 97

Table 18. Forest inventory using Pleiades for pine.................................................. 102

Table 19. Forest Inventory using Göktürk-2 for pine ................................................ 107

Table 20. Forest inventory using Göktürk-2 for oak ................................................. 112 


\section{Preface}

This master thesis has one overview. The thesis organized in standard paper format and it will be published in peer reviewed journals. Mustafa Kagan Ozkal, who conducted all the analyzes, created figures and tables, and successfully completed the writing is the first author for this master thesis. The advisor, Robert E. Froese, contributed to this master thesis with designing methodology, building the problem statement, and professional editing. No writing is under copyright and no material has been submitted for publication. 


\section{Acknowledgement}

I appreciate the Republic of Turkey, Ministry of National Education, Ministry of Forestry and Water Affairs, and General Directorate of Forestry for supporting me during my graduate work.

Furthermore, I would like to thank my advisor, Robert E. Froese, for teaching and supporting me. I would not have finished my master without his help. I thank my committee members who are Nan Pond and Curtis Edson.

Moreover, I also would like thank my professors, friends, office mates at Michigan Tech. Some of them are Mike Hyslop, Scott Hillard, Shawn O'Neill, Nancy French, and Mike Battaglia.

As well, I owe many thanks to BIMTAS' workers: Gürcan Büyüksalih, Serdar Bayburt, and other staff who provided Pleiades image and LiDAR data to me.

Additionally, I thank my future colleagues: Rüstem Kiriş, Gediz Metin Kocaeli, Mahmut Aydın, Murat Altunal, Ayten Özdemir and Mustafa Elmas.

Likewise, I would like to thank Ahmet Kutlu, Taşkın Kırgezer, and other staff for help me in the field.

Additionally, I would like to thank Ayşen Sözen, İskender Demirtaş, Nuray Gül, Hüseyin Köse, Behrouz Khoshbakht Irdmousa, Prof. Dr. Ramazan Özçelik, Stephen Jukuri and Turkish community in the US for their reinforcement.

Moreover, I would like to thank my mother Dudu Özkal, my father İbrahim Özkal, my brother Kamil Özkal, and my nephew İbrahim Erdem Özkal and the rest of my family. I could not complete my master's without their support.

Finally, I would like to thank Ömer Halisdemir (RIP), Fethi Sekin (RIP), Neşet Ertaş (RIP), Erkan Oğur and Behzat Ç. for motivating me. 


\begin{abstract}
Active remote sensing technology (LiDAR) and passive remote sensing technology (Pleiades and Göktürk-2 satellites) were used to find a meaningful relationship between ground data and remote sensing instruments for Istanbul Forest, Turkey. Two dominant species in the field, oak (deciduous trees) and maritime pine (coniferous trees), were researched. There were 86 plots total, 41 for maritime pine and 45 for oak. Three diameter at breast height $(\mathrm{DBH})$ thresholds were studied. Trees of any $\mathrm{DBH}(\mathrm{DBH} \geq 0.1$ $\mathrm{cm})$, trees $\geq 8 \mathrm{~cm} \mathrm{DBH}$ thresholds and, trees $\geq 10 \mathrm{~cm}$ DBH thresholds. Both satellite image metrics were derived from Grey Level Co-occurrence Measures (GLCM). All metrics derived from satellite images and LiDAR data were incorporated into a hybrid approach. All metrics were separated and compared to each other to investigate how they are functioning separately. Linear regression, randomForest, and randomForest imputation models were used. The best $\mathrm{R}^{2}$ was 0.90 using three remote sensing instruments for tree counts based on the plot level for oak species. The highest $\%$ explained variances were $67.15 \%$ for tree count based on the plot level for oak species in randomForest model and $55.85 \%$ for tree count based on the plot level for oak species in randomForest Imputation. LiDAR data had a better relationship with ground data. Band 2 and band 4 of both satellite images were stronger predictors for deciduous trees. Band 3 and band 4 of both satellite images were used more for coniferous trees. Some of the most useful GLCM options were entropy for deciduous trees and correlation, variance and second moment for coniferous trees.
\end{abstract}




\section{Introduction ${ }^{1}$}

The remote-sensing discipline has been a source of information used in forest inventory for many years. For instance, in British Columbia, satellite images have been used to update cutting records and maps. Sachs et al., (1998) studied detecting landscape changes in British Columbia using Landsat Thematic Mapper and Multispectral Scanner. Thermal scanners have been used to figure out how many hectares of burning forest lands are in the western United States (Avery and Burkhart, 2002). For example, Fuller (2000) used Landsat thematic mapper and SPOT for biomass burning. The potential of these tools and others to be used for forestry work such as forest type recognition, identifying individual species, timber type maps, measuring heights, tree-crown diameters, tree counts, volume, and crown closure is great, but many technical issues remain to be resolved (Avery and Burkhart, 2002).

Satellite images have been used to predict forest parameters such as tree species, volume, and biomass. Since 1963, terrestrial measurements and aerial photos have been used for forest inventory method to support forest management plans in Turkey (Özkan and Yeşil, 2016).

Volume of individual trees or stands can be estimated with statistics related to ground data and image measurements for selected plots. Then, the results can be extrapolated for large areas. Such methods are usually used for inventory attributes like stand area, stocking, individual tree height or stand height, and tree-crown diameter (Lillesand et al., 2014).

\subsection{LiDAR Remote Sensing}

LiDAR stands for Light Detection and Ranging which is a technology that measures distance with the use of a laser. Aerial LiDAR is an active remote sensing system that sends thousands of laser light pulses per second that hit and then reflect from objects on

\footnotetext{
${ }^{\mathrm{T}}$ This thesis is in preparation for submission to a journal. It might be published in the future.
} 
the ground. The LiDAR system measures distances based on the time of flight for the laser and uses many of the same systems a typical aerial photogrammetric system uses, including global navigation satellite systems (GNSS) and an inertial measurement unit (IMU) mounted in the aircraft to determine the correct location where a laser pulse strikes. LiDAR has an important role in making a forest inventory. LiDAR can measure tree heights relatively quickly and accurately over large areas (Price and Gordon, 2016; Swatantran, 2016).

The LiDAR point clouds give some information about the structure of stands and individual trees, and are useful when paired with ground data (Lillesand et al., 2014). LiDAR can be used for many forest applications such as; forest management (Wulder et al., 2008, Sasaki et al., 2016), forest fire management (Almeida et al., 2016, Hudak et al., 2016), forest biomass and carbon storage (Hopkinson et al, 2016, Singh et al., 2016), and forest inventory (Maack et al., 2016, Hu et al., 2016). Recent research shows that LiDAR can be used for different areas. For instance, Almeida et al., (2016) used a portable profiling LiDAR for fire susceptibility and contrasting fire damage in the Central Amazon. Hopkinson et al., (2016) monitored biomass and carbon storage change in the boreal forest using airborne laser scanning. Moreover, LiDAR and very high resolution images can be used for the horizontal structure characterization in the tropical forest canopy (Dupuy et al, 2013)

Garcia et al., (2010) studied models of different biomass fractions such as branches, total aboveground, and foliage with LiDAR data using stepwise regression analyses for Mediterranean trees. They found $\mathrm{R}^{2}$ as $0.85,0.70$ and 0.90 for black pine (Pinus nigra), Spanish juniper (Juniperus thurifera) and Holm oak (Quercus ilex), respectively.

LiDAR has not been used for Turkish forests in the past. Istanbul is located in between Mediterranean and European-Siberian Flora region, so LiDAR might be an effective way to analyze the Istanbul forest. 


\subsection{Spaceborne Imagery}

Previous studies show us that a grey level co-occurrence matrix (GLCM) could be used for very high resolution satellite images to calculate some forest applications (Franklin et al., 2001; Coburn and Roberts, 2004; Kayitakire et al., 2006; Murray et al., 2010; Wunderle et al., 2007; Ozdemir and Karnieli, 2011; Castillo et al., 2010; Beguet et al., 2012). GLCM, which is a texture analysis, can characterize the relationship between two gray-tone neighboring pixels with four directions $\left(0^{\circ}, 45^{\circ}, 90^{\circ}\right.$, and $\left.135^{\circ}\right)$ (Haralick et al., 1973). These pixels are called reference and neighbor pixels. The amount of neighbor pixels are set with process window sizes (Murray et al., 2010).

Many windows processing sizes may be useful to find compatible windows processing for the field similar to what was done by Dash et al., (2015). Those authors mentioned that they calculated GLCM with four different window sizes that were $3 \times 3,5 \times 5,15 \times$ 15 and $25 \times 25$ pixels for seven vegetation indices such as Normalized difference vegetation index (NDVI), Enhanced vegetation index (EVI), Red edge ratio (RE), Simple ratio (SR), Green ratio (GR), Vegetation index (VI), and Brightness computed from $5 \mathrm{~m}$ resolution RapidEye satellite data. The authors did this to characterize forest structure with airborne laser scanning data.

Beguet et al., (2012) mentioned that very high resolution satellites have been used to estimate forest inventories for many years. Many approaches have been used to obtain metrics from high resolution imagery satellites. Grey Level Co-occurrence Matrix (GLCM) is one of them. GLCM can provide better results and easier processing than other approaches for forest parameter estimations. GLCM, which are second order statistics built by $2 \mathrm{D}$ histograms, has 8 different features types that were used in remote sensing recently. Its application could be less complex compared with other texture applications such as wavelets and Gabor filters. Higher $\mathrm{R}^{2}$ and the coefficient of correlation can be found using GLCM process for Pleiades satellite image with multiple 
linear regression for forest structure variables such as tree height, diameter at breast height (DBH), basal area, age, density, tree spacing, and crown diameter.

Eckert (2012) described that aboveground biomass and carbon stock have increased attention in the scientific world with the United Nations Framework Convention on Climate Change (UNFCCC) and the Kyoto Protocol. Some remote sensing approaches could be applied for these forest attributes. GLCM texture measures were calculated for WorldView-2 satellite images which have $0.5 \mathrm{~m}$ spatial resolution using five different windows sizes from $15 \times 15$ pixels to $23 \times 23$ pixels. Stepwise multiple linear regression models were calculated for the estimation of carbon stock and biomass.

Remote sensing also has important roles in mapping and classification of land cover features. Kalkan et al., (2011) demonstrated how vegetation discrimination was important using very high resolution satellite images (Göktürk-2) and Landsat-8. They applied some vegetation indices such as the NDVI. The results showed that both satellite images gave almost the same result in using NDVI. Other investigations determined that using only vegetation indices may not be enough to calculate forest inventories for Göktürk-2 images. So, the GLCM can be readily applied to Göktürk-2 satellite image because SPOT-5 XS have the same spatial resolution with Göktürk-2. GLCM was applied to SPOT-5 XS satellite image to estimate basal area, tree volume, and biomass by CastilloSantiago et al., (2010).

There is little research about Göktürk-2 in the forestry discipline. So, this situation enforced need for this project to find a new method using previous research that used satellites having similar feature such as SPOT-5 XS, ALOS, CARTOSAT-1. According to Ozdemir (2004), SPOT and Landsat satellites have been used for making inventories. These satellites pass over Turkey during the morning hours which is a disadvantage for satellite inventories because the sunshine cannot brighten the trees uniformly, and the tree shadows attenuate the satellite images. So the satellite image should be acquired around June to minimize this disadvantage. 
Satellite image inventories should include near infrared $(0.7-3 \mu \mathrm{m})$ to categorize plant cover for getting maximum benefit. The healthy components of vegetation reflects near infrared and infrared. In this case, the researchers usually use near infrared and infrared band in their satellite images studying. Also, the 4th band of Landsat TM and ETM, which has 0.76-0.90 $\mu \mathrm{m}$, and 3rd band of SPOT, which has $0.78-0.89 \mu \mathrm{m}$, could be used to categorize plant cover (Ozdemir, 2004). The Band 4 of Pleiades which is NIR (0.75$0.95 \mu \mathrm{m})$ and the band 4 of Göktürk-2 image which is NIR band $(0.76-0.90 \mu \mathrm{m})$ may provide excellent results for forest inventory.

Dalponte et al. (2012), described that they used two LiDAR acquisitions: 0.48 points per $\mathrm{m}^{2}$ and 8.6 points $\mathrm{m}^{2}$ combined with airborne high spatial resolution hyperspectral and high spatial resolution multispectral images for tree species classification in the southeastern part of the Province of Trento, Italy, in the Southern Alps. They found that high density LiDAR can provide more information about tree species classification when combined with either multispectral or hyperspectral data.

LiDAR and satellite images were not used for only forest parameters. They were also used for predicting avian diversity. Wallis et al. (2016) claims that they used the NIR band image of Quickbird satellite to calculate GLCM metrics for three vegetation indices, which are NDVI, Physiological reflectance index (PRI), and carotenoid/chlorophyll ratio, and some LiDAR metrics for predicting avian diversity in a tropical forest in the southeastern Ecuador.

\subsection{Statistical methods for inventory modelling}

A number of statistical methods have been used for modeling of inventory data (Brosofske et al., 2014). Popular methods include (i) Random Forest (RF) (Hudak et al., 2008; Falkowski et al., 2009; and Guo et al., 2011), (ii) $k$-nearest neighbor $(k N N)$ imputation, (Hudak et al., 2008; Martinuzzi et al., 2009; and Hudak et al., 2009) and (iii) linear regression analysis (Hyde et al., 2005; Brandtberg et al., 2005; and Popescu et al., 
2003). Each could be used to find a correlation between remote sensing instruments and ground data for this research.

$\mathrm{RF}$, which is a statistical method, is an ensemble method for regression and classification. $\mathrm{RF}$ is run by building a multitude of decision trees that become a large forest. It develops lots of decision tree based on random selection of data and random selection of variables. (Breiman, 2001). RF has been successfully used for classification and prediction of forest inventory. For example, Beguet et al., (2014) performed an RF classification to derive four forest structure classes using a Pleiades satellite image. Panchromatic and multispectral had the best performing texture features. Texture, which is one of the important qualifications, can be used in detecting patterns in satellite images or an aerial photograph (Haralick et al,, 1973).

Another method is $k$-nearest neighbor $(k \mathrm{NN})$ imputation, where multiple forest variables are predicted for unsampled pixels from average $k$ closest samples in $k \mathrm{NN}$ at the same time (Ohmann and Gregory, 2002). In this case, $k$ means the number of nearest neighbors.

According to Hudak et al., (2009) there were many approaches to the nearest neighbors when constructing maps using $k \mathrm{NN}$ imputation. These include normalized and unnormalized Euclidean distance, RF, canonical correspondence Analysis, Mehalanobis distance, canonical correspondence analysis, and independent component analysis. When $\mathrm{RF}$ is used with $k \mathrm{NN}$ (hence, RF- $k \mathrm{NN}$ ) an RF model is first fit and then used to select the nearest neighbor. Hudak et al., (2009) found that random forest outcomes had better Root Mean Square Distance (RMSD) for basal area and tree density.

RF- $k$ NN has become popular for forest inventory modelling. For example, Falkowski et al., (2010), used $k \mathrm{NN}$ imputation models to incorporate LiDAR data to tree level inventory data such as DBH, species and individual tree height. They had high forest inventory metrics respectively, but the error of small trees forest inventory metrics were considerably higher. 
Dash et al., (2015) developed RF $k \mathrm{NN}$ imputation models to define ground data and some vegetation indices derived from the GLCM method using yaImpute package of the R statistical software to characterize forest structure using both RapidEye satellite imagery and airborne laser scanning (ALS). RF- $k \mathrm{NN}$ imputation can be applied efficiently to very large datasets (Deo et al., 2016).

$\mathrm{RF}$ and RF- $k \mathrm{NN}$ are nonparametric techniques that take advantage of modern computing power, but an alternative is the use of linear regression. Regression has an advantage over $\mathrm{RF}-k \mathrm{NN}$ in that interpolation is possible, and over RF in that if the regression surface is mechanistically meaningful then more accurate interpolation is possible. Andersen, McGaughey, and Reutebuch (2005) used stepwise regression to create possible forest canopy models. They found higher $\mathrm{R}^{2}$ for crown bulk density, canopy height and canopy base height. However, increasing the number of independent variables in the regression models decreases the degrees of freedom (Pandey and Bright, 2008) and therefore applying regression to small data sets may be problematic.

According to U.S. Forest Service LiDAR training (2014), they specified predictors from the regsubsets function in $\mathrm{R}$ to find top 4 variable sets for regression analysis. Similarly, in this research, the top 3 variables from RF importance tables were used to detect predictors for regression analysis because of having a large dataset.

\subsection{Goals and objectives}

Turkey's forestland is divided into 1484 forest districts. Each district has its own forest management plans which have information about the forest such as economic, ecological, and sociocultural functions the history and current state of the forest, and planning the future condition of the forest. There is little research using Pleiades and Gökturk-2 for forest inventory globally and no research about LiDAR forest research in Turkey. Recently, LiDAR data were collected for the Istanbul Forest. Hence, there is a great opportunity to advance the use of remote sensing for forest inventory and management in Turkey. 
The goal of this research was to develop inventory models for Istanbul forests using the best available remote sensing data and evaluate their quality. The first objective of this thesis is to demonstrate that very high resolution images and LiDAR data can be used to improve forest inventory techniques. The second objective is to determine how very high resolution satellite images combined and separated with LiDAR data affect making forest inventories. This project was supported by the Republic of Turkey, Ministry of National Education, Ministry of Forestry and Water Affairs, and General Directorate of Forestry.

\section{Methods}

\subsection{Approach}

The overall strategy was to fit many models using competing contemporary methods to predict inventory attributes from remote sensing variables. Afterwards, the models were compared based on fit statistics and, based on visual assessment of predictions, the apparent utility for generating output maps.

To fit the models ground data was georeferenced to link to the remote sensing data using GPS coordinates. Many remote sensing metrics were calculated, and LiDAR and optical data were combined in different ways to find the best model based on fit statistics like $\mathrm{R}^{2}$ (for linear regression models) or \% explained variance (for random forest models.).

A generalized representation of the workflow involved in processing remote sensing data sets, combining field data and predictors, fitting and then applying models, is shown in Figure 1 and described in detail in the following sections. Software used included ERDAS Imagine 2015, ENVI version 5.2, ArcGIS 10.3.1, Fusion 3.60, RStudio version 0.98.1103, and R 3.2.0. 


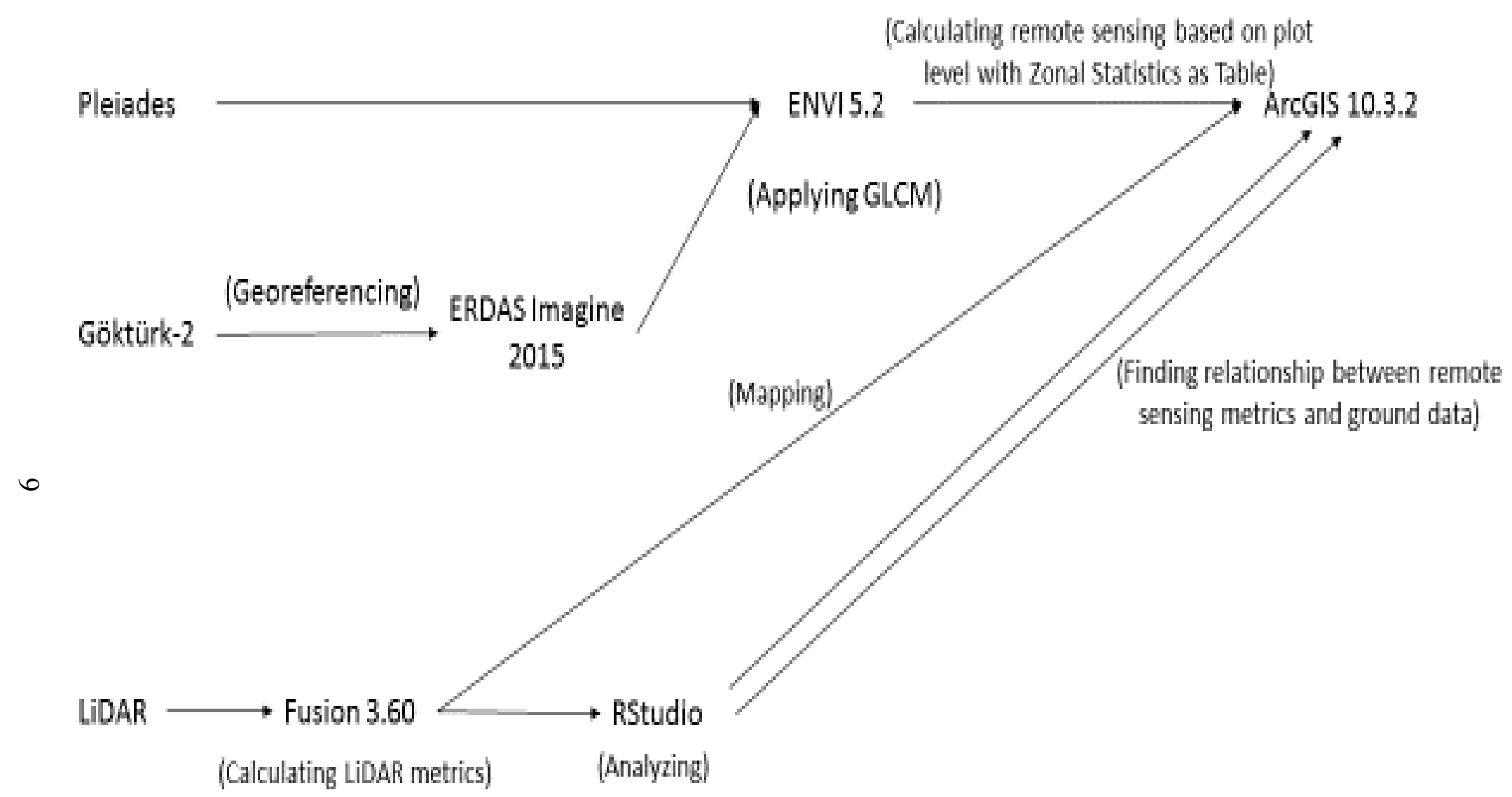

Figure 1. Process of LiDAR data and satellite images 


\subsection{Study Area}

The study area is a portion of Istanbul Forest, located in Turkey (Figure 2). This location was chosen because it was an interesting opportunity to study a forest in the eastern Mediterranean where LiDAR data were available. The area includes legacy irrigation infrastructure dating to the 1600 s to satisfy people's water needs. So, the research field is known as Bentler which means "embankments" in Turkish.

The study area boundary is an administrative unit of the Turkish Forest Service and thus provides a general frame of reference, not an absolute limit on the area interest. In the Geographic Coordinate System; it is located between $41^{\circ} 13^{\prime} 31^{\prime \prime}-41^{\circ} 08^{\prime} 54^{\prime \prime}$ the northern latitude and $28^{\circ} 55^{\prime} 59^{\prime \prime}-29^{\circ} 01^{\prime} 02^{\prime \prime}$ the east longitude. The study area is a $\sim 3000$ ha administrative unit of the Turkish Forest Service. 


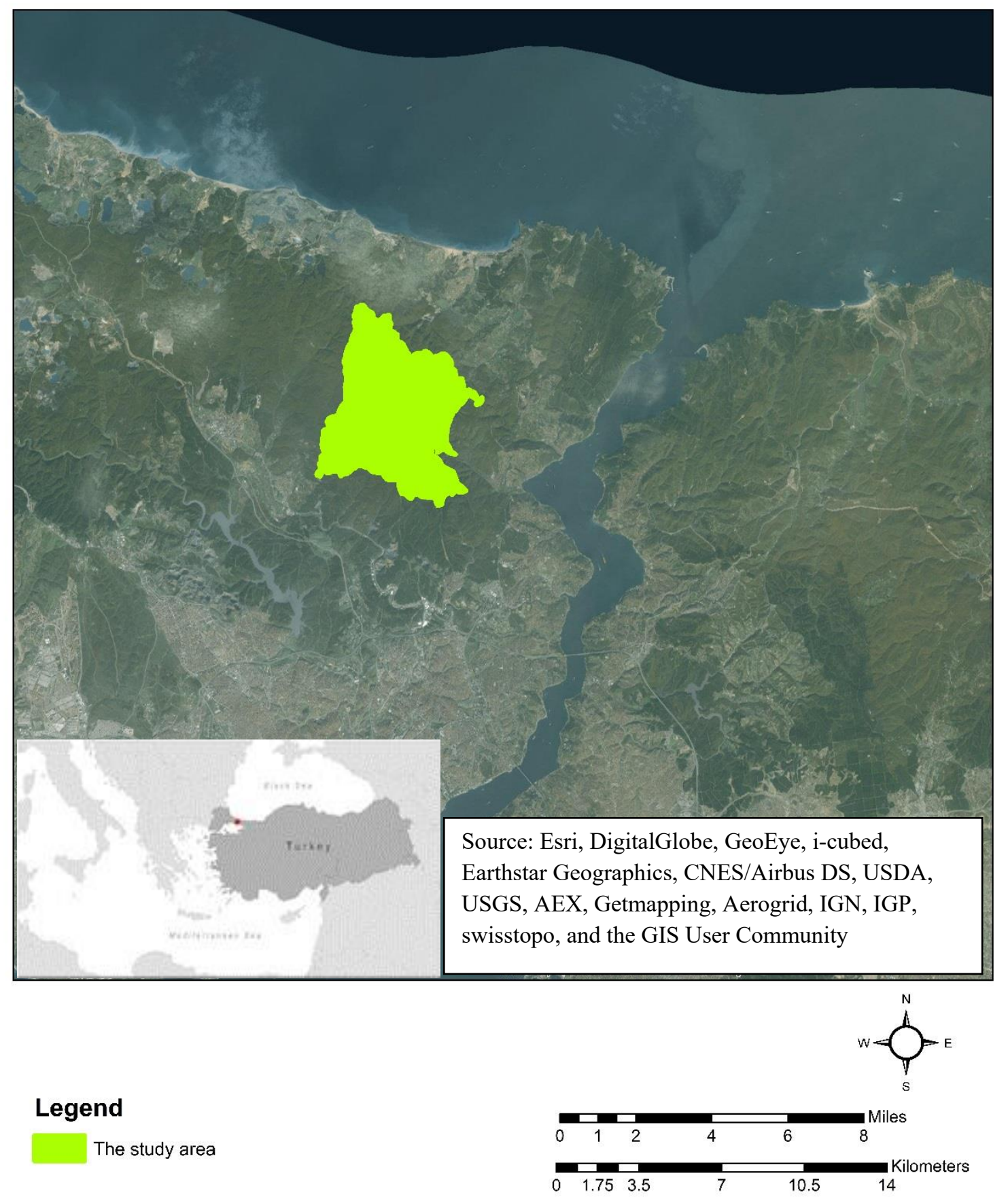

Figure 2. Location of the Istanbul Forest, within the city limits of Istanbul, Turkey 
The altitude in the study area ranges from 30-219 $\mathrm{m}$ above sea level. The highest hill in the study area is the Kokmus (219 m). Other main hills are Tavsan (177 m), Kumluk, Küçükbaglar (136 m), and Havuzlar (132 m).

According to the Bentler forest management plan (2012), the forest area is 3094 ha. Of this, 2892 ha is wooded and 202 ha is unwooded. Furthermore, 2591 ha is productive, 326 ha is unproductive, and 177 ha is open area.

The area is volcanic dating from Paleozoic, Neogene, Quarternary, and Eruptive geologic time periods. The soil structure of the study area is mostly rockless, with some conglomerate and less lime. The soil type is brown forest soil (Forest management plan, 2012).

The Istanbul Forest is located in the Marmara region of northwestern Turkey. The Marmara climate is hot and arid in the summer, and is temperate and rainy in the winter. Annual precipitation is $1074.4 \mathrm{~mm}$. The annual relative humidity rate average is $73 \%$ (Forest management plan, 2012).

According to meteorological data, the highest temperature is $39.7^{\circ} \mathrm{C}$ in August and the lowest temperature is $-15.8{ }^{\circ} \mathrm{C}$ in January. Annual average temperature is $12.8^{\circ} \mathrm{C}$. According to the forest management plan, the eight month growing period is between April and November. The average temperature is $15.8^{\circ} \mathrm{C}$ during the vegetation period. Frost present is 33 days (Figure 3). 


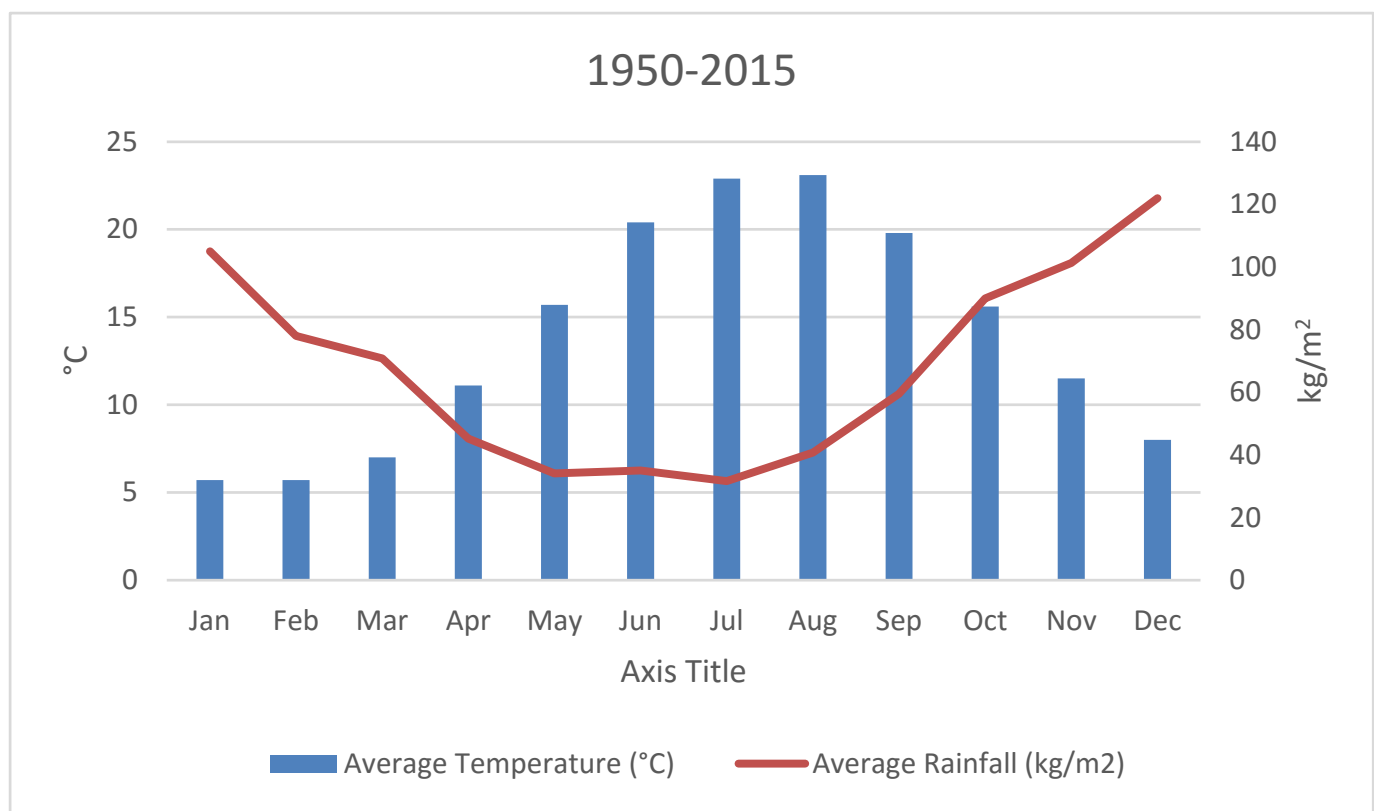

Figure 3. Average temperature and rainfall for Istanbul (1950-2015)

The major trees in the field are oak (Quercus spp.), beech (Fagus spp.), hornbeam (Carpinus spp.), chestnut (Castenea spp.), alder (Alnus spp.), ash (Fraxinus spp.), linden (Tilla spp.), Turkish red pine (Pinus brutia), black pine (Pinus nigra), yellow pine (Pinus sylvestris), nut pine (Pinus pinea), and maritime pine (Pinus pinaster). Cover types dominated by oak and maritime pine were chosen for this thesis because they are the dominant species for hardwood and softwood.

The plants in the field are Middle European and Balkan's flora. There are more than 50 woody plants which are: sessile oak (Quercus petraea), English oak (Q.robur), Aleppo oak, (Q.infectoria),Hungarian oak (Q.frainetto), Turkey oak (Q.cerris), kermes oak (Q.coccifera), oriental beech (Fagus orientalis), sweet chestnut Castanea sativa, common alder (Alnus glutinosa), European hornbeam (Carpinus betulus), common hazel (Corylus avellana), European aspen (Populus tremula), white willow (Salix alba), grey willow (Salix cinerea),field elm (Ulmus minor), bay laurel (Laurus nobilis), Gallipoli rose (Cistus salvifolius), hawthorn (C.cretigus), silver linden (Tilia tomentosa), the field maple (Acer campestre), Heldreich's maple (A.trautvetteri), common holly (Ilex 
aquifolium), European spindletree (Evonymus europeus), alder buckthorn (Frangula alnus), osyris (Osyris alba), European blackberry (Rubus fruticosus), hirsute raspberry (R.hirsitus), woolly blackberry (R.tomentosus), dog-rose (Rosa canina), gallic rose (R.gallica), wild service tree (Sorbus torminalis), oleaster-leafed pear (Pyrus alaegrifolia), the European crab apple (Malus sylvestris), the scarlet firethorn (Pyracantha coccinea), single-seeded hawthorn (Crataegus monogyna), common medlar (Mespilus germanica), cherry plum (Prunus divaricate), cherry laurel (P. laurocerasus), wild cherry (P.avium), blackthorn (P.spinosa), Dyer's greenweed (Genista tinctoria), genista (G.carinalis), Spanish broom (Spartium junceum), twin-flowered (Daphne pontica), cornelian cherry (Cornus mas), midwinter fire (Cornus sanguinea), strawberry tree (Arbutus unedo), tree heath (Erica arborea),erica (E.verticillata), heather (Calluna vulgaris), green olive tree (Phyllyrea latifolia), European privet (Ligustrum vulgare), and danewort (Sambucus ebulus).

There were some insect and woodpecker damaged in the field (Figure 4).

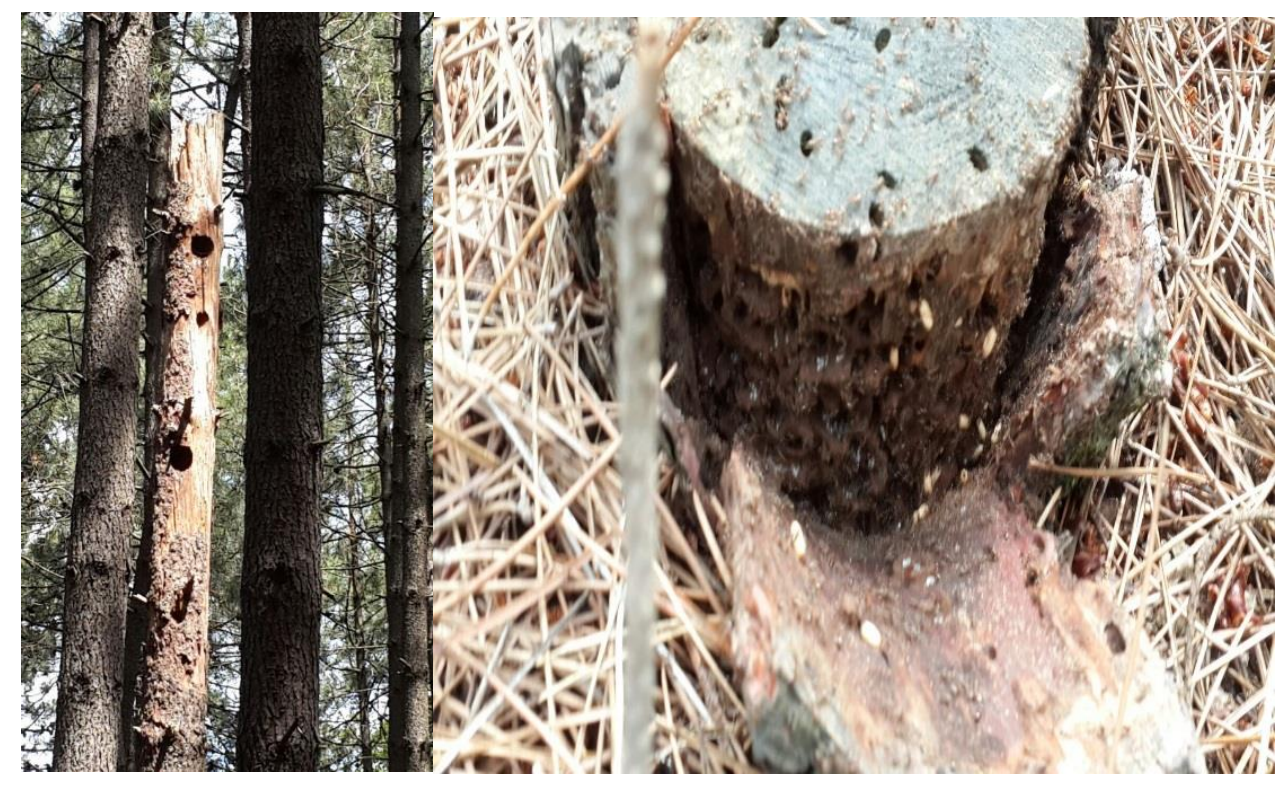

Figure 4. Insect and woodpecker damaged in the field

The crown closure is generally high and more ground cover and under story occur under coniferous species than deciduous trees (Figure 5 and Figure 6). 


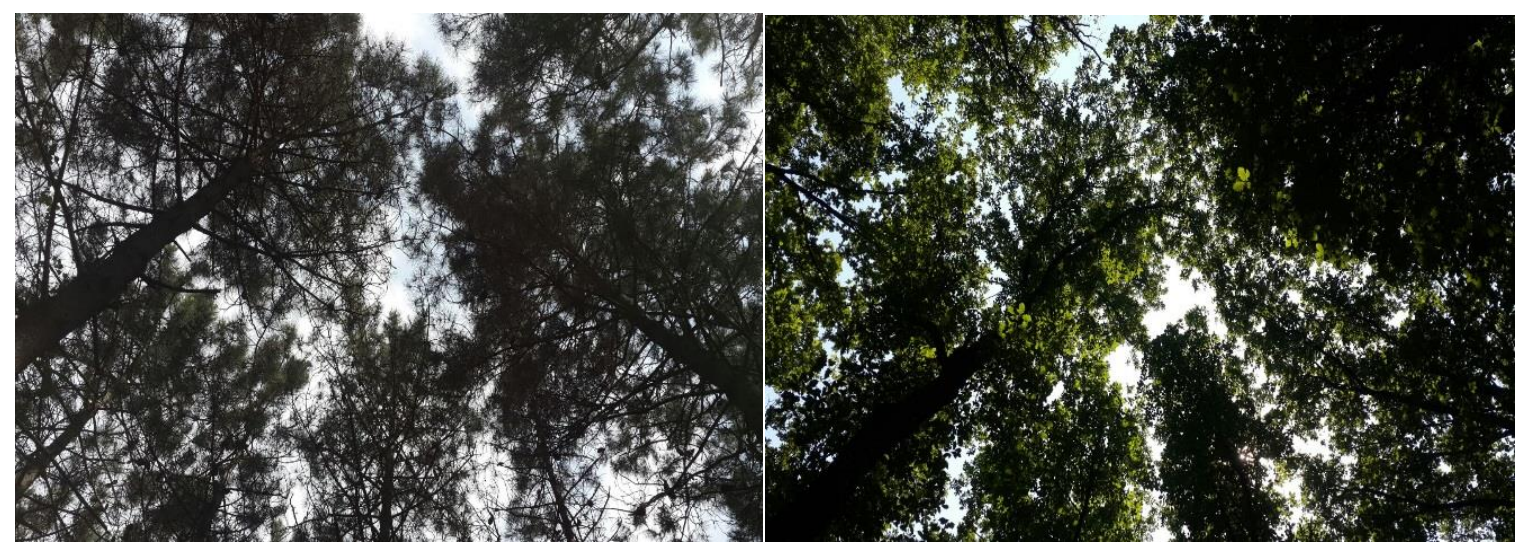

Figure 5. Typical crown closure for coniferous (left) and deciduous (right) cover types.

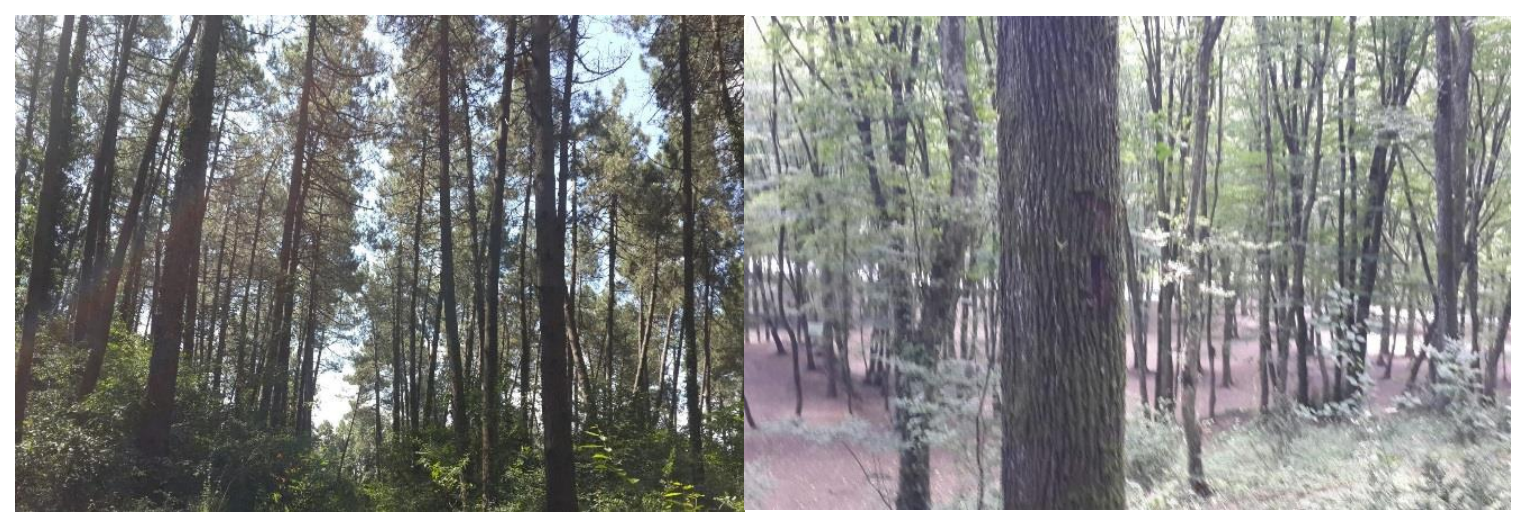

Figure 6. Typical ground cover for coniferous (left) and deciduous (right) cover types.

\subsection{Remote Sensing Data}

The data sets that were available for this research include: (1) LiDAR, in the form of LAS files, where the data were collected in early October 2012; (2) a Pleiades image, which was taken on May 12 2014; and, (3) a Göktürk-2 image which was obtained in July 2015 (Table 1). 
Table 1. General information about remote sensing data

\begin{tabular}{|c|c|c|c|}
\hline Data & Data collected & $\begin{array}{c}\text { Spatial Resolution } \\
\boldsymbol{\&}\end{array}$ & $\begin{array}{c}\text { Spectral Bands for } \\
\text { satellites } \\
\end{array}$ \\
& & $\begin{array}{c}\text { Pulse Density for } \\
\text { LiDAR }\end{array}$ & \\
\hline LiDAR & Early October, in & $12-16$ pulses per $\mathrm{m}^{2}$ & \\
& 2012 & & \\
\hline Pleiades & May 12, 2014 & $0.5 \mathrm{~m}$ & R G B IR \\
\hline Göktürk-2 & July 23, 2015 & $2.5 \mathrm{~m}$ & R G B IR \\
\hline Landsat-8 & May 30, 2014 & $15 \mathrm{~m}$ & 11 Bands \\
\hline
\end{tabular}

LiDAR data were collected with a RIEGL Q680i airborne scanning system during leaf-on conditions by Boğaziçi İnşaat Mühendislik A.Ş. (BİMTAŞ), which is a company working under the Istanbul Metropolitan Municipality in Turkey (Table 2). After collecting the LiDAR data, their aims are to restore historical places, infrastructure, superstructure, etc. The flight altitude was $500 \mathrm{~m}$ above ground level and the pulse density was 12 pulses per meter in urban places and was 16 pulses per meter in forested places. The reason for more pulses in forested places was that there were not enough objects to absorb the laser.

Table 2. Information about RIEGL Q680i airborne scanning system

\begin{tabular}{|c|c|}
\hline Minimum Range & $30 \mathrm{~m}$ \\
\hline Accuracy & $20 \mathrm{~mm}$ \\
\hline Precision & $20 \mathrm{~mm}$ \\
\hline Laser Pulse Repetition Rate & Up to $400000 \mathrm{~Hz}$ \\
\hline Effective Measurement Rate & Up to $266 \mathrm{kHz} @ 60^{\circ}$ scan angle \\
\hline Laser Wavelength & Near infrared \\
\hline Laser Beam Divergence & $\leq 0.5 \mathrm{mrad}$ \\
\hline
\end{tabular}


The Pleiades satellite image was also provided by BIMTAS who bought the data from NIK System, a distributor of remote sensing products in Turkey. Pleiades satellites were launched in 2011 and 2012 by Centre National D'Etudes Spatiales (CNES). The satellites are used for civil and military purposes. The imaging swath is $20 \mathrm{~km}$ at nadir and the revisit interval is daily. They have single pass mosaics up to $100 \mathrm{~km} \times 100 \mathrm{~km}$ (Table 3). The satellite image for this study was taken on May 12, 2014.

Table 3. Information about Pleiades satellite

\begin{tabular}{|c|c|}
\hline \multirow{4}{*}{ Spatial Resolution } & Panchromatic: $50 \mathrm{~cm}$ \\
\cline { 2 - 2 } & Multispectral: $2 \mathrm{~m}$ \\
\cline { 2 - 2 } & Pan-sharpened: $50 \mathrm{~cm}$ \\
\hline \multirow{4}{*}{ Spectral Bands } & Panchromatic: $0.48-0.83 \mu \mathrm{m}$ \\
\cline { 2 - 2 } & Blue: $0.43-0.55 \mu \mathrm{m}$ \\
\cline { 2 - 2 } & Green: $0.49-0.61 \mu \mathrm{m}$ \\
\cline { 2 - 2 } & Red: $0.6-0.72 \mu \mathrm{m}$ \\
\cline { 2 - 2 } & Near Infrared: $0.75-0.95 \mu \mathrm{m}$ \\
\hline
\end{tabular}

Göktürk-2, which is a sun synchronous satellite, data were obtained by Scientific and Technological Research Council of Turkey (TÜBİTAK) and built by TÜBİTAK Space Technologies Research Institute (TÜBITTAK UZAY) and Turkish Aerospace Industries (TUSAŞ) for the Turkish Ministry of National Defense. It was launched in 2012 with a planned lifetime is 5 years. Göktürk-2 is used for security, disaster response, environmental mapping, urban planning, coastal zone monitoring and water resource management (Table 4). Göktürk means "Sky Turk" in Turkish. 
Table 4. Information about Göktürk-2

\begin{tabular}{|c|c|}
\hline \multirow{4}{*}{ Spatial Resolution } & Panchromatic: $2.5 \mathrm{~m}$ \\
\cline { 2 - 2 } & Multispectral: $5 \mathrm{~m}$ \\
\cline { 2 - 2 } & Pan-sharpened: $2.5 \mathrm{~m}$ \\
\hline \multirow{4}{*}{ Spectral Bands } & Panchromatic: $0.42-0.75 \mu \mathrm{m}$ \\
\cline { 2 - 2 } & Blue: $0.422-0.512 \mu \mathrm{m}$ \\
\cline { 2 - 2 } & Green: $0.5-0.584 \mu \mathrm{m}$ \\
\cline { 2 - 2 } & Red: $0.596-0.75 \mu \mathrm{m}$ \\
\cline { 2 - 2 } & Near Infrared: $0.762-0.894 \mu \mathrm{m}$ \\
\hline
\end{tabular}

\subsection{Field data}

The field data were collected in summer 2015. There are 86 plots, 41 for the maritime pine and 45 for the oak cover type. The plots in the field were distributed across the cover type and they were purposefully selected, not randomly (Figure 7). The plots were stratified by cover class. Before the field work, the distribution of species map in the Turkish forest management plan was used to consider plot locations and plot sizes. Turkish forest management plans have schemes for classifying stands into structure classes including canopy closure, and a map of stands that have structure class identified. The plots were sampled sample from across that classification schemes. Oak covers $90 \%$ of the study area. Sampling from some areas just outside of the reference study area boundary was useful to capture certain forest conditions in the fitting data. A Trimble GeoXH 6000 global positioning system receiver was used to establish the coordinates at plot center with post-processing in the Pathfinder Office software. Final horizontal accuracy was $1.00 \mathrm{~m}$ or less. 


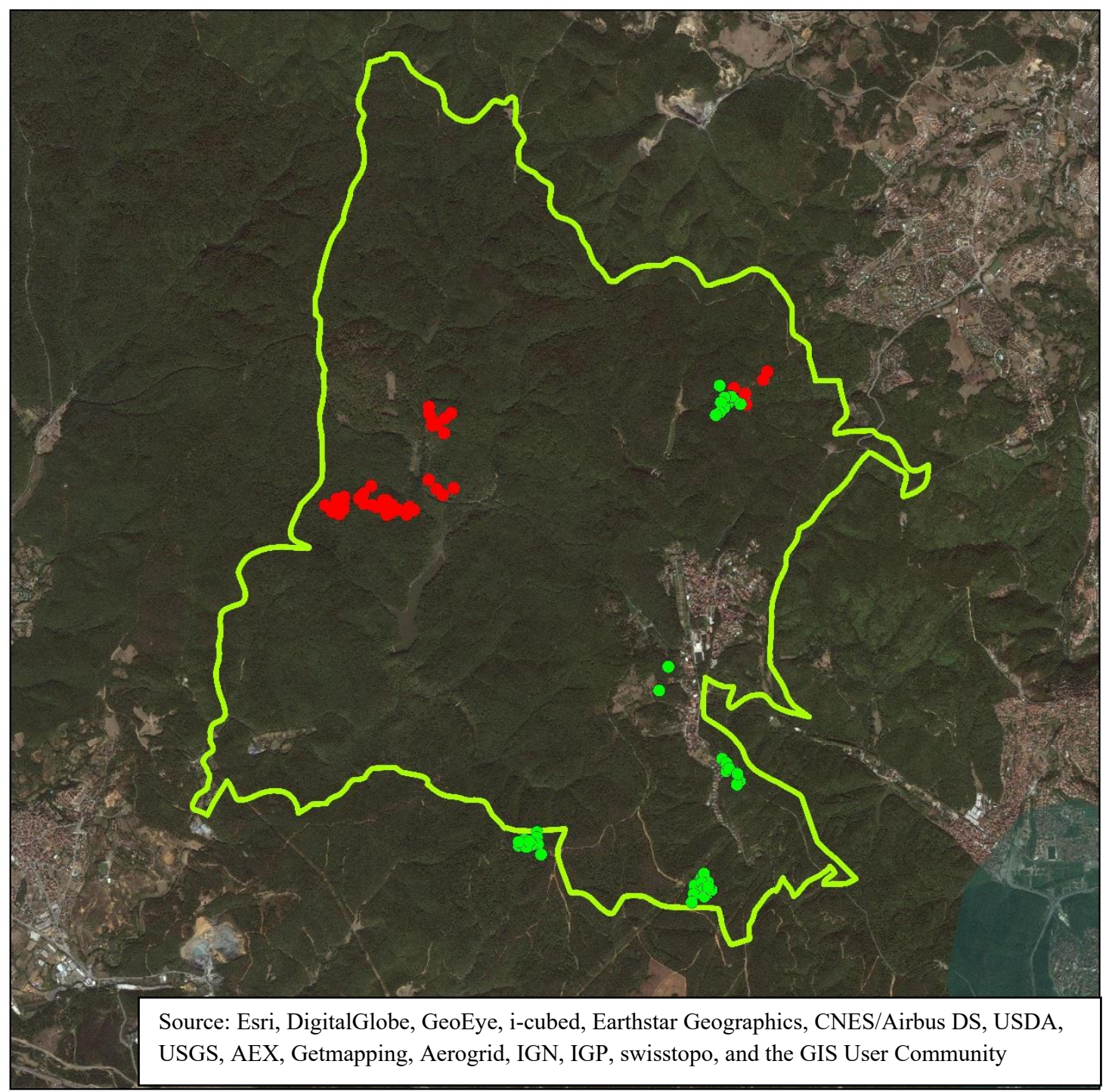

\section{Legend}

- Pine

- Oak

The study area

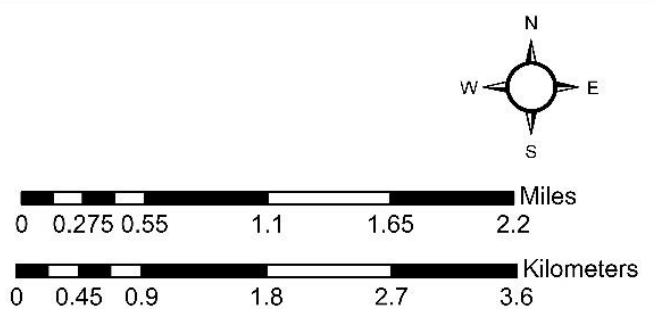

Figure 7. The distribution of plots on the field 
Fixed-area ground plots were used because it is suitable for LiDAR and remote sensing studies (Means et al., 2000; Nelson et al., 1997). The plot radius was chosen to be a $10 \mathrm{~m}$ for subplots and $20 \mathrm{~m}$ for plots (Figure 8). Tees less than $10 \mathrm{~cm}$ diameter at breast height $(\mathrm{DBH})$ and greater than $1.3 \mathrm{~m}$ in height, were tallied in subplots. Trees greater than $\geq 10$ $\mathrm{cm} \mathrm{DBH}$ and over than $1.3 \mathrm{~m}$ in height, were tallied in larger plots. Each tree falling within the plot or subplot as defined was identified to the species level and DBH was measured to the nearest $0.1 \mathrm{~cm}$ using a caliper. The plot locations were selected based on target tree species.

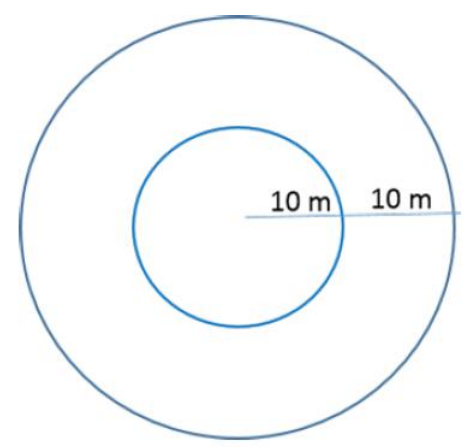

Figure 8 . The shape of a sample plot

\subsection{Responses and responses estimations}

Castillo-Santiago et al., (2010), explained that they established three concentric plots with three DBH thresholds. The first concentric plots were $100 \mathrm{~m}^{2}$ for all trees with $\mathrm{DBH} \geq 5$ $\mathrm{cm}$ and a height of at least $1.3 \mathrm{~m}$. The second concentric plots were $500 \mathrm{~m}^{2}$ for trees with $\mathrm{DBH} \geq 10 \mathrm{~cm}$. The third concentric plots were $1000 \mathrm{~m}^{2}$ for all trees with $\mathrm{DBH} \geq 20 \mathrm{~cm}$. Their aim was to see different plot sizes how to affect forest attributes.

In this research two concentric plots were established. Trees in this study were assigned to three classes based on a minimum threshold $\mathrm{DBH}$. The first threshold was all trees higher than $1.3 \mathrm{~m}$, which were measured for subplot because these smaller DBH trees could be scanned by the LiDAR system and it would be important to know how smaller DBH could affect forest inventories. The second DBH threshold was $\geq 8 \mathrm{~cm} \mathrm{DBH}$ and larger because this is a value that is used in Turkish Forestry. The third DBH threshold 
was $\geq 10 \mathrm{~cm} \mathrm{DBH}$ and bigger. This $\geq 10 \mathrm{~cm}$ DBH threshold was used in most remote sensing articles, so the results of this research may be comparable with other scientific studies. All DBH thresholds must have $1.3 \mathrm{~m}$ height and greater (Figure 9).

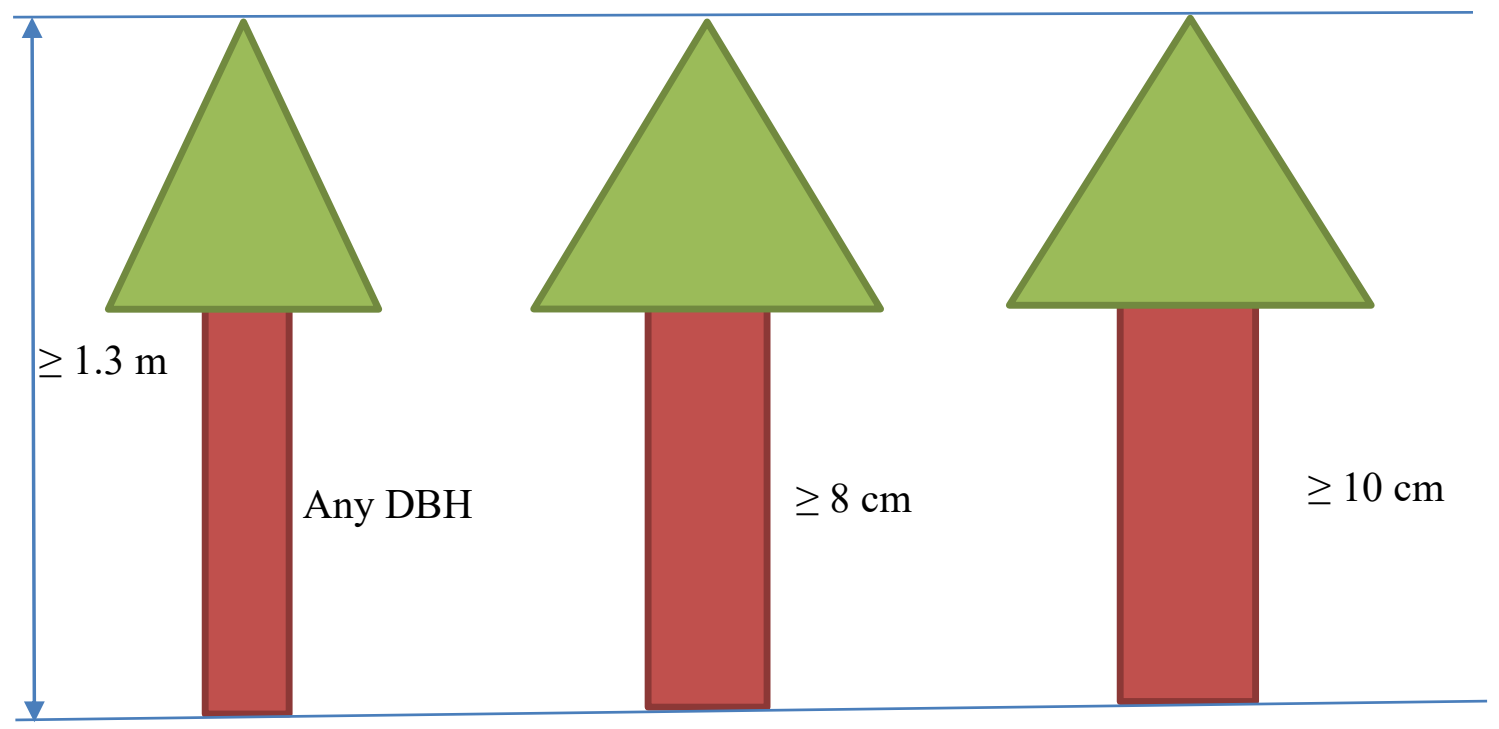

Figure 9. DBH thresholds

Basal area, volume, increment, above ground biomass, underground biomass, general biomass, litter and ground cover biomass, the amount of carbon deposition, and carbon deposition in soil were derived from DBH. The number of trees were counted.

\subsubsection{The estimation of basal area (BA)}

The following formula shows how to calculate BA in $\mathrm{m}^{2}$ from $\mathrm{DBH}$. DBH must be in $\mathrm{cm}$ for this equation.

$$
\mathrm{BA}=0.00007854 \times \mathrm{DBH}^{2}
$$

Then, the result must be multiplied by the inverse of plot area to put the result on a per ha basis. Basal area is expressed as $\mathrm{m}^{2} /$ ha. 


\subsubsection{Estimating number of trees}

The trees in every plot were counted. Then, the number of trees per hectare was calculated by multiplying the sum by the inverse of plot area in ha.

\subsubsection{The estimation of Volume \& Increment}

Volume and increment tables developed for the Turkish forest management plan (2012) were used to calculate volume and increment in the field data collected for this research. According to the Turkish forest management plan (2012), a DBH-height curve was drawn from measured trees and average height for every diameter step was calculated for trees $\geq 8 \mathrm{~cm}$ DBH. Each species has individual curves derived from measured trees. Average volume was estimated from a two-way entry table for each average height form constructed from different forest conditions.

In the Turkish forest management plan, the increment was calculated with the Meyer increment method. Increment cores were taken from $1.30 \mathrm{~m}$ height of trees to calculate annual growth increment for the first 10 years. The Meyer increment table was developed based on 10 years annual rings and double bark thickness for each species (Forest management plans, 2012). This procedure was repeated for at least three trees per species for each plot. After all the processes, the increment tables were compiled for a $4-\mathrm{cm}$ interval starting from $\geq 8 \mathrm{~cm} \mathrm{DBH}$ trees (Table 5). 
Table 5. Volume and Increment Tables for two species

\begin{tabular}{|c|c|c|c|c|c|c|c|}
\hline \multirow[b]{2}{*}{$\begin{array}{l}\text { Diameter } \\
\text { Category } \\
(\mathrm{cm})\end{array}$} & \multirow[b]{2}{*}{$\begin{array}{l}\text { Mean } \\
\text { DBH } \\
(\mathrm{cm})\end{array}$} & \multicolumn{2}{|c|}{ Quercus (Oak) } & \multirow[b]{2}{*}{$\begin{array}{l}\text { Diameter } \\
\text { Category } \\
(\mathrm{cm})\end{array}$} & \multirow[b]{2}{*}{$\begin{array}{l}\text { Mean } \\
\text { DBH } \\
(\mathrm{cm})\end{array}$} & \multicolumn{2}{|c|}{ Maritime Pine } \\
\hline & & $\begin{array}{c}\text { Volume } \\
\text { per } \\
\text { decade } \\
\left(\mathrm{m}^{3}\right)\end{array}$ & $\begin{array}{c}\text { Increment } \\
\text { per } \\
\text { decade } \\
\left(\mathrm{m}^{3}\right)\end{array}$ & & & $\begin{array}{c}\text { Volume } \\
\text { per } \\
\text { decade } \\
\left(\mathrm{m}^{3}\right)\end{array}$ & $\begin{array}{c}\text { Increment } \\
\text { per } \\
\text { decade } \\
\left(\mathrm{m}^{3}\right)\end{array}$ \\
\hline $1-3.99$ & 2 & 0.00103 & 0.0017 & $1-3.99$ & 2 & 0.00101 & 0.0002 \\
\hline $4-7.99$ & 6 & 0.01384 & 0.0019 & $4-7.99$ & 6 & 0.01302 & 0.0015 \\
\hline $8-11.9$ & 10 & 0.047 & 0.002 & $8-11.9$ & 10 & 0.034 & 0.004 \\
\hline $12-15.9$ & 14 & 0.108 & 0.004 & $12-15.9$ & 14 & 0.076 & 0.007 \\
\hline $16-19.9$ & 18 & 0.202 & 0.006 & $16-19.9$ & 18 & 0.14 & 0.013 \\
\hline $20-23.9$ & 22 & 0.334 & 0.007 & $20-23.9$ & 22 & 0.226 & 0.019 \\
\hline $24-27.9$ & 26 & 0.501 & 0.009 & $24-27.9$ & 26 & 0.338 & 0.027 \\
\hline $28-31.9$ & 30 & 0.717 & 0.011 & $28-31.9$ & 30 & 0.477 & 0.036 \\
\hline $32-35.9$ & 34 & 0.975 & 0.013 & $32-35.9$ & 34 & 0.645 & 0.045 \\
\hline $36-39.9$ & 38 & 1.275 & 0.015 & $36-39.9$ & 38 & 0.843 & 0.055 \\
\hline $40-43.9$ & 42 & 1.62 & 0.017 & $40-43.9$ & 42 & 1.041 & 0.066 \\
\hline $44-47.9$ & 46 & 2.01 & 0.017 & $44-47.9$ & 46 & 1.239 & 0.074 \\
\hline $48-51.9$ & 50 & 2.433 & 0.018 & $48-51.9$ & 50 & 1.437 & 0.083 \\
\hline $52-55.9$ & 54 & 2.884 & 0.018 & $52-55.9$ & 54 & 1.635 & 0.092 \\
\hline $56-59.9$ & 58 & 3.38 & 0.018 & & & & \\
\hline $60-63.9$ & 62 & 3.908 & 0.017 & & & & \\
\hline $64-67.9$ & 66 & 4.445 & 0.016 & & & & \\
\hline $68-71.9$ & 70 & 5 & 0.014 & & & & \\
\hline $72-75.9$ & 74 & 5.588 & 0.014 & & & & \\
\hline $76-79.9$ & 78 & 6.209 & 0.01 & & & & \\
\hline $80-83.9$ & 82 & 6.862 & 0.007 & & & & \\
\hline $84-87.9$ & 86 & 7.548 & 0.005 & & & & \\
\hline
\end{tabular}


There was no information about the volume for $\leq 8 \mathrm{~cm}$ DBH in the existing table in the Turkish forest management plan. The tables were extrapolated to smaller classes by fitting exponential equations to the existing tables then volume was calculated using the equations for $\leq 8 \mathrm{~cm}$ DBH trees for each species. The equations of volume and increment for smaller trees are shown in Figure 10.
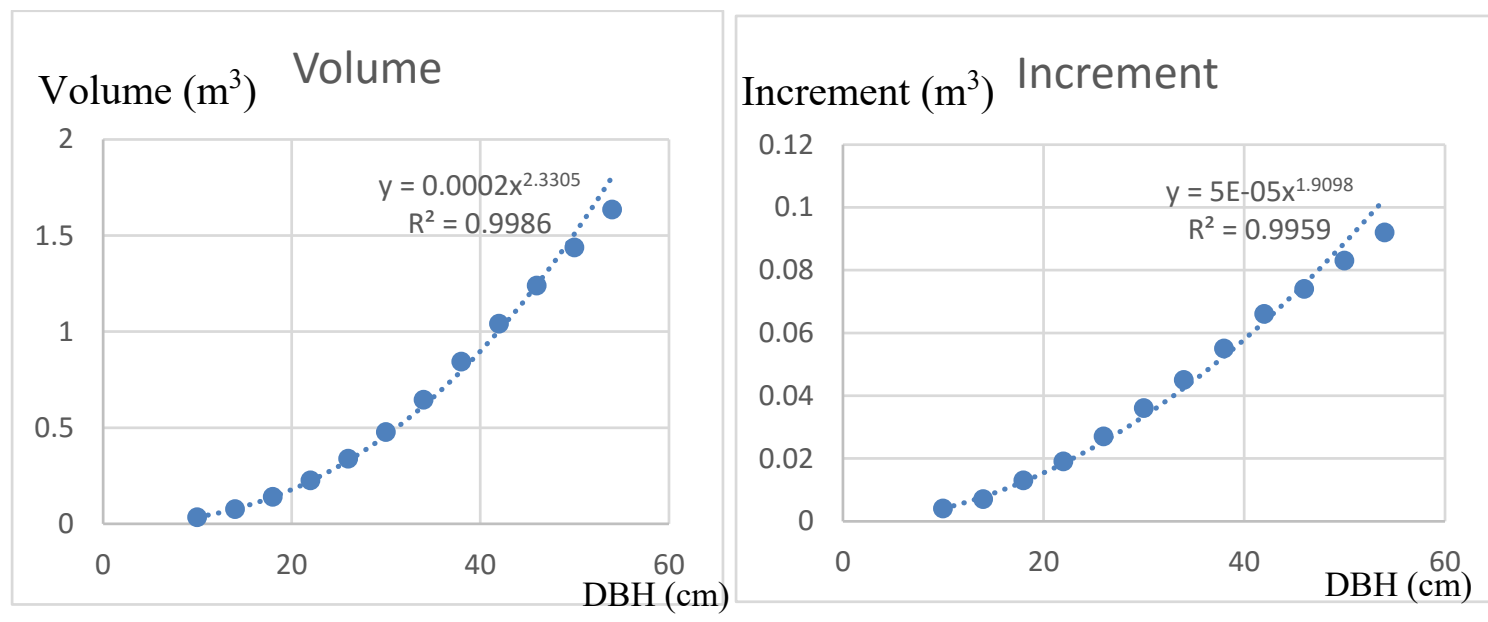

Figure 10. Volume (left) and diameter increment (right) for maritime pine

\subsubsection{The estimation of Biomass and Carbon Sequestration}

The carbon sequestration and balance sheet in the forests are calculated based on the distribution of the organic mass on the forest concerning tree species and the oven-dry converted matter amount. In the calculations it is accepted that $0.45 \mathrm{Mg}$ of carbon are present in 1 ton of oven dry organic matter and this amount is equivalent to $3.66 \mathrm{Mg} \mathrm{CO} 2$ (Raev et al., 1997). In this study, the biomass (in the stem, branch and leaf) over the soil is determined first and then the biomass under the soil is estimated for the study region using conversion factors published by Asan, (1995) for the same species in the study area. 
$>$ Above Ground Biomass(AGB) $=$ Volume $\mathrm{x}$ Oven-dried converted matter amount(ODCMA) x Conversion factor(CF)

Asan (1995) describes ODCMA values of 0.640 for deciduous trees and 0.473 for coniferous. $\mathrm{CF}$ is described as 1.20 for coniferous species and 1.25 for deciduous trees.

$>$ Underground Biomass (UB) $=\mathrm{AGB} \times \mathrm{CF}$

Asan (1995) describes CF as 0.15 for deciduous trees and 0.20 for coniferous trees.

$>$ Litter and ground cover Biomass $(\mathrm{LGCB})=(\mathrm{AGB}+\mathrm{UB}) \times \mathrm{CF}$

Asan (1995) states CF as 0.40.

$>$ General Biomass $(\mathrm{GB})=\mathrm{AGB}+\mathrm{UB}+\mathrm{LGCB}$

Carbon Sequestration $(\mathrm{CS})=\mathrm{GB} \times \mathrm{CF}$

Asan (1995) explains CF as 0.45 .

$>$ Carbon Sequestration in soil $=\mathrm{CS} \times \mathrm{CF}$

Asan (1995) mentions CF as 0.58. 


\subsubsection{The Abbreviations of Responses}

A total of 124 response variables were derived at the plot level as individual-tree averages, plot totals, or plot totals on a per-ha basis (Table 6). These variables were selected because they are common summaries used in forest inventory. Abbreviations start with $\underline{A}$ (for All) which means all DBH threshold, $\underline{E}$ (for Eight) which means $\geq 8 \mathrm{~cm}$ DBH threshold, and $\underline{T}$ (for Ten) which means $\geq 10 \mathrm{~cm}$ DBH threshold.

Table 6. Summary of the response variables and the abbreviations used.

\begin{tabular}{|l|l|}
\hline av.ba.ha & Average BA per ha \\
\hline Sum.Ba.ha & Sum BA per ha \\
\hline Sum.DBH & Sum DBH based on the plot level \\
\hline Av.DBH & Average DBH based on the plot level \\
\hline Av.BA & Average BA based on the plot level \\
\hline Sum.BA & Sum BA based on the plot level \\
\hline Tree & Tree amount based on the plot level \\
\hline Tpha & Tree per ha \\
\hline sum.vol & Sum volume based on the plot level \\
\hline av.vol & Average volume based on the plot level \\
\hline sum.inc & Sum increment based on the plot level \\
\hline av.inc & Average increment based on the plot level \\
\hline sum.vol.pha & Sum volume per ha \\
\hline av.vol.pha & Average volume per ha \\
\hline sum.inc.pha & Sum increment per ha \\
\hline av.inc.pha & Average increment per ha \\
\hline sum.above & Sum aboveground biomass based on the plot level \\
\hline av.above & Average aboveground biomass based on the plot level \\
\hline sum.under & Sum underground biomass based on the plot level \\
\hline
\end{tabular}




\begin{tabular}{|l|l|}
\hline av.under & Average underground biomass based on the plot level \\
\hline sum.litter & Sum litter and ground cover biomass based on the plot level \\
\hline av.litter & $\begin{array}{l}\text { Average litter and ground cover biomass based on the plot } \\
\text { level }\end{array}$ \\
\hline sum.gen & Sum General biomass based on the plot level \\
\hline av.gen & Average General biomass based on the plot level \\
\hline sum.car & Sum carbon based on the plot level \\
\hline av.car & Average carbon based on the plot level \\
\hline sum.car.soil & Sum Carbon value of the soil based on the plot level \\
\hline av.car.soil & Average Carbon value of the soil based on the plot level \\
\hline sum.above.pha & Sum aboveground biomass pha \\
\hline av.above.pha & Average aboveground biomass pha \\
\hline sum.under.pha & Sum underground biomass pha \\
\hline av.under.pha & Average underground biomass pha \\
\hline sum.litter.pha & Sum litter and ground cover biomass pha \\
\hline av.litter.pha & Average litter and ground cover biomass pha \\
\hline sum.gen.pha & Sum General biomass pha \\
\hline av.gen.pha & Average General biomass pha \\
\hline sum.car.pha & Sum carbon value pha \\
\hline av.car.pha & Average carbon pha \\
\hline sum.car.soil.pha & Sum Carbon value of the soil pha \\
\hline av.car.soil.pha & Av Carbon value of the soil pha \\
\hline
\end{tabular}




\subsection{LiDAR Processing}

The available LiDAR data covered nearly the entire forest management administrative unit that was selected as a representative study area, and also included much surrounding forest area. All of the field plots were located well within the available coverage of the LiDAR and remote sensing data products. The LiDAR data were processed using version 3.60 of FUSION software, which was developed by the United States Department of Agriculture-Forest Service (USDAFS) (McGaughey, 2016). LiDAR metrics in the below table were calculated using a 2-m bare earth (BE), digital elevation model (DEM) which were derived from the LiDAR data via FUSION for each plot (Table 7). BE was used to create canopy surface and canopy height models.

Table 7. LiDAR metrics that were calculated for the models.

\begin{tabular}{|l|l|}
\hline count & Number of returns above the minimum height \\
\hline densitytotal & total returns used for calculating cover \\
\hline densityabove & returns above heightbreak \\
\hline densitycell & Density of returns used for calculating cover \\
\hline min & minimum value for cell \\
\hline max & maximum value for cell \\
\hline mean & mean value for cell \\
\hline mode & modal value for cell \\
\hline stddev & standard deviation of cell values \\
\hline variance & variance of cell values \\
\hline cv & coefficient of variation for cell \\
\hline cover & cover estimate for cell \\
\hline abovemean & $\begin{array}{l}\text { proportion of first (or all) returns above the } \\
\text { mean }\end{array}$ \\
\hline
\end{tabular}




\begin{tabular}{|l|l|}
\hline abovemode & $\begin{array}{l}\text { proportion of first (or all) returns above the } \\
\text { mode }\end{array}$ \\
\hline skewness & skewness computed for cell \\
\hline kurtosis & kurtosis computed for cell \\
\hline aAD & $\begin{array}{l}\text { average absolute deviation from mean for the } \\
\text { cell }\end{array}$ \\
\hline p01 & $\begin{array}{l}\text { 1st percentile value for cell (must be p01, not } \\
\text { p1) }\end{array}$ \\
\hline p05 & $\begin{array}{l}\text { 5th percentile value for cell (must be p05, not } \\
\text { p5) }\end{array}$ \\
\hline p10 & 10th percentile value for cell \\
\hline p20 & 20th percentile value for cell \\
\hline p25 & 25th percentile value for cell \\
\hline p30 & 30th percentile value for cell \\
\hline p40 & 40th percentile value for cell \\
\hline p50 & 50th percentile value (median) for cell \\
\hline p60 & 60th percentile value for cell \\
\hline p70 & 70th percentile value for cell \\
\hline p75 & 75th percentile value for cell \\
\hline p80 & 80th percentile value for cell \\
\hline p90 & 90th percentile value for cell \\
\hline p95 & 95th percentile value for cell \\
\hline p99 & 99th percentile value for cell \\
\hline allabovemean & (all returns above mean ht) / (total returns) \\
\hline allabovemode & (all returns above ht mode) / (total returns) \\
\hline afabovemean & (all returns above mean ht) / (total first returns) \\
\hline afabovemode & (all returns above ht mode) / (total first returns) \\
\hline fcountmean & number of first returns above mean ht \\
\hline fcountmode & number of first returns above ht mode \\
\hline
\end{tabular}




\begin{tabular}{|l|l|}
\hline allcountmean & number of returns above mean ht \\
\hline allcountmode & number of returns above ht mode \\
\hline totalfirst & total number of 1st returns \\
\hline totalall & total number of returns \\
\hline
\end{tabular}

\subsection{Satellite Image Processing}

ERDAS IMAGINE 2015 software was used for georeferencing satellite images in the WGS-84 datum. At least 25 control points were added for georeferencing.

ENVI Version 5.2 was used to perform GLCM analysis with 8 options: mean, variance, homogeneity, contrast, dissimilarity, entropy, second moment, and correlation with cooccurrence measures tools. The equations of these options were calculated by Haralick et al., (1973). The equations are;

- Mean: Mean value of processing windows.

- Variance: Variance of processing windows.

$$
\text { Variance }=\sum_{i} \sum_{j}(i-u)^{2} p(i, j)
$$

- Homogeneity: Homogeneity of processing windows. Its range is from 0 to 1.

Homogeneity $=\sum_{i} \sum_{j} \frac{1}{1+(i-j)^{2}} p(i, j)$

- Contrast: Contrast of processing windows.

$$
\begin{gathered}
\text { Contrast }=\sum_{n=0}^{N g-1} n^{2}\left\{\sum_{i=1}^{N g} \sum_{j=1}^{N g} p(i, j)\right\} \\
|i-j|=n
\end{gathered}
$$

- Dissimilarity: Dissimilarity of processing windows.

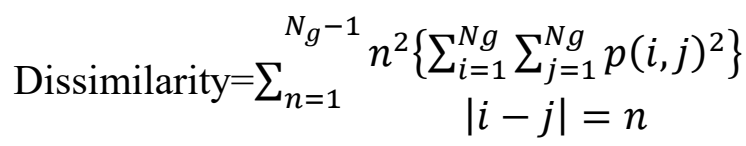


- Entropy: Entropy of processing windows. Its range starts from 0.

Entropy $=-\sum_{i} \sum_{j} p(i, j) \log (p(i, j))$

- Second Moment: Angular second moment of processing windows. Its range is from 0 to 1 .

Second Moment $=\sum_{i} \sum_{j}\{p(i, j)\}^{2}$

- Correlation: Correlation of processing windows. Its range is from -1 to 1 .

Correlation $=\frac{\sum_{i} \sum j(i j) p(i, j)-\mu_{x}-\mu_{y}}{\sigma_{x}-\sigma_{y}}$

Five different convolution windows processing sizes, which are $3 \times 3,5 \times 5,7 \times 7,9 \times 9$, and 11x11 were applied to all bands for both satellite images.

After GLCM processing for both satellites, Zonal Statistics as Table tools in ArcMap 10.3.1 was used to summarize the result of satellite images data to the plot level. The tools derive the following: count, area, min, max, range, mean, std. dev., and sum. Then, more consistent derived statistics from the tools with ground data were created via Zonal Statistics in ArcMap.

All metrics derived from LiDAR and both satellite images were created as a raster file at a $40 \mathrm{~m}$ x $40 \mathrm{~m}$ pixel size because the plot radius is $20 \mathrm{~m}$. In this case, the individual forest inventory plot can theoretically be fit in one pixel (Figure 11). 


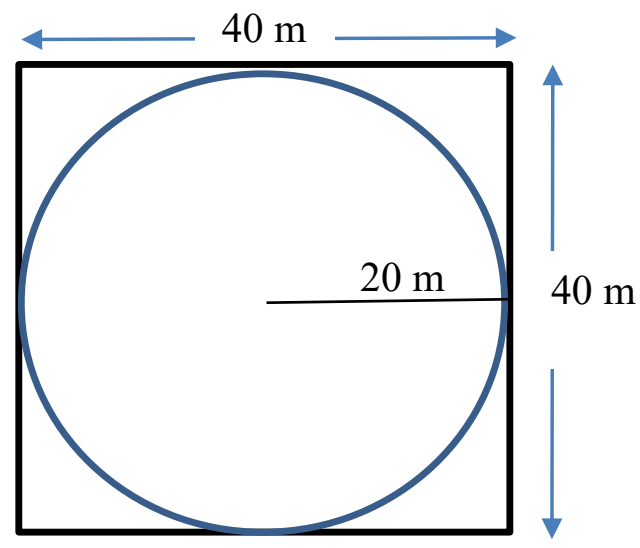

Figure 11. The plot position in the one pixel

Vegetation indices including Difference Vegetation Index (DVI), Enhanced Vegetation Index (EVI), Global Environmental Monitoring Index (GEMI), The Green Normalized Difference Vegetation Index (GNDVI), Green-Red Vegetation Index (GRVI), Infrared Percentage Vegetation Index (IPVI), Leaf area index (LAI), Modified Simple Ratio (MSR), Normalized difference vegetation index (NDVI), Non-Linear Index (NLI), Renormalized difference vegetation index (RDVI), and Ratio Vegetation Index (RVI) were applied to Pleiades and Landsat-8 in ArcMap and ENVI.

\subsection{Statistical Process}

At the end of all the remote sensing data processes, there are 3628 variables derived from satellite images and LiDAR data. RF, RF- $k \mathrm{NN}$, and regression methods used to find a correlation between remote sensing instruments and ground data.

The R software was used along with the RF packages for RF analysis, and the yaImpute packages were used for RF- $k \mathrm{NN}$ imputation. Base $\mathrm{R}$ stats packages were used for fitting linear models. The yaImpute package, which is designed for the R software, can make 
accurate mapping and find a better relationship using $k \mathrm{NN}$ models (Crookston and Finley, 2008). Totally, 2976 analyses were done.

$\mathrm{RF}$ models were trained on the data for each of the 124 response variables, separately for the two cover types and four sets of predictor variables. Each forest was fit using 1000 trees and the \%explained variance recorded for comparison with the other methods.

The RF method picks the predictor variables randomly and creates a model using the selected variables (Pal 2005). The variable importance can be calculated by comparing the difference between a model using a given predictor and the same model where the values of the predictor are scrambled; the amount of explained variance that is lost when scrambled reflects the "importance" of the predictor. The top three predictors based on variable importance in RF models were used in the regression models, including their 1st and 2 nd order interactions. Thus, if the three variables were $\{a, b$, and $c\}$, then the variables used in the regression were $\{a, b, c, a b, a c$, and $b c\}$ for a total of six predictors.

For example, the standard deviation of dissimilarity within $9 \times 9$ processing windows for band 4 from Pleiades (STD.p.b4_9_dissimi), the standard deviation of dissimilarity within 9x9 processing windows for band 4 from Göktürk-2 (STD.b4_9_dissimi), and the 20th percentile elevation (Elev.P20) from LiDAR were chosen as predictors for $\geq 8 \mathrm{~cm}$ DBH thresholds tree amount based on the plot level for oak (Figure 12). Table 8 shows the best 3 predictors for some responses for used in regression analysis. 
Table 8. Top three predictors chosen for regression analysis for some responses

\begin{tabular}{|l|l|l|l|}
\hline Parameter & $\begin{array}{l}\text { Predictor 1 } \\
\text { (LiDAR) }\end{array}$ & $\begin{array}{l}\text { Predictor 2 } \\
\text { (Pleiades) }\end{array}$ & $\begin{array}{l}\text { Predictor 3 } \\
\text { (Göktürk-2) }\end{array}$ \\
\hline $\begin{array}{l}\text { Tree count for } \geq 8 \\
\text { cm DBH threshold } \\
\text { using all } \\
\text { instruments for oak }\end{array}$ & Elev.P20 & $\begin{array}{l}\text { The standard } \\
\text { deviation of } \\
\text { dissimilarity within } \\
9 x 9 \text { processing } \\
\text { windows for band } \\
4\end{array}$ & $\begin{array}{l}\text { The standard } \\
\text { deviation of } \\
\text { dissimilarity within } \\
9 x 9 \text { processing } \\
\text { windows for band 4 }\end{array}$ \\
\hline $\begin{array}{l}\text { Average basal area } \\
\text { per ha for all } \\
\text { threshold using } \\
\text { LiDAR for oak }\end{array}$ & Elev.L1 & Elev.mean & Elev.SQRT.mean.SQ \\
\hline $\begin{array}{l}\text { Tree per ha for } \geq 10 \\
\text { cm DBH threshold } \\
\text { using Göktürk-2 } \\
\text { for oak }\end{array}$ & $\begin{array}{l}\text { The range of } \\
\text { entropy within 7x7 } \\
\text { processing } \\
\text { windows for band } \\
2\end{array}$ & $\begin{array}{l}\text { The maximum of } \\
\text { entropy within 9x9 } \\
\text { processing } \\
\text { windows for band } \\
2\end{array}$ & $\begin{array}{l}\text { The mean of } \\
\text { correlation within } \\
\text { 9x9 processing } \\
\text { windows for band 1 }\end{array}$ \\
\hline
\end{tabular}




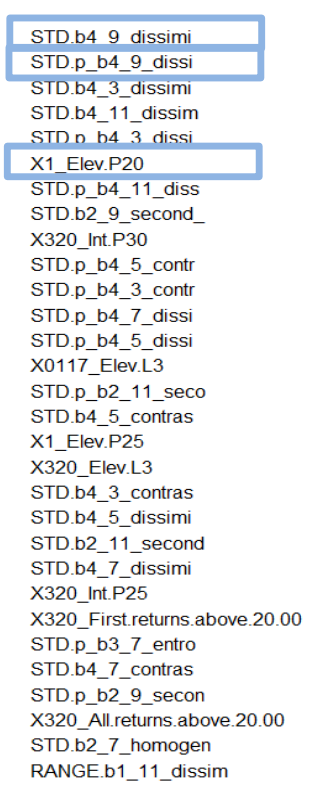

RANGE.b1_11_dissim

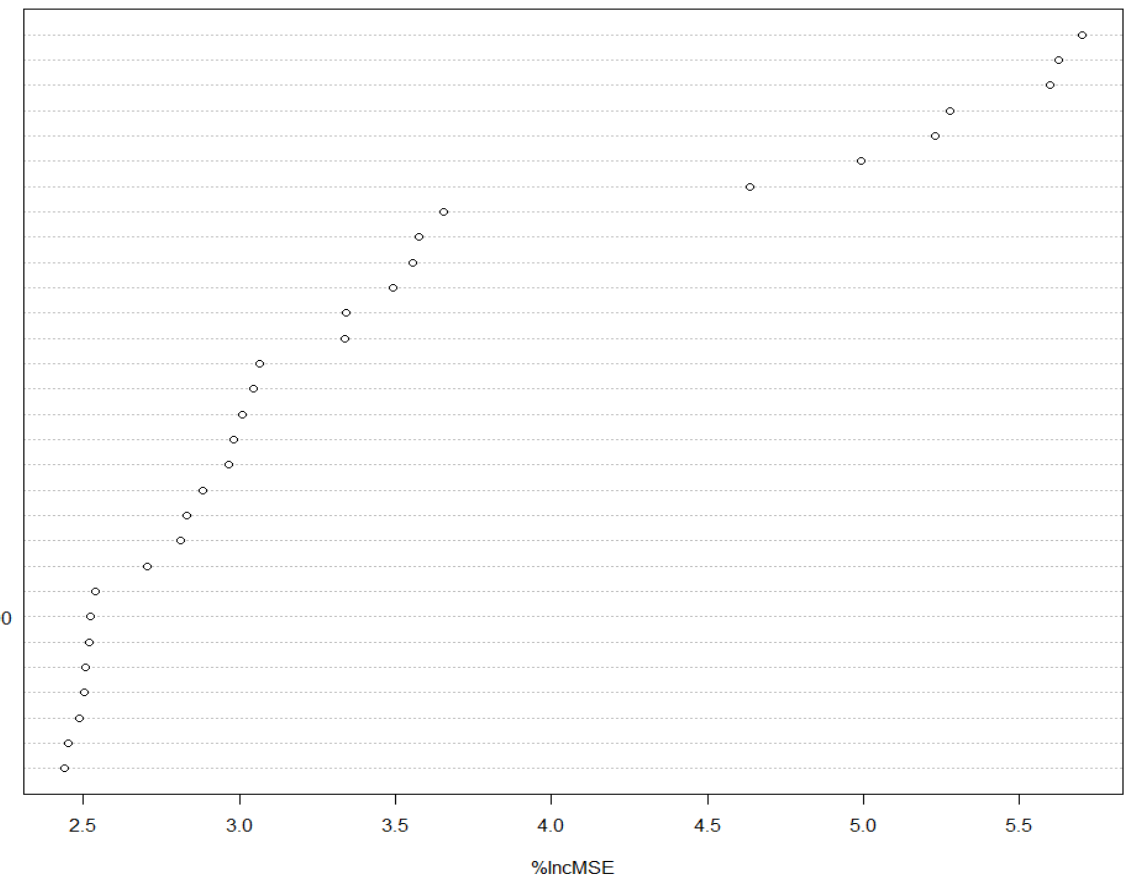

Figure 12. The best 30 predictors derived from RF for the tree count of oak for $\geq 8 \mathrm{~cm}$ DBH threshold.

After statistical processes, 2976 analyses were completed from the satellite images and LiDAR data for oak and maritime pine species. 2976 analyses comes from 124 responses times 4 remote sensing variables (LiDAR, Göktürk-2, Pleiades, and all) times 3 statistical methods ( $\mathrm{rF}, \mathrm{rF}, k \mathrm{NN}$, and regression) times 2 cover types (oak and maritime pine).

In mapping process, forest mask was applied with Raster Calculator to remove urban area, lake, road etc. Thresholds were specified with the "identify bottom" feature in ArcMap for masking. After that, the values of non-forest area were removed via Raster Calculator.

\section{Results}

Fit statistics ( $\mathrm{R}^{2}$ for regression, \%explained variance for $\mathrm{RF}$ and $\mathrm{RF}-k \mathrm{NN}$ ) for all 2976 analyses are presented in Appendix A, while results for some specific cases are presented in more detail here. 
Additionally, table 9 shows plot-level summary statistics for tree per hectare and basal area per hectare for oak and maritime pine cover types. This table, which was derived from ground data, includes minimum, maximum, mean and standard deviation.

Table 9. Plot-level summary statistics for two attributes for oak and maritime pine cover types

\begin{tabular}{cccccc}
\hline Species & Responses & Min & Max & Mean & $\begin{array}{c}\text { Standard } \\
\text { Deviation }\end{array}$ \\
\hline Oak & $\begin{array}{c}\text { Tree per ha } \\
\text { Basal Area per } \\
\text { ha }\end{array}$ & 254.65 & 1973.52 & 620.35 & 353.03 \\
& 14.90 & 42.22 & 29.74 & 6.43 \\
\hline $\begin{array}{c}\text { Maritime } \\
\text { Pine }\end{array}$ & $\begin{array}{c}\text { Tree per ha } \\
\text { Basal Area per } \\
\text { ha }\end{array}$ & 485.42 & 1050.42 & 719.69 & 128.49 \\
\hline
\end{tabular}

Figure 13 shows the plots of regression diagnostics for the model of tree count using all instruments for $\geq 8 \mathrm{~cm}$ threshold which has the best $\mathrm{R}^{2}$ for oak. Figure 14 shows similar plots for the model of increment for all thresholds which has the lowest $\mathrm{R}^{2}$ for oak. In the residuals vs fitted plot of Figure 13, the line tends to rise, although the line tends to go down in the residuals vs fitted plot of Figure 14. Besides, in Normal Q-Q plots and scalelocation plots, Figure 13 goes up regularly better than Figure 14. It is appropriate to say that there is no strong trend in residuals for either model, indicating no significant lackof-fit, and the Q-Q plots suggest there are no issues with normality in the residuals. 

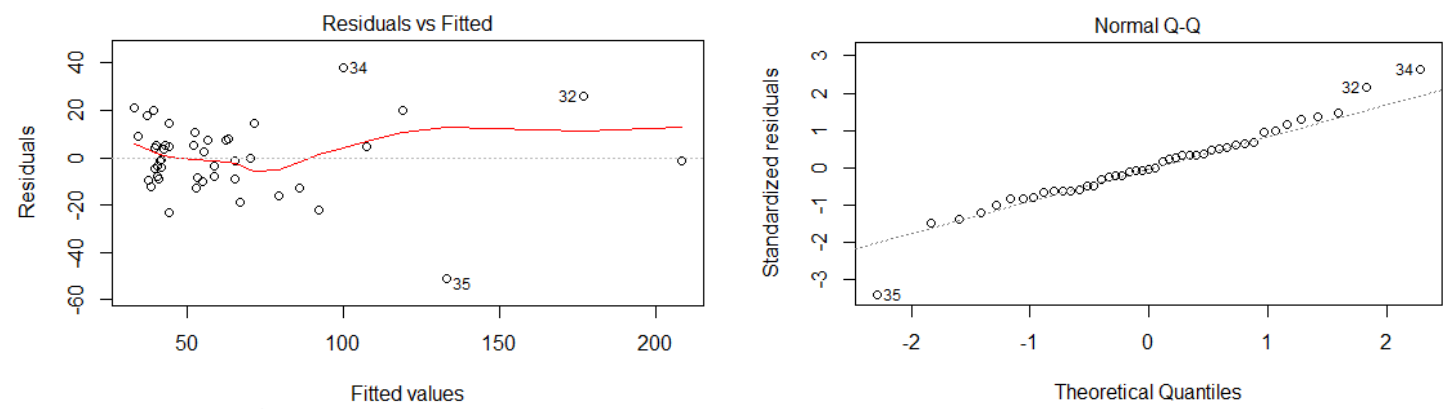

Figure 13. Regression diagnostics for the model of tree count using all instruments for $\geq 8$ cm threshold
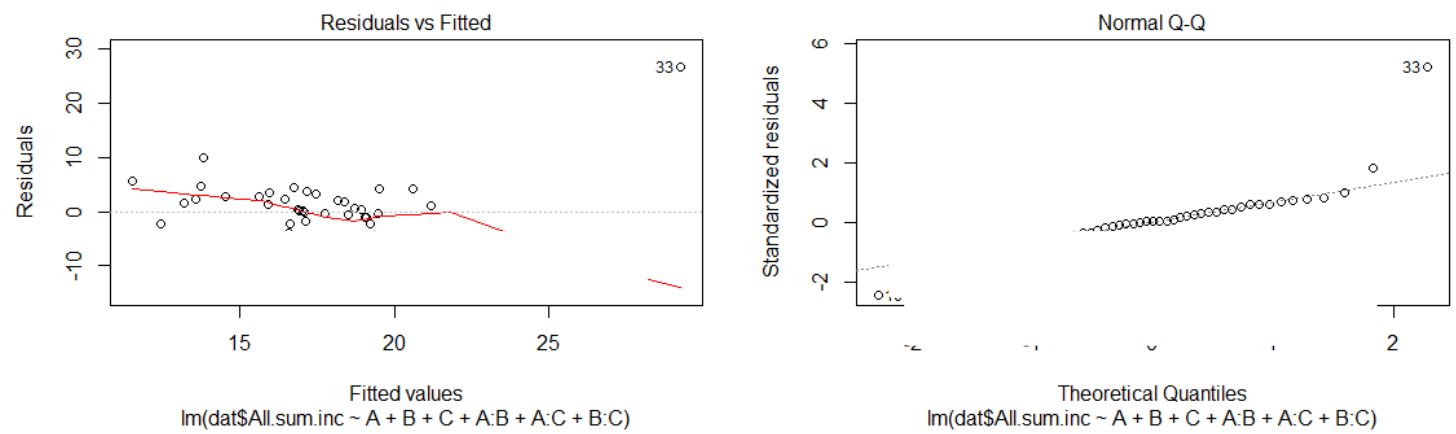

Figure 14. Regression diagnostics for model of tree count using all instruments for all thresholds

\subsection{Modeıs usıng all remote sensing instrumenıs ı⿻上 vak}

In using all remote sensing instruments for oak, the best $\mathrm{R}^{2}$ for regression analysis is 0.90 for $\geq 8 \mathrm{~cm}$ DBH thresholds tree count based on the plot level for oak (Figure 15). In the $\mathrm{RF}$ analysis, the best result was found to be $67.15 \%$ variance explained for all $\mathrm{DBH}$ thresholds based on the plot level. The best \% variance explained in the RF- $k \mathrm{NN}$ analysis is $33.06 \%$ for $\geq 8 \mathrm{~cm} \mathrm{DBH}$ thresholds. 


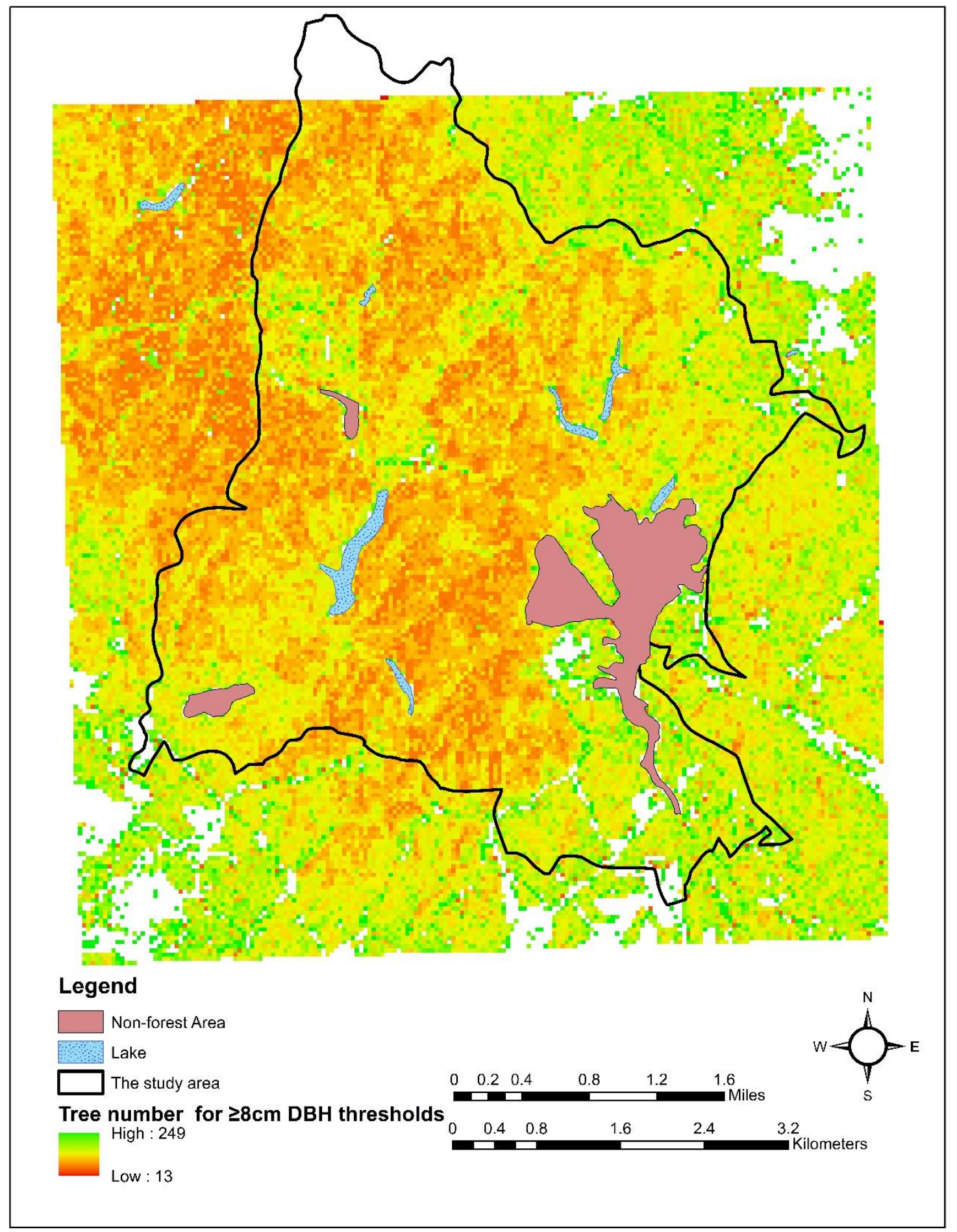

Figure 15. Tree count for $\geq 8 \mathrm{~cm}$ DBH thresholds oak species based on the plot size derived from regression analysis. 


\subsection{Models using all remote sensing instruments for maritime pine}

Using all remote sensing instruments for maritime pine the best $\mathrm{R}^{2}$ was 0.75 for the model with $\geq 8 \mathrm{~cm}$ DBH thresholds for biomass based on the plot level in the regression analysis. The best model using RF was $52.46 \%$ variance explained for $\geq 8 \mathrm{~cm} \mathrm{DBH}$ thresholds diameter at breast height based on the plot level. In RF- $k$ NN analysis, the best $\%$ variance explained is $45.99 \%$ for $\geq 10 \mathrm{~cm}$ DBH thresholds average carbon amount per hectare. The $\geq 8 \mathrm{~cm}$ DBH thresholds sum of diameter at breast height based on the plot level map was created for linear regression (Figure 16). 


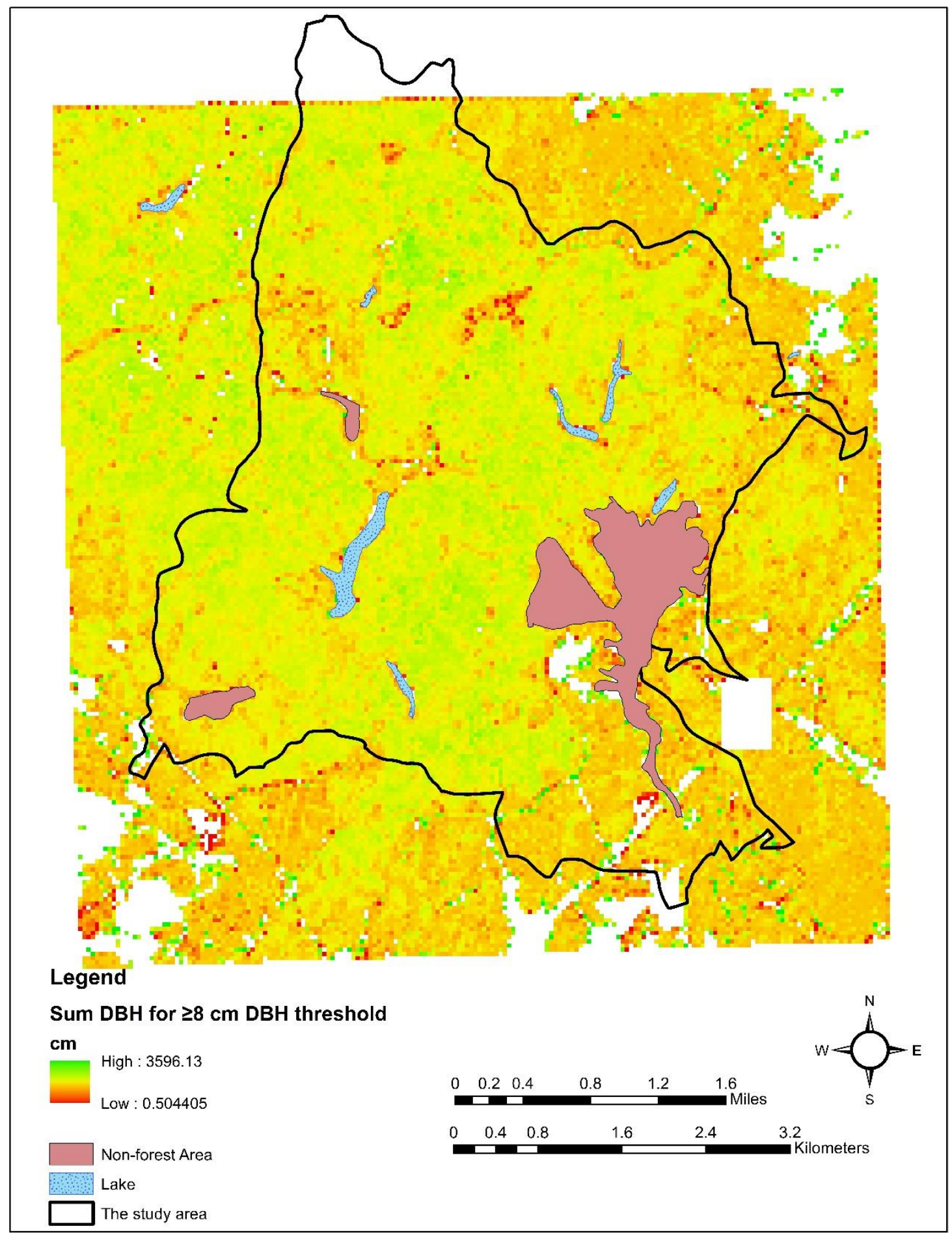

Figure 16. Sum DBH for $\geq 8 \mathrm{~cm}$ DBH thresholds Maritime Pine based on the plot size derived from regression analysis 


\subsection{Models Using LiDAR for maritime pine}

Some of the maritime pine's responses were calculated from LiDAR data. The best $\mathrm{R}^{2}$ using linear regression is 0.80 for $\geq 8 \mathrm{~cm}$ DBH thresholds average underground biomass. The best $\%$ variance explained for $\mathrm{RF}$ is $53.67 \%$ for $\geq 10 \mathrm{~cm}$ DBH thresholds sum general biomass based on the plot level. The 51.05\% variance explained was the best result in RF- $k \mathrm{NN}$ analysis for $\geq 8 \mathrm{~cm}$ DBH thresholds sum litter and ground cover biomass per hectare. The $\geq 8 \mathrm{~cm}$ DBH thresholds average underground biomass per hectare maps were created from linear regression (Figure 17) and RF- $k$ NN (Figure 18). 


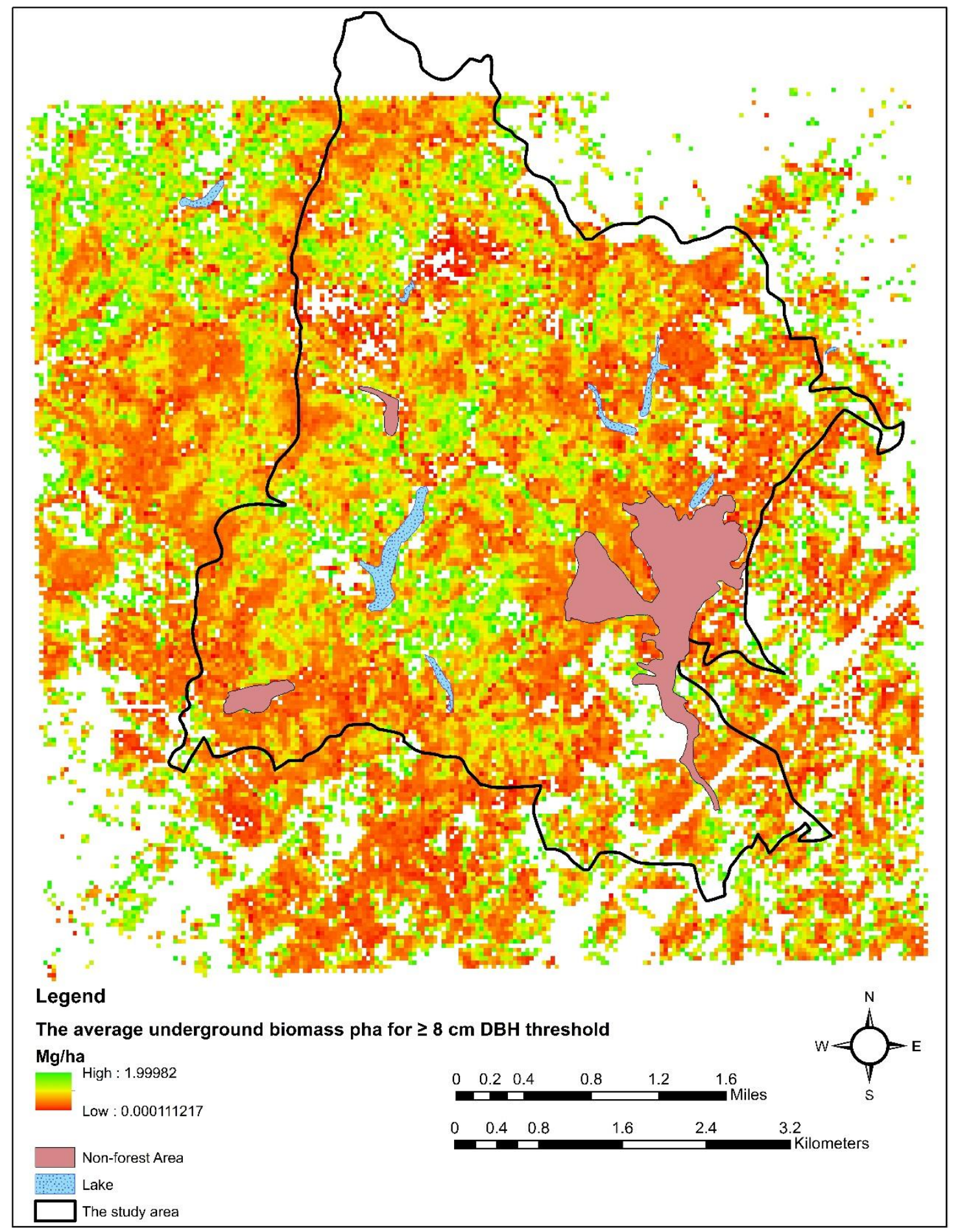

Figure 17. The average underground biomass of Maritime Pine using LiDAR for $\geq 8 \mathrm{~cm}$ DBH threshold derived from regression analysis 


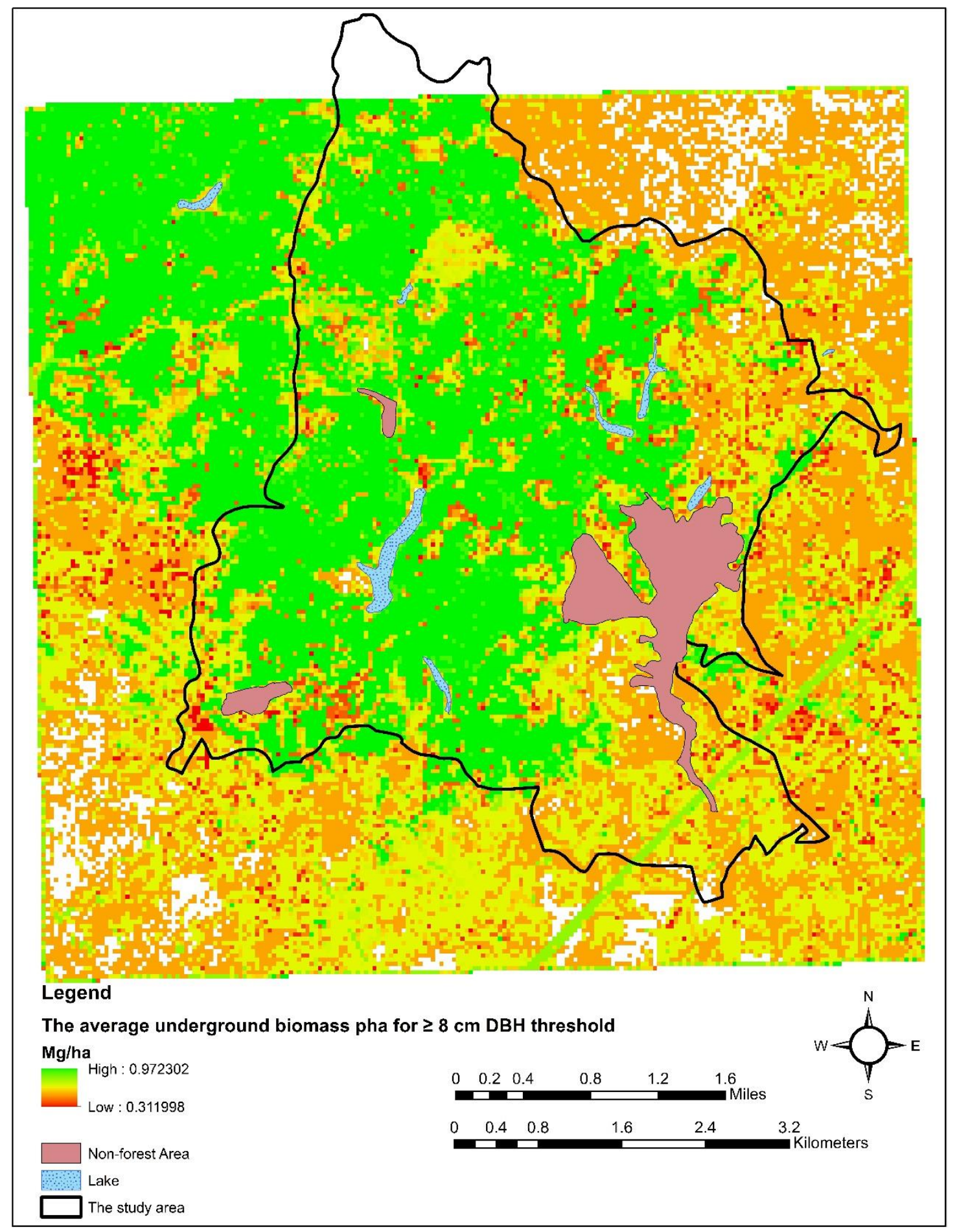

Figure 18. The average under biomass pha for $\geq 8 \mathrm{~cm}$ DBH threshold of Maritime Pine using LiDAR derived from RF-kNN analysis 


\subsection{Models using LiDAR for oak}

In LiDAR metrics for oak species, the best $\mathrm{R}^{2}$ is 0.80 for $\geq 8 \mathrm{~cm} \mathrm{DBH}$ thresholds tree count per hectare using linear regression. The explained \% variance of all DBH thresholds tree count is the best result for RF analysis and RF- $k \mathrm{NN}$ which are $64.78 \%$ for all DBH thresholds tree count based on the plot level and $55.85 \%$ for $\geq 8 \mathrm{~cm} \mathrm{DBH}$ thresholds tree count based on the plot level. Two maps, which include $\geq 10 \mathrm{~cm} \mathrm{DBH}$ thresholds average carbon amount in the soil per hectare, were created using linear regression (Figure 19) and RF- $k \mathrm{NN}$ (Figure 20). 


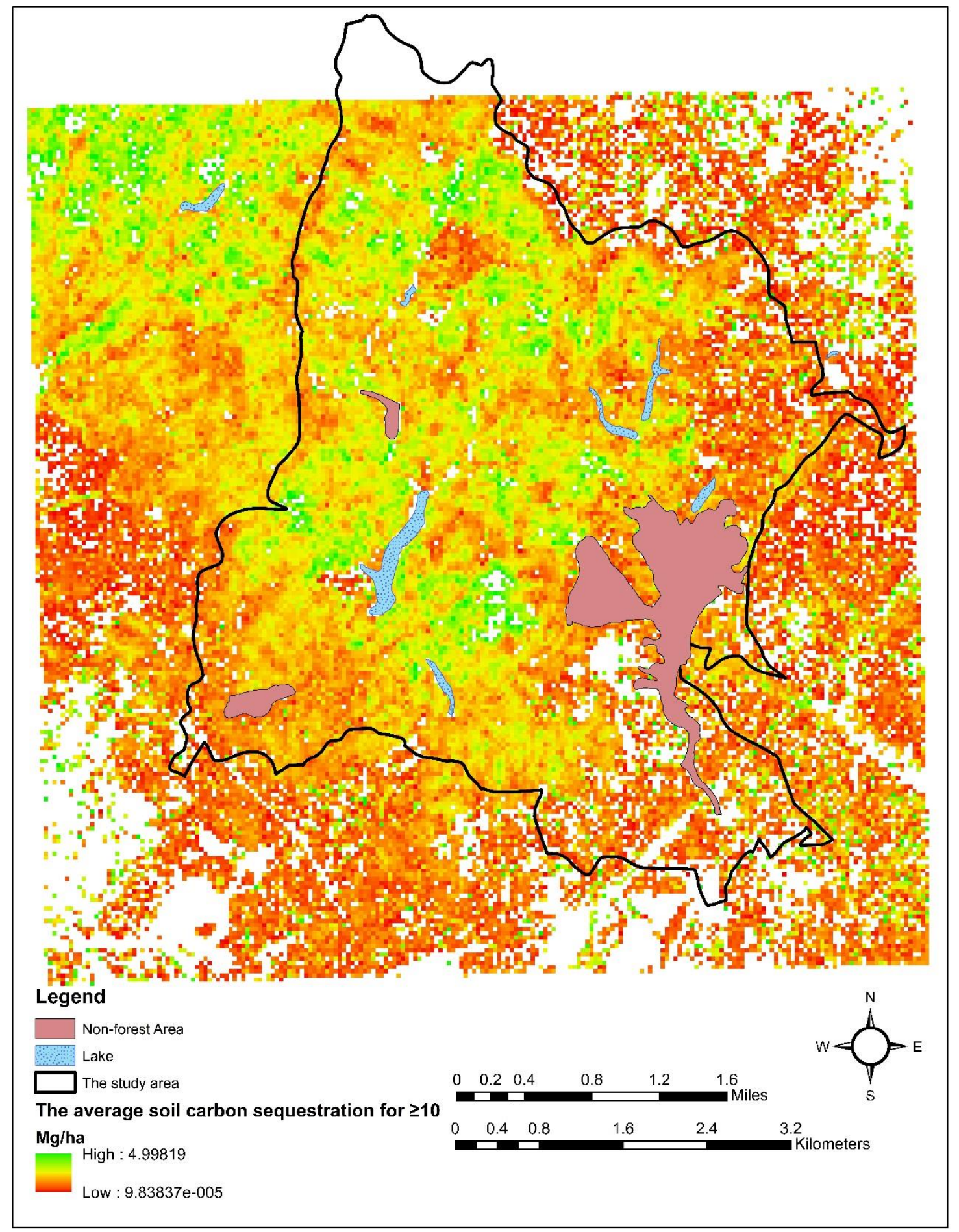

Figure 19. Average soil carbon sequestration for $\geq 10 \mathrm{~cm}$ DBH threshold derived from regression analysis 


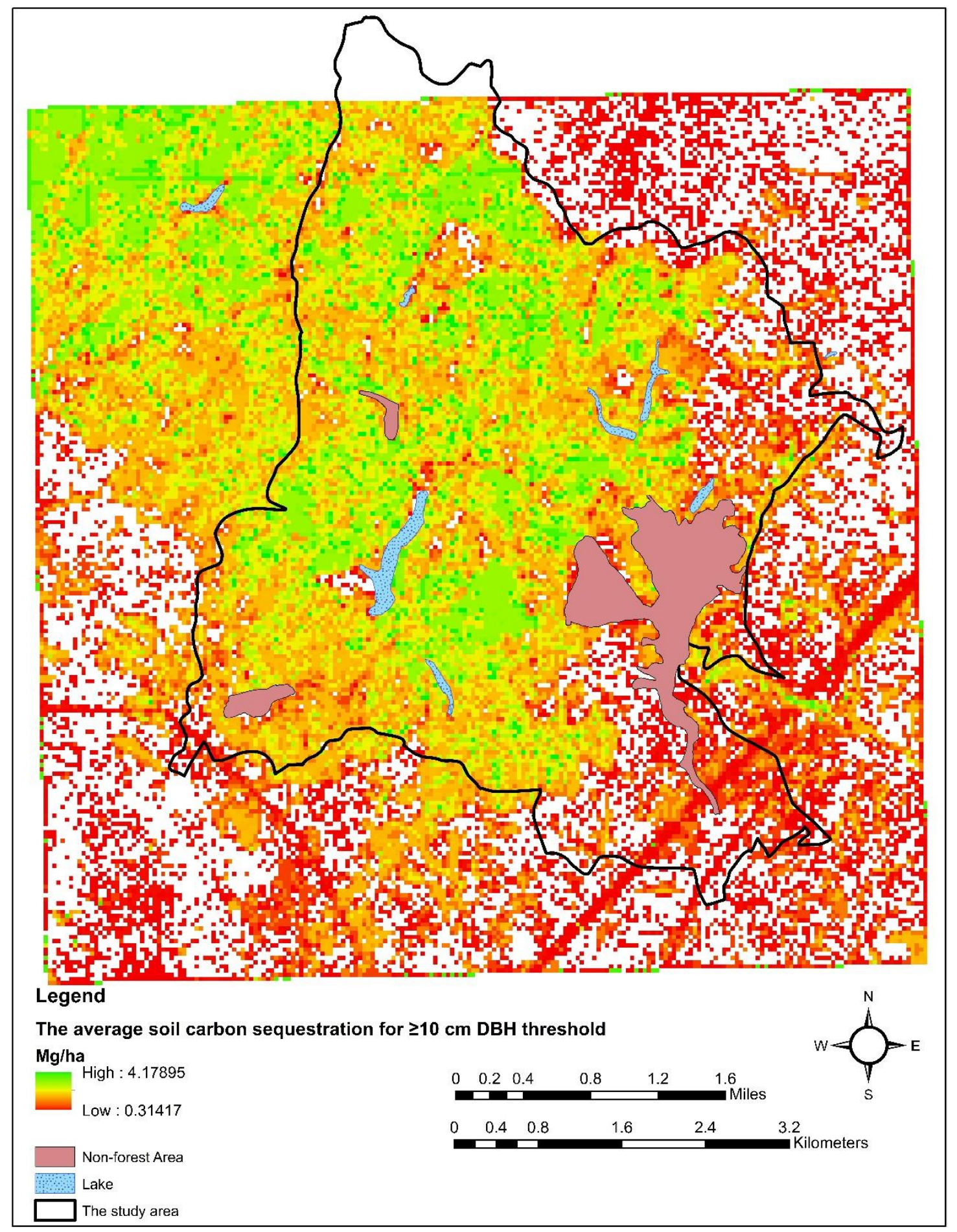

Figure 20. The average carbon amount in the soil for $\geq 10 \mathrm{~cm}$ DBH thresholds derived from RF- $k$ NN analysis 


\subsection{Models using Pleiades for oak}

Also, the metrics derived from the Pleiades satellite were used for calculating oak species responses. The best $\mathrm{R}^{2}$ of linear regression is 0.83 within $\geq 8 \mathrm{~cm}$ DBH thresholds tree count per hectare. The best $\%$ explained variances are $50.10 \%$ and $30.46 \%$ for RF and RF- $k$ NN. All DBH thresholds average volume based on the plot level maps created using linear regression (Figure 21) and RF- $k$ NN (Figure 22). 


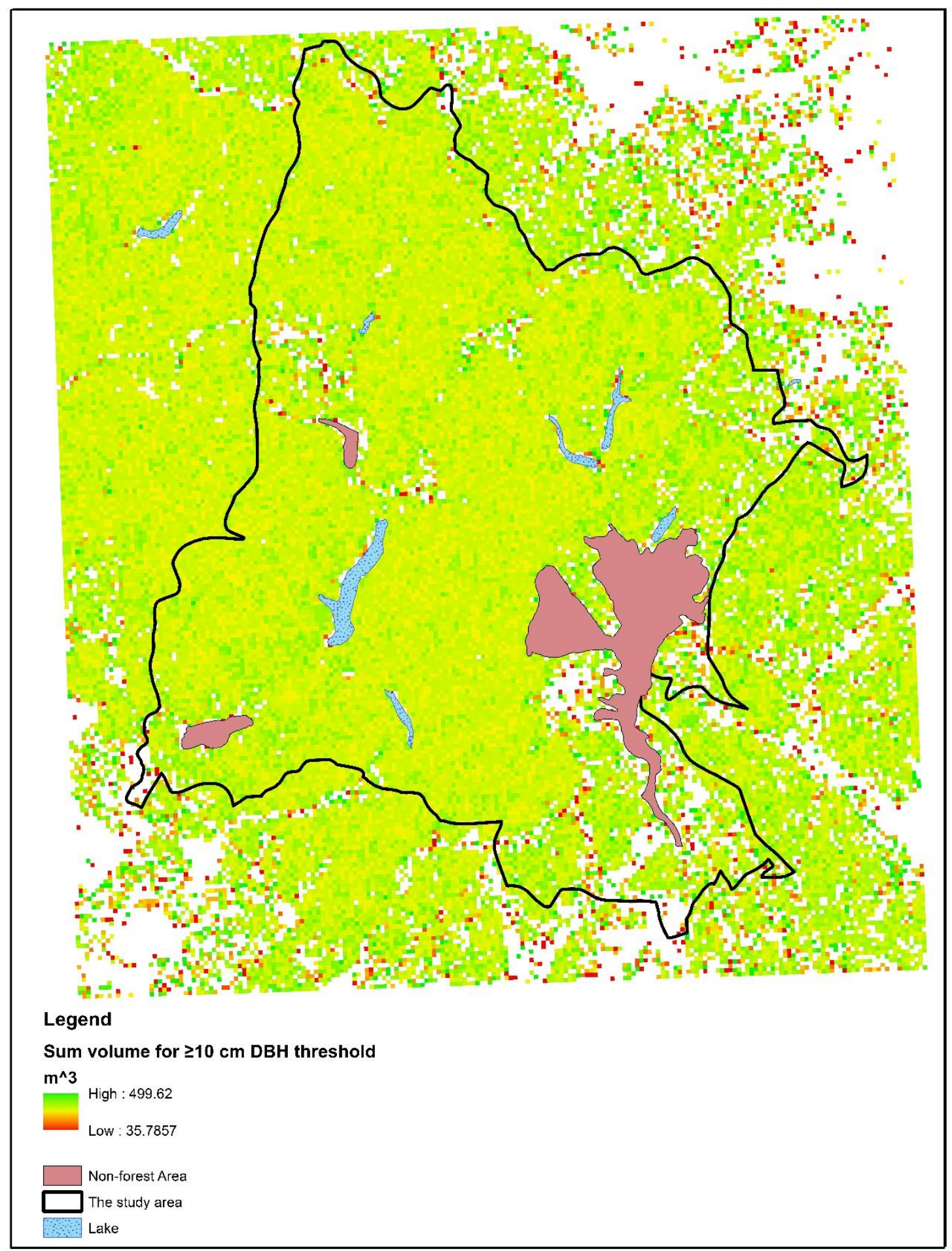

Figure 21.Sum volume based on the plot level derived from regression 


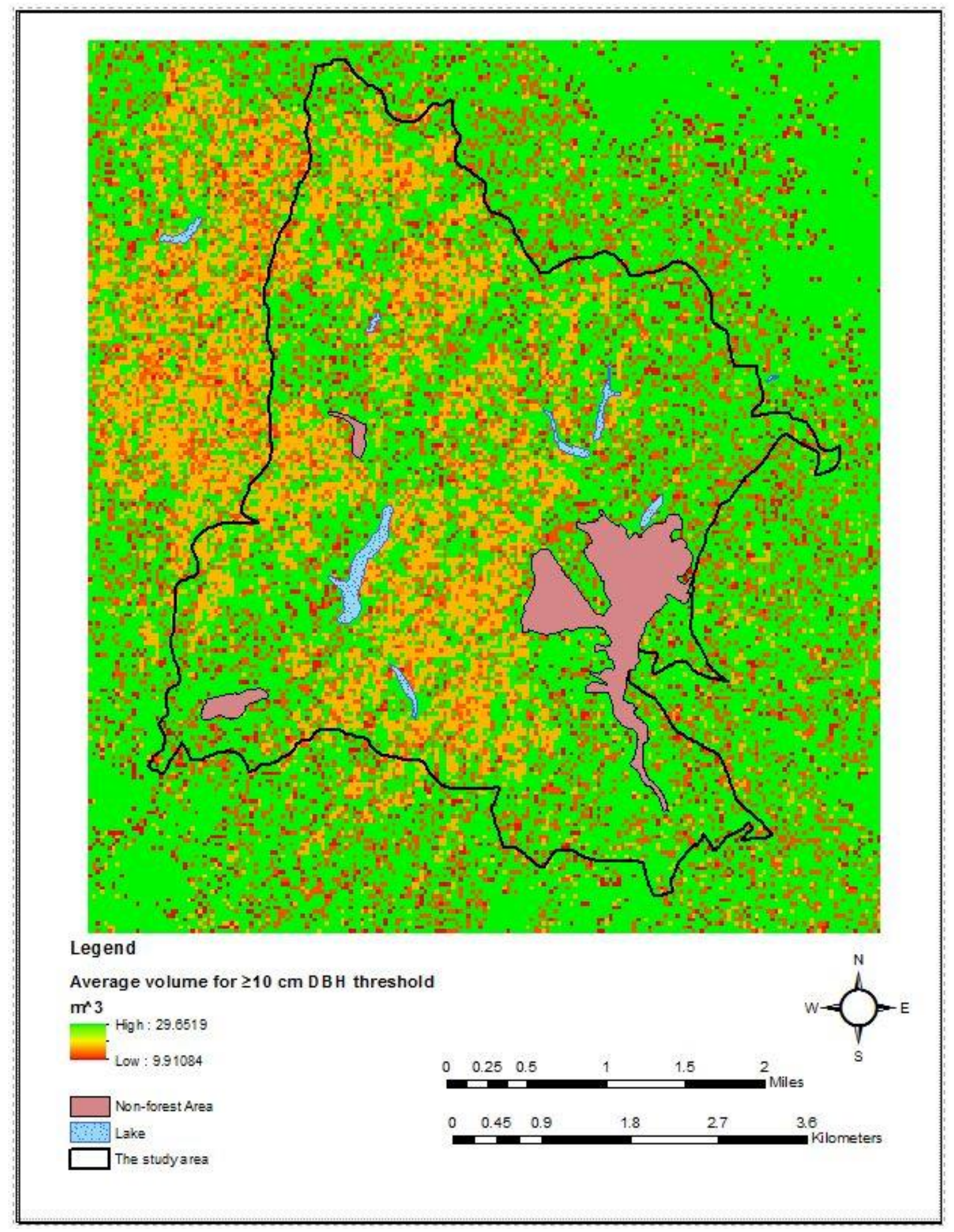

Figure 22. Average volume based on the plot level derived from RF- $k$ NN 


\subsection{Models using Pleiades for maritime pine}

Furthermore, the Pleiades satellite metrics were used for maritime pine. The best result of $\mathrm{R}^{2}$ in linear regression is 0.65 for all $\mathrm{DBH}$ thresholds average carbon amount in the soil based on the plot level, average general biomass per hectare, average carbon amount per hectare, and average carbon amount in the soil per hectare. The best \% explained variances are $39.56 \%$ for $\geq 10 \mathrm{~cm}$ DBH thresholds sum diameter at breast height in RF analysis and $32.87 \%$ for all DBH thresholds sum increment per hectare in RF- $k$ NN. Two average carbon amount per hectare maps were created using regression analysis (Figure 23) and RF- $k$ NN (Figure 24). 


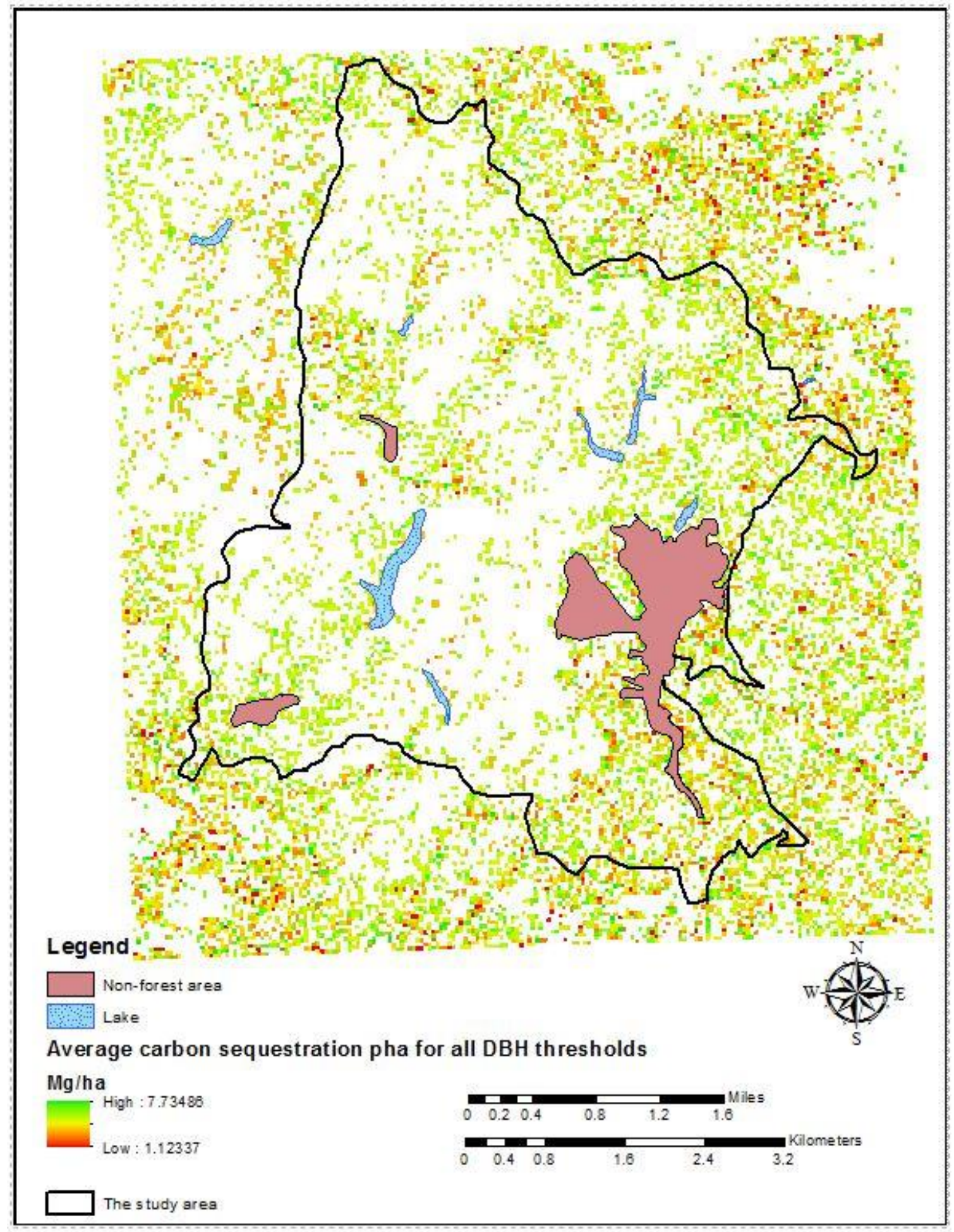

Figure 23. The average carbon amount per hectare for all DBH thresholds derived from regression 


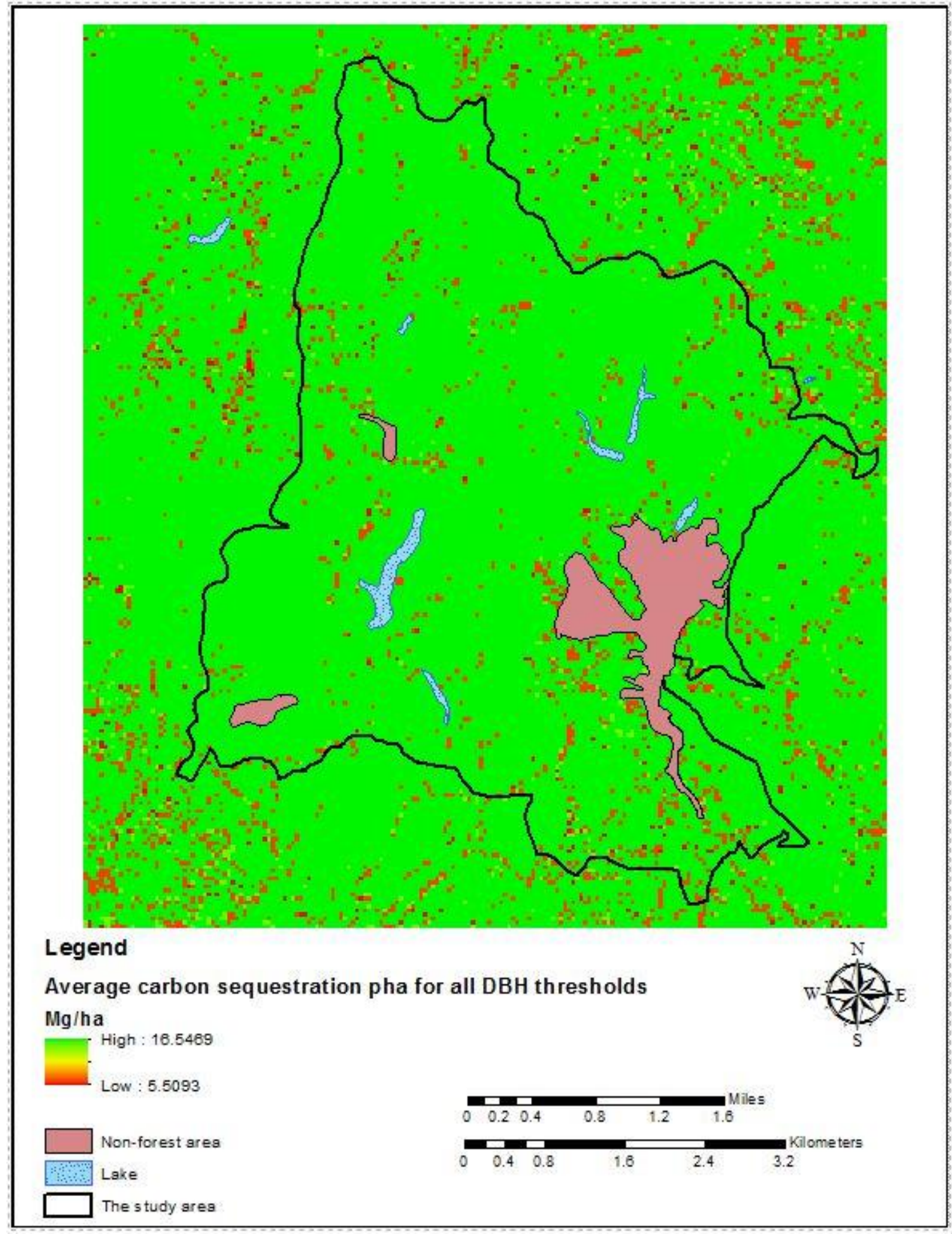

Figure 24. The average carbon amount per hectare for all DBH thresholds derived from RF- $k \mathrm{NN}$ 


\subsection{Models using Göktürk-2 for maritime pine}

Moreover, some maritime pine responses were correlated with the Göktürk-2 metrics. After this process, the best $\mathrm{R}^{2}$ was 0.63 for all $\mathrm{DBH}$ thresholds for average general biomass based on the plot size and per hectare. The best \% explained variances are $39.56 \%$ for $\geq 10 \mathrm{~cm}$ DBH thresholds sum diameter at breast height in RF analysis, and $32.87 \%$ for all DBH thresholds sum increment per hectare in RF- $k \mathrm{NN}$ method. All average carbon amount per hectare maps were created using regression analysis (Figure 25) and RF- $k$ NN (Figure 26). 


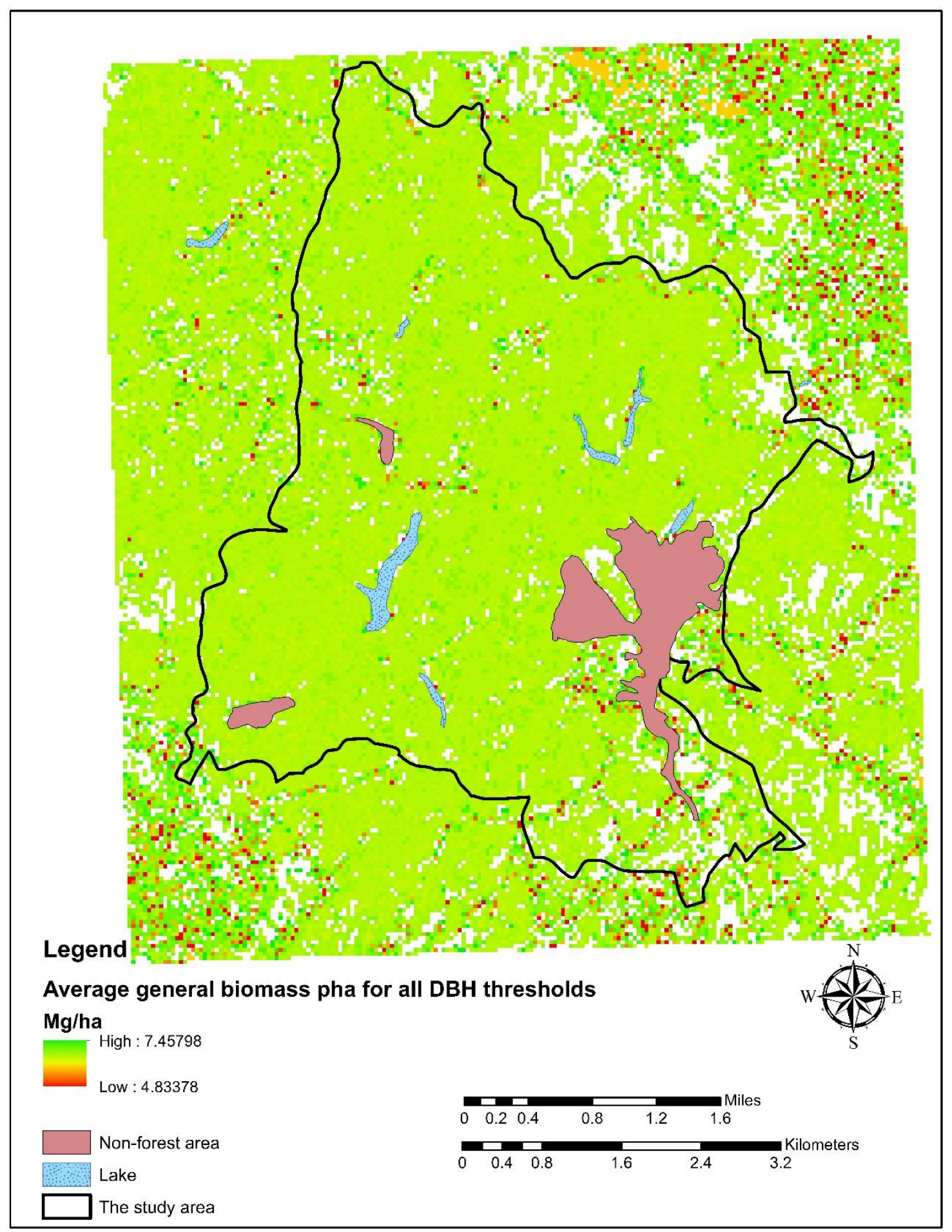

Figure 25. The average general biomass per hectare for all DBH thresholds of maritime pine derived from regression 


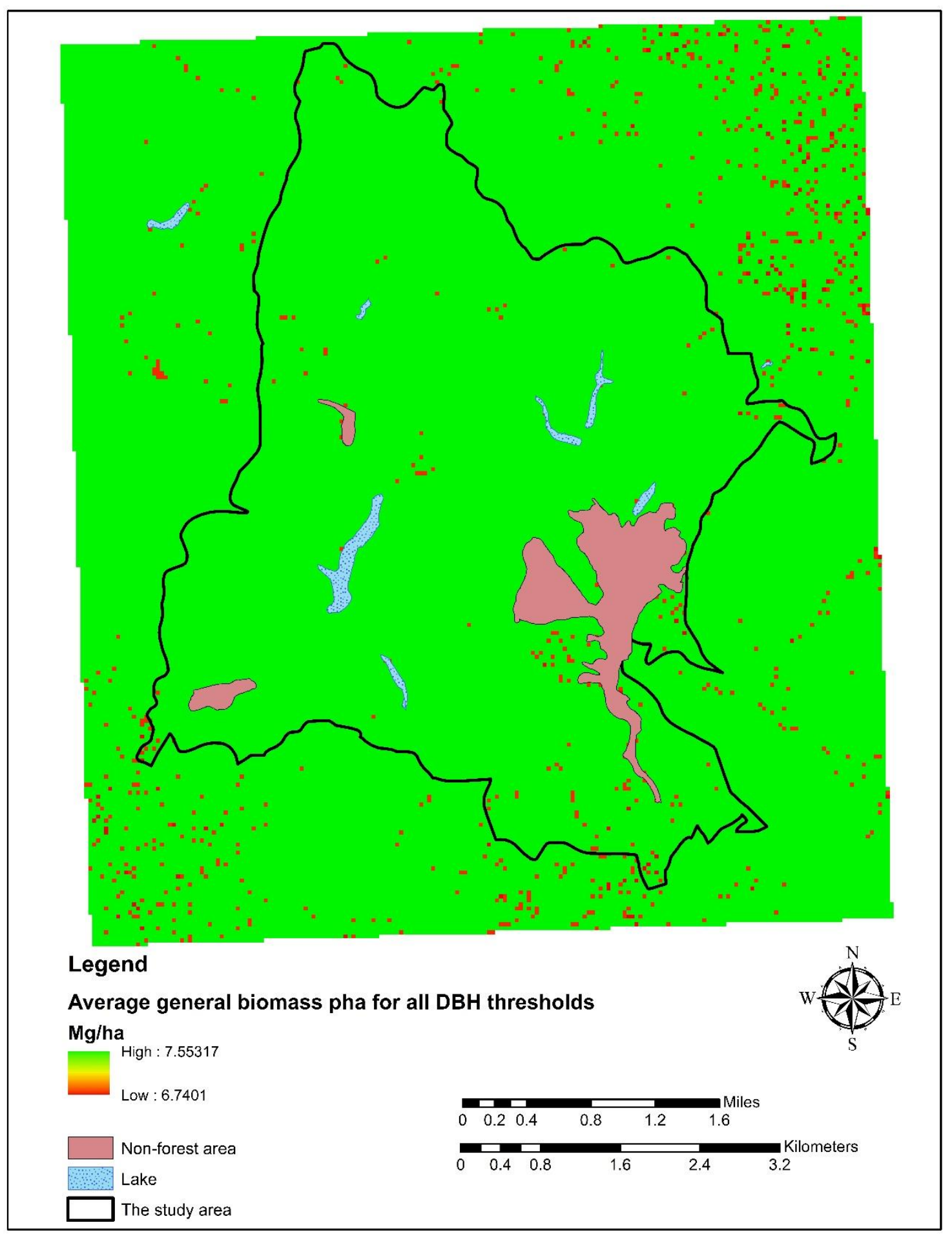

Figure 26. The average general biomass per hectare for all DBH thresholds of maritime pine derived from RF- $k \mathrm{NN}$ 


\subsection{Models using Göktürk-2 for oak}

Last, the Göktürk- 2 metrics were used for oak species. The best $\mathrm{R}^{2}$ is 0.65 for $\geq 8 \mathrm{~cm}$ DBH thresholds increment per hectare. The best \% explained variances are $19.7 \%$ for $\geq 10 \mathrm{~cm}$ DBH thresholds average general biomass based on the plot level in RF method and $6.86 \%$ for $\geq 10 \mathrm{~cm}$ DBH thresholds average basal area per ha in RF- $k \mathrm{NN}$. Two $\geq 8 \mathrm{~cm}$ DBH thresholds increment maps were created using regression analysis (Figure 27) and RF- $k$ NN (Figure 28). 


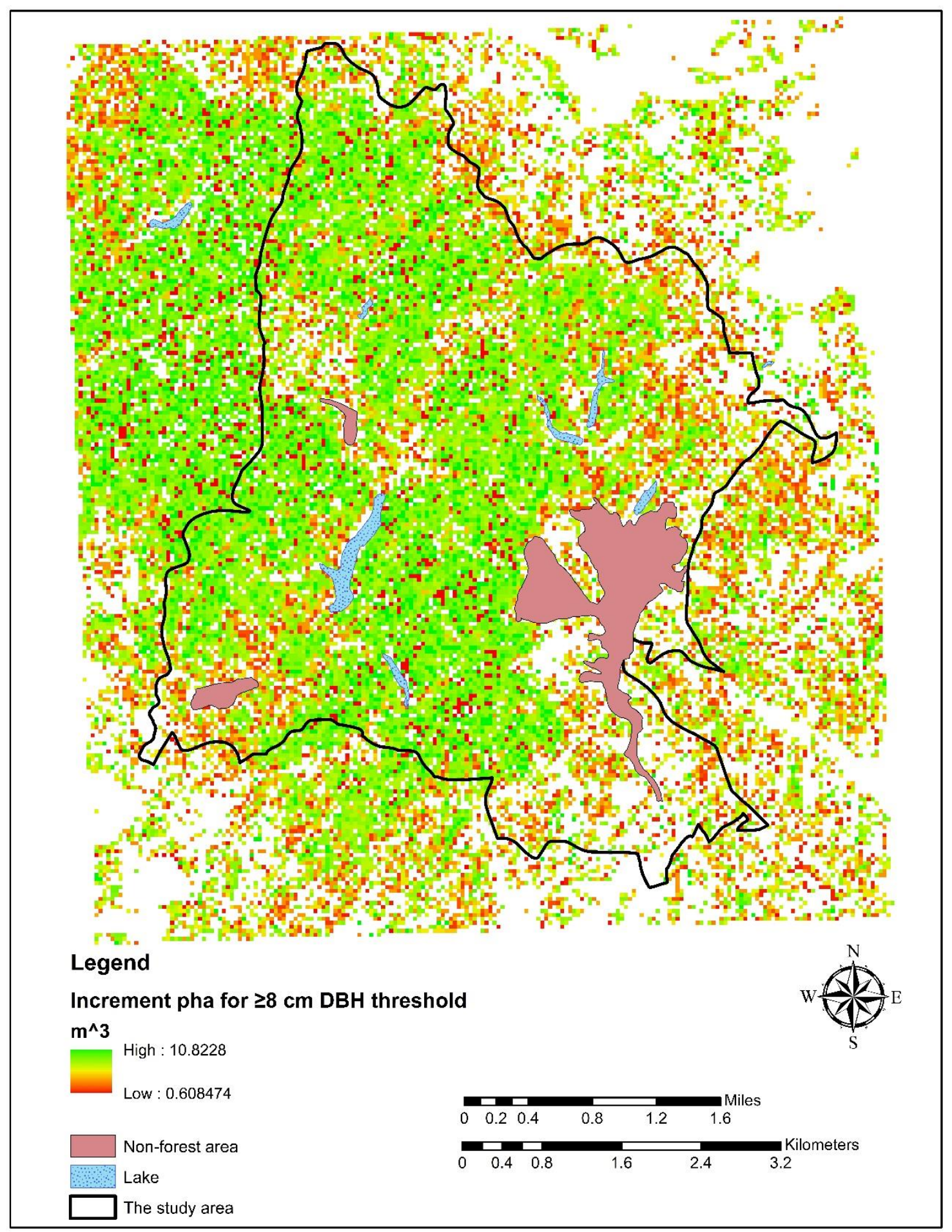

Figure 27. Increment per hectare of oak using regression 


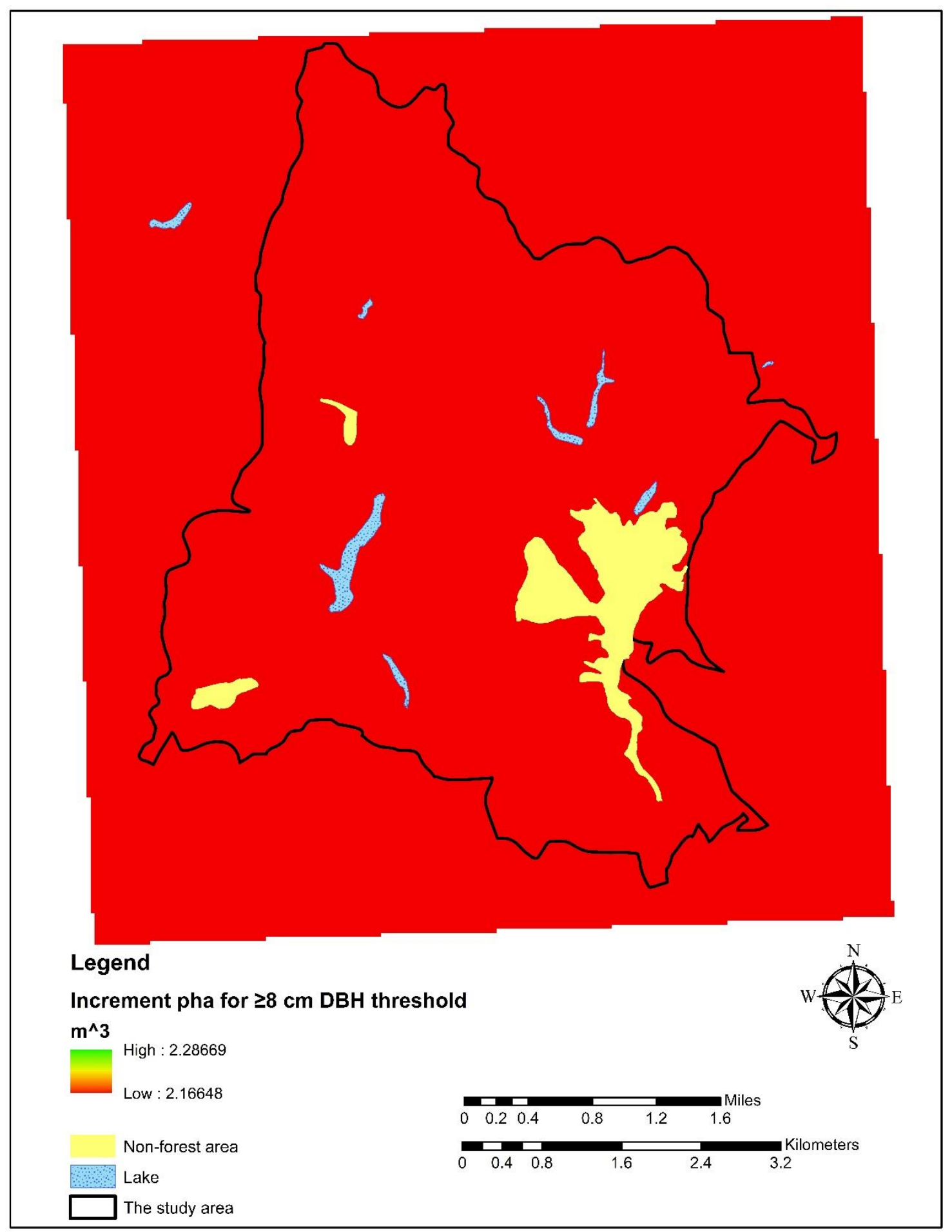

Figure 28. Increment per hectare for $\geq 8 \mathrm{~cm} \mathrm{DBH}$ threshold of oak using RF- $k \mathrm{NN}$ 


\subsection{Comparisons of predictor sources and modelling methods}

Comparisons were made for three select response variables between models using the four predictor sources and three modelling methods (Tables 10,11, and 12). These response variables (trees/ha, volume/ha, and basal area/ha) were chosen because they are of typical interest in forest inventory modelling. These results provide a synthesis of the larger set of results shown in Appendix A. They reveal that the fit statistics are almost always highest for the regression models, regardless of species, predictor source, or response variable. The results also show that explained variance is usually much greater for RF compared to RF- $k \mathrm{NN}$ models trained on the same data. In some cases the \%explained variance was negligible and even negative for RF and RF- $k \mathrm{NN}$ models suggesting almost no explanatory power. Finally, the models for trees/ha were usually better than the models for volume, and the models for volume usually better than the models for basal area.

Table 10 shows fit statistics for the models for tree per ha for the $\geq 10 \mathrm{~cm}$ DBH threshold. 
Table 10. Tree per ha for $\geq 10 \mathrm{~cm} \mathrm{DBH}$ threshold

\begin{tabular}{ccccc}
\hline \multirow{3}{*}{ Species } & Predictor & Adjusted R & Explained & Explained \\
& Source & & Variance & Variance \\
& & & RF & RF- $k$ NN \\
\hline \multirow{3}{*}{ Oak } & All Instruments & $88 \%$ & $61 \%$ & $33 \%$ \\
& LiDAR & $76 \%$ & $61 \%$ & $54 \%$ \\
& Pleiades & $83 \%$ & $50 \%$ & $27 \%$ \\
\hline \multirow{3}{*}{ Pine } & Gokturk-2 & $27 \%$ & $11 \%$ & $0.1 \%$ \\
& All Instruments & $67 \%$ & $41 \%$ & $27 \%$ \\
& LiDAR & $60 \%$ & $39 \%$ & $33 \%$ \\
& Pleiades & $51 \%$ & $30 \%$ & $19 \%$ \\
\hline
\end{tabular}

Table 11 shows fit statistics for volume for $\geq 10 \mathrm{~cm}$ DBH threshold as the response variable. 
Table 11. Volume for $\geq 10 \mathrm{~cm}$ DBH threshold

\begin{tabular}{ccccc}
\hline \multirow{3}{*}{ Species } & $\begin{array}{c}\text { Predictor } \\
\text { Source }\end{array}$ & Adjusted $\mathrm{R}^{2}$ & $\begin{array}{c}\text { Explained } \\
\text { Variance } \\
\mathrm{RF}\end{array}$ & $\begin{array}{c}\text { Explained } \\
\text { Variance } \\
\text { RF- } k \mathrm{NN}\end{array}$ \\
\hline \multirow{3}{*}{ Oak } & All Instruments & $66 \%$ & $57 \%$ & $22 \%$ \\
& LiDAR & $71 \%$ & $58 \%$ & $46 \%$ \\
& Pleiades & $46 \%$ & $30 \%$ & $14 \%$ \\
& Gokturk-2 & $8 \%$ & $17 \%$ & $4 \%$ \\
\hline \multirow{3}{*}{ Pine } & All Instruments & $54 \%$ & $9 \%$ & $9 \%$ \\
& LiDAR & $70 \%$ & $51 \%$ & $32 \%$ \\
& Pleiades & $30 \%$ & $0.8 \%$ & $-6 \%$ \\
& Gokturk-2 & $36 \%$ & $1 \%$ & $-7 \%$ \\
\hline
\end{tabular}

Table 12 shows basal area for $\geq 10 \mathrm{~cm}$ DBH threshold for oak and maritime pine. 
Table 12. Basal area for $\geq 10 \mathrm{~cm}$ DBH threshold

\begin{tabular}{ccccc}
\hline \multirow{3}{*}{ Species } & Predictor & Adjusted $\mathrm{R}^{2}$ & $\begin{array}{c}\text { Explained } \\
\text { Variance } \\
\text { RF }\end{array}$ & $\begin{array}{c}\text { Explained } \\
\text { Variance } \\
\text { RF- } k \mathrm{NN}\end{array}$ \\
\hline \multirow{3}{*}{ Oak } & All Instruments & $25 \%$ & $10 \%$ & $-3 \%$ \\
& LiDAR & $29 \%$ & $17 \%$ & $15 \%$ \\
& Pleiades & $12 \%$ & $-9 \%$ & $-13 \%$ \\
& Gokturk-2 & $16 \%$ & $-4 \%$ & $-15 \%$ \\
\hline \multirow{3}{*}{ Pine } & All Instruments & $62 \%$ & $49 \%$ & $18 \%$ \\
& LiDAR & $62 \%$ & $49 \%$ & $34 \%$ \\
& Pleiades & $31 \%$ & $7 \%$ & $8 \%$ \\
& Gokturk-2 & $27 \%$ & $9 \%$ & $4 \%$ \\
\hline
\end{tabular}

\section{Discussion}

A weakness of this thesis research is that LiDAR data cannot specify the tree species. This research would have been stronger if the models of species had been constructed, but given past research show that this is not possible with LiDAR. For example, LiDAR could be not compatible in the mixed forests, unless used in a hybrid methodology with other remotely sensed information such as multispectral or hyperspectral imagery (Holmgren, et al., 2008; Naidoo, et al., 2012). Alternatively, the plots should be established thru the tree species carefully in the mixed forest. Turkish forests are mixed forests mostly.

According to the results, LiDAR performed better in the conifer cover type compared to the deciduous type. This may be because of the difference in leaf structure. So, leaf-off LiDAR collection would be important to consider in future work. Lu et al., (2012) 
mentioned that segmenting individual deciduous trees using leaf-off LiDAR point cloud data had good potential. Koch et al., (2006) described that a segmentation algorithm worked better in coniferous stands, but; LiDAR data were not sufficient in dense deciduous stands for merging crowns.

LiDAR and satellite technology is still expensive. According to a LiDAR report published by Aydin (2014), although the planning cost per hectare with LiDAR was 17.5 Turkish Liras (TL), the planning cost using the classic forest inventory techniques was between 7 and 10 TL for 2014-2015 forest management plans. It means that making a forest inventory using LiDAR was between 75\%-125\% more than making a forest inventory using classic inventory techniques. However, McRoberts et al., (2012) stated that the two types of inventory can be used for different purposes, and they can be combined so that fewer plots are needed to get the same precision which is called poststratification.

LiDAR data were obtained in early October, 2012 although the ground data were measured in summer 2015. This situation is not so important because the most stands in the field were already mature, or over-mature. The amount of DBH growth in three years was relatively small. Thus, the disparity between ground data and LiDAR collection dates is not a concern.

After the mapping process, the maps produced using RF- $k \mathrm{NN}$ are not compatible in satellite image mapping for this research likely because of small sample size or poor distribution across forest condition. For instance, the predicted variables in RF- $k \mathrm{NN}$ mode go through the nearest neighbor to be fitted. In figure 26, every pixels may go to the same plot's value. So, the whole map was red. RF- $k$ NN may not be a good choice when having a small sample size. Brosofske et al., (2014) described that both regression and $\mathrm{RF}$ allow us to interpolate, while RF- $k \mathrm{NN}$ does not, because of the $k \mathrm{NN}$ part. Also, RF- $k$ NN flexibly and easily handles multivariate responses which are then intrinsically compatible, because of the $k \mathrm{NN}$ part, especially when $k$ equals 1 . 
Mosaic patterns appeared in the maps produced using the GLCM process. When pixels were set as $40 \mathrm{~m}$ x $40 \mathrm{~m}$ in ArcMap 10.3.1, the mosaic patterns disappeared, because when the pixels were set as $40 \mathrm{~m}$, the necessary averaging combined the patterns pixels with other pixels. Also, forest mask was applied with Raster Calculator to remove urban area, lake, road etc. because there could be value for non-forest area. For instance, before forest mask, there could be high or low biomass in non-forest area in the maps. So, these values must be removed. Next research could be to find different methods to remove nonforest area to have optimum method.

The power lines appeared prominently in some maps but not in others. The reason of this could be that the model may use LiDAR data mainly because in LiDAR data, the power lines is conspicuous.

The strengths of this research are that more stand and landscape level analyses can be done with fewer plots using LiDAR and satellite technology, which in the long run creates a lower cost per area. For example, in the operational Turkish inventory 368 plots were established to calculate forest parameters such as volume, DBH, etc. in study area for Turkish forest management plan. In this research, just 86 plots were used for the same study area. So, the field working cost might be less using remote sensing because a forest inventory can be done with less plots. If confidence is gained, then even fewer ground plots would be needed. LiDAR and satellite imagery technologies can create less work, time and money (Susan et al., 2011). If remote sensing data are enhanced with some statistical methods such as $k \mathrm{NN}$-assigned reference sample plot data, the cost could decrease (Holmström et al., 2003).

LiDAR and very high resolution satellite imagery can estimate crown closure, height with high accuracy. These parameters have key roles for forest inventory. Tree height, basal area, crown closure, volume, biomass, carbon deposition, and the number of trees can be calculated using LiDAR and satellite images with greater ease and accuracy than the classic forest inventory techniques (Goetz et al., 2009; Gonzalez et al., 2010). 
High accuracy GPS with a high precision rating of $1.00 \mathrm{~m}$ or less was used for the plots location. The plots location should be fit smoothly in the remote sensing data. Many location errors cause wrong estimations with recreation GPSs. So, high-accuracy GPS should be used for remote sensing working. Frazer et al., (2011) mentioned that they discussed three possible ways that optimization of plot size, sample selection, and the deployment of GPS resources could be used for LiDAR data for biomass calculation. There has been much work done in this area, though it is outside of the scope of my research. For example, see Gobakken and Naesset (2008).

The pulse density of the LiDAR data used in this research was between 12 and 16 per $\mathrm{m}^{2}$. This may be insufficient to scan small DBH trees which are to various degrees masked by larger trees. So, the pulse density should be higher than current pulse density if the small DBH trees need to be measured.

The next study would be making segmentation on LiDAR data and satellite images to partition the areas to the same small areas. Stratifying the forest into cover types using LiDAR and satellite data may be done.

The metrics from only the vegetation indices of Pleiades and Landsat- 8 images were not compatible with forest inventory data. On the other hand, Dash et al., (2015) applied some vegetation indices which are normalized difference vegetation index (NDVI), enhanced vegetation index (EVI), red edge ratio (RE), simple ratio (SR), green ratio (GR), vegetation index (VI), and brightness using four different sizes $(3 \times 3,5 \times 5,15 \times 15$, and $25 \times 25)$. The same process might be applied for Pleiades and Göktürk-2 images.

In this thesis, active remote sensing, LiDAR and passive remote sensing, the Pleiades and the Göktürk-2 were combined and compared. According to the result, LiDAR is the best remote sensing instrument for forest inventory without concerning about the cost of LiDAR data acquisition. The LiDAR had better result than satellite systems (Gonzalez et al., 2010). 
The Pleiades satellite has $0.5 \mathrm{~m}$ resolution while Göktürk-2 has $2.5 \mathrm{~m}$ resolution. The Pleiades had better result for deciduous trees based on RF analysis even though Göktürk2 had better result for coniferous trees. The resolution and spectral differences between two satellite images may affect results of coniferous and deciduous trees (Tuominen \& Pekkarinen, 2005). According to these results, the higher-resolution satellite image is preferred be used for deciduous trees.

Generally, band 2 (Green) and band 4 (NIR) were the best bands for calculating forest inventory attributes in deciduous trees. Band 3 (Red) and band 4 were useful bands to correlate between satellite images and the ground data for coniferous trees. Ozdemir, (2005) described that NIR bands were useful for forest inventory studies.

This research showed that the regression analysis was the best statistical analysis because the higher results were calculated using regression analysis. Then, RF analysis had better result than RF- $k \mathrm{NN}$. When the maps created from regression analysis and RF- $k \mathrm{NN}$ were interpreted, the regression maps are more consistent in this research. The threshold of the regression maps are very close to the ground data which is important, because it lends confidence to the result. Mcinerney et al., (2010) mentioned that a good correlation was found between LiDAR data and ground data using $k \mathrm{NN}$ estimation for forest canopy height retrieval, but; they found worse results using $k \mathrm{NN}$ methods when satellite image and LiDAR data were combined.

There were three DBH thresholds which are all DBH thresholds, $\geq 8 \mathrm{~cm}$ DBH thresholds and $\geq 10 \mathrm{~cm}$ DBH thresholds. This project indicated that bigger DBH thresholds had better outcome. In some forest inventory, $\geq 8 \mathrm{~cm}$ DBH thresholds had a better product, although in the others, $\geq 10 \mathrm{~cm}$ DBH thresholds had better results.

While making the GLCM process in ENVI software, the ENVI allows us to select which image process windows texture evaluation can be set. The working area can be selected. This research showed that if the size of image process windows was close to the plot size, the models have better outputs (Lu \& Batistella, 2005). For instance, the Göktürk-2 has $2.5 \mathrm{~m}$ resolution which means that its one pixel is a $2.5 \mathrm{~m} \times 2.5 \mathrm{~m}$ square. The plot radius 
was $20 \mathrm{~m}$. The image process windows should be set as 9x9 or $11 \times 11$. In this case, the image process windows can cover all the plot, and the better result can be obtained.

GLCM has 8 options: mean, variance, homogeneity, contrast, dissimilarity, entropy, second moment, and correlation. Entropy option showed more predictive power for deciduous trees more. Correlation, variance, and second moment options were used more for coniferous trees. Champion et al., (2013) described that contrast, second moment, homogeneity, and correlation had strong relationship with forest stand structure such as forest rows and stand density. Energy and entropy were highly correlated with stand age.

\subsection{Conclusion}

The aim of this study was to develop inventory models for Istanbul forests using the best available remote sensing data and evaluate their quality. So, many forest inventory approaches were calculated with Pleiades, Göktürk-2, and LiDAR data separately and together. RF, RF- $k \mathrm{NN}$, and regression were used for statistical methods. After all process, the remote sensing instruments can be applied for Istanbul forests with less plot amount for forest inventory calculations.

This study showed that the remote sensing instruments such as satellite images, LiDAR data can be contributed Turkish forest management plans for large areas forest inventory with less work. 


\section{References}

Almeida, D. R., Nelson, B. W., Schietti, J., Gorgens, E. B., Resende, A. F., Stark, S. C., \& Valbuena, R. (2016). Contrasting fire damage and fire susceptibility between seasonally flooded forest and upland forest in the Central Amazon using portable profiling LiDAR. Remote Sensing of Environment, 184, 153-160. doi:10.1016/j.rse.2016.06.017

Andersen, H., McGaughey, R. J., \& Reutebuch, S. E. (2005). Estimating forest canopy fuel parameters using LIDAR data. Remote Sensing of Environment, 94(4), 441449. doi:10.1016/j.rse.2004.10.013

Asan, Ü. (1995). Global climate change and carbon accumulation in Turkish forests. Journal of the Faculty of Forestry Istanbul University| İstanbul Üniversitesi Orman Fakültesi Dergisi, 45(1-2), 23-38.

Avery, T. E., \& Burkhart, H. E. (2001). Forest measurements 5th ed.

Beguet, B., Chehata, N., Boukir, S., \& Guyon, D. (2014, July). Classification of forest structure using very high resolution Pleiades image texture. In 2014 IEEE Geoscience and Remote Sensing Symposium (pp. 2324-2327). IEEE.

Brandtberg, T. (2007). Classifying individual tree species under leaf-off and leaf-on conditions using airborne lidar. ISPRS Journal of Photogrammetry and Remote Sensing, 61(5), 325-340.

Breiman, L. (2001). Random forests. Machine learning, 45(1), 5-32.

Brosofske, K. D., Froese, R. E., Falkowski, M. J., \& Banskota, A. (2014). A review of methods for mapping and prediction of inventory attributes for operational forest management. Forest Science, 60(4), 733-756.

Castillo-Santiago, M. A., Ricker, M., \& de Jong, B. H. J. (2010). Estimation of tropical forest structure from SPOT-5 satellite images. International Journal of Remote Sensing, 31(10), 2767-2782. doi:10.1080/01431160903095460 
Coburn, C. A., \& Roberts, A. C. B. (2004). A multiscale texture analysis procedure for improved forest stand classification. International Journal of Remote Sensing, 25(20), 4287-4308. doi:10.1080/0143116042000192367

Crookston, N. L.; Finley, A. O. 2007. yalmpute: An R Package for k-NN Imputation. Journal of Statistical Software. 23(10):1-16.

Dash, J. P., Watt, M. S., Bhandari, S., \& Watt, P. (2015). Characterising forest structure using combinations of airborne laser scanning data, RapidEye satellite imagery and environmental variables. Forestry, cpv048.

Deo, R. K., Froese, R. E., Falkowski, M. J., \& Hudak, A. T. (2016). Optimizing Variable Radius Plot Size and LiDAR Resolution to Model Standing Volume in Conifer Forests. Canadian Journal of Remote Sensing, 42(5): 428-4421.

Dalponte, M., Bruzzone, L., \& Gianelle, D. (2012). Tree species classification in the Southern Alps based on the fusion of very high geometrical resolution multispectral/hyperspectral images and LiDAR data. Remote Sensing of Environment, 123, 258-270. doi:10.1016/j.rse.2012.03.013

Dupuy, S., Lainé, G., Tassin, J., \& Sarrailh, J. M. (2013). Characterization of the horizontal structure of the tropical forest canopy using object-based LiDAR and multispectral image analysis. International Journal of Applied Earth Observation and Geoinformation, 25, 76-86. doi:10.1016/j.jag.2013.04.001

Eckert, S. (2012). Improved forest biomass and carbon estimations using texture measures from WorldView-2 satellite data. Remote sensing, 4(4), 810-829.

Falkowski, M. J., Evans, J. S., Martinuzzi, S., Gessler, P. E., \& Hudak, A. T. (2009). Characterizing forest succession with lidar data: An evaluation for the Inland Northwest, USA. Remote Sensing of Environment, 113(5), 946-956. doi:10.1016/j.rse.2009.01.003 
Falkowski, M. J., Hudak, A. T., Crookston, N. L., Gessler, P. E., Uebler, E. H., \& Smith, A. M. S. (2010). Landscape-scale parameterization of a tree-level forest growth model: ak-nearest neighbor imputation approach incorporating LiDAR data. Canadian Journal of Forest Research, 40(2), 184-199. doi:10.1139/x09-183

Frazer, G., Magnussen, S., Wulder, M., and Niemann, K. (2011). Simulated impact of sample plot size and co-registration error on the accuracy and uncertainty of LiDAR-derived estimates of forest stand biomass Remote Sensing of Environment, 115(2), 636-649.

Fuller, D. O. (2000). Satellite remote sensing of biomass burning with optical and thermal sensors. Progress in Physical Geography, 24(4), 543-561.

General Directorate of Forestry, T. (2012). Ecosystem-Based Functional Forest Management Plan. Istanbul: the Republic of Turkey, Ministry of Forestry and Water Affairs.

García, M., Riaño, D., Chuvieco, E., \& Danson, F. M. (2010). Estimating biomass carbon stocks for a Mediterranean forest in central Spain using LiDAR height and intensity data. Remote Sensing of Environment, 114(4), 816-830. doi:10.1016/j.rse.2009.11.021

Goetz, S. J., Baccini, A., Laporte, N. T., Johns, T., Walker, W., Kellndorfer, J., ... \& Sun, M. (2009). Mapping and monitoring carbon stocks with satellite observations: a comparison of methods. Carbon balance and management, 4(1), 2.

Gonzalez, P., Asner, G. P., Battles, J. J., Lefsky, M. A., Waring, K. M., \& Palace, M. (2010). Forest carbon densities and uncertainties from Lidar, QuickBird, and field measurements in California. Remote Sensing of Environment, 114(7), 1561-1575.

Guo, L., Chehata, N., Mallet, C., \& Boukir, S. (2011). Relevance of airborne lidar and multispectral image data for urban scene classification using Random Forests. ISPRS Journal of Photogrammetry and Remote Sensing, 66(1), 56-66. 
Haralick, R. M., \& Shanmugam, K., \& Dinstein, I. (1973). Textural features for image classification. IEEE Transactions on systems, man, and cybernetics, (6), 610-621.

Haralick, R. M. (1979). Statistical and structural approaches to texture. Proceedings of the IEEE, 67(5), 786-804.

Holmgren, J., Persson, Å., \& Söderman, U. (2008). Species identification of individual trees by combining high resolution LiDAR data with multi- spectral images. International Journal of Remote Sensing, 29(5), 1537-1552.

Holmstrom, H., Kallur, H., \& Stahl, G. (2003). Cost-plus-loss analyses of forest inventory strategies based on $\mathrm{kNN}$-assigned reference sample plot data. Silva Fennica, 37(3), 381-398.

Hopkinson, C., Chasmer, L., Barr, A. G., Kljun, N., Black, T. A., \& McCaughey, J. H. (2016). Monitoring boreal forest biomass and carbon storage change by integrating airborne laser scanning, biometry and eddy covariance data. Remote Sensing of Environment, 181, 82-95. doi:10.1016/j.rse.2016.04.010

Hu, T., Su, Y., Xue, B., Liu, J., Zhao, X., Fang, J., \& Guo, Q. (2016). Mapping Global Forest Aboveground Biomass with Spaceborne LiDAR, Optical Imagery, and Forest Inventory Data. Remote Sensing, 8(7), 565. doi:10.3390/rs8070565

Hudak, A. T., Bright, B. C., Pokswinski, S. M., Loudermilk, E. L., O’Brien, J. J., Hornsby, B. S., Silva, C. A. (2016). Mapping Forest Structure and Composition from Low-Density LiDAR for Informed Forest, Fuel, and Fire Management at Eglin Air Force Base, Florida, USA. Canadian Journal of Remote Sensing, 42(5), 411-427. doi:10.1080/07038992.2016.1217482

Hudak, A. T., Crookston, N. L., Evans, J. S., Hall, D. E., \& Falkowski, M. J. (2008). Nearest neighbor imputation of species-level, plot-scale forest structure attributes from LiDAR data. Remote Sensing of Environment, 112(5), 2232-2245. doi:10.1016/j.rse.2007.10.009 
Hudak, A. T., Evans, J. S., \& Stuart Smith, A. M. (2009). LiDAR utility for natural resource managers. Remote Sensing, 1(4), 934-951.

Hummel, S., Hudak, A. T., Uebler, E. H., Falkowski, M. J., \& Megown, K. A. (2011). A comparison of accuracy and cost of LiDAR versus stand exam data for landscape management on the Malheur National Forest. Journal of forestry, 109(5), 267273.

Hyde, P., Dubayah, R., Peterson, B., Blair, J., Hofton, M., Hunsaker, C., Walker, W. (2005). Mapping forest structure for wildlife habitat analysis using waveform lidar: Validation of montane ecosystems. Remote Sensing of Environment, 96(34), 427-437. doi:10.1016/j.rse.2005.03.005

Kalkan, K., Filiz, B. G., Özer, O., \& Teke, M. (2015). Vegetation discrimination analysis from Göktürk-2 imagery. In Recent Advances in Space Technologies (RAST), 2015 7th International Conference on (pp. 329-332). IEEE.

Kayitakire, F., Hamel, C., \& Defourny, P. (2006). Retrieving forest structure variables based on image texture analysis and IKONOS-2 imagery. Remote Sensing of Environment, 102(3-4), 390-401. doi:10.1016/j.rse.2006.02.022

Koch, B., Heyder, U., \& Weinacker, H. (2006). Detection of individual tree crowns in airborne lidar data. Photogrammetric Engineering \& Remote Sensing, 72(4), 357363.

Lak, A. M., Zoej, M. J. V., \& Mokhtarzade, M. (2016). A new method for road detection in urban areas using high-resolution satellite images and Lidar data based on fuzzy nearest-neighbor classification and optimal features. Arabian Journal of Geosciences, 9(5), 1-11.

Lillesand, T., Kiefer, R. W., \& Chipman, J. (2014). Remote sensing and image interpretation. John Wiley \& Sons. 
Lu, D., \& Batistella, M. (2005). Exploring TM image texture and its relationships with biomass estimation in Rondônia, Brazilian Amazon. Acta Amazonica, 35(2), 249257.

Lu, X., Guo, Q., Li, W., \& Flanagan, J. (2014). A bottom-up approach to segment individual deciduous trees using leaf-off LiDAR point cloud data. ISPRS Journal of Photogrammetry and Remote Sensing, 94, 1-12.

Maack, J., Lingenfelder, M., Weinacker, H., \& Koch, B. (2016). Modelling the standing timber volume of Baden-Württemberg - A large-scale approach using a fusion of Landsat, airborne LiDAR and National Forest Inventory data. International Journal of Applied Earth Observation and Geoinformation, 49, 107-116. doi:10.1016/j.jag.2016.02.004

Martinuzzi, S., Vierling, L. A., Gould, W. A., Falkowski, M. J., Evans, J. S., Hudak, A. T., \& Vierling, K. T. (2009). Mapping snags and understory shrubs for a LiDARbased assessment of wildlife habitat suitability. Remote Sensing of Environment, 113(12), 2533-2546. doi:10.1016/j.rse.2009.07.002

Mcinerney, D. O., Suarez-Minguez, J., Valbuena, R., \& Nieuwenhuis, M. (2010). Forest canopy height retrieval using LiDAR data, medium-resolution satellite imagery and kNN estimation in Aberfoyle, Scotland. Forestry, 83(2), 195-206.

McRoberts, R., Gobakken, T., \& Næsset, E. (2012). Post-stratified estimation of forest area and growing stock volume using lidar-based stratifications. Remote Sensing of Environment, 125, 157-166.

Means, J. E., Acker, S. A., Fitt, B. J., Renslow, M., Emerson, L., \& Hendrix, C. J. (2000). Predicting forest stand characteristics with airborne scanning lidar. Photogrammetric Engineering and Remote Sensing, 66(11), 1367-1372.

Murray, H., Lucieer, A., \& Williams, R. (2010). Texture-based classification of subAntarctic vegetation communities on Heard Island. International Journal of 
Applied Earth Observation and Geoinformation, 12(3), 138-149.

doi:10.1016/j.jag.2010.01.006

Naidoo, L., Cho, M. A., Mathieu, R., \& Asner, G. (2012). Classification of savanna tree species, in the Greater Kruger National Park region, by integrating hyperspectral and LiDAR data in a Random Forest data mining environment. ISPRS Journal of Photogrammetry and Remote Sensing, 69, 167-179.

Nelson, R., Oderwald, R., \& Gregoire, T. G. (1997). Separating the ground and airborne laser sampling phases to estimate tropical forest basal area, volume, and biomass. Remote Sensing of Environment, 60(3), 311-326.

Ohmann, Janet L., \& Gregory, Matthew J. (2002). Predictive mapping of forest composition and structure with direct gradient analysis and nearest- neighbor imputation in coastal Oregon, U.S.A. Canadian Journal of Forest Research, 32(4), 725-741. doi:10.1139/x02-011

Özdemir, İ. (2004). Possibilities of using satellite data in forest inventory. Turkish Journal of Forestry| Türkiye Ormanc1lık Dergisi, 1, 84-96.

Ozdemir, I., \& Karnieli, A. (2011). Predicting forest structural parameters using the image texture derived from WorldView-2 multispectral imagery in a dryland forest, Israel. International Journal of Applied Earth Observation and Geoinformation, 13(5), 701-710.

Özkan, U. Y., \& Yeşil, A.. (2016). Producing forest stand maps from Ikonos image based on object-based classification. İstanbul Üniversitesi Orman Fakültesi Dergisi, 66(2). doi:10.17099/jffiu.95674

Pal, M. (2005). Random forest classifier for remote sensing classification. International Journal of Remote Sensing, 26(1), 217-222. doi:10.1080/01431160412331269698

Pandey S., \& Bright, C.L. (2008). What are degrees of Freedom? Soc Work Res, 2 pp. $119-128$ 
Price, O. F., \& Gordon, C. E. (2016). The potential for LiDAR technology to map fire fuel hazard over large areas of Australian forest. J Environ Manage, 181, 663-673. doi:10.1016/j.jenvman.2016.08.042

Raev, I., Asan, Ü., \& Grozev, O. (1997). Accumulation of $\mathrm{CO}_{2}$ in the above-ground biomass of the forests In Bulgaria and Turkey in the recent decades. In Proceedings of the XI world Forestry Congress (Vol. 1, pp. 131-138).

Sasaki, N., Asner, G. P., Pan, Y., Knorr, W., Durst, P. B., Ma, H. O., . . Putz, F. E. (2016). Sustainable Management of Tropical Forests Can Reduce Carbon Emissions and Stabilize Timber Production. Frontiers in Environmental Science, 4. doi: $10.3389 /$ fenvs. 2016.00050

Sachs, D. L., Sollins, P., \& Cohen, W. B. (1998). Detecting landscape changes in the interior of British Columbia from 1975 to 1992 using satellite imagery. Canadian Journal of Forest Research, 28(1), 23-36.

Singh, K. K., Bianchetti, R. A., Chen, G., \& Meentemeyer, R. K. (2016). Assessing effect of dominant land-cover types and pattern on urban forest biomass estimated using LiDAR metrics. Urban Ecosystems. doi:10.1007/s11252-016-0591-8

Swatantran, A., Tang, H., Barrett, T., DeCola, P., \& Dubayah, R. (2016). Rapid, HighResolution Forest Structure and Terrain Mapping over Large Areas using Single Photon Lidar. Sci Rep, 6, 28277. doi:10.1038/srep28277

Tuominen, S., \& Pekkarinen, A. (2005). Performance of different spectral and textural aerial photograph features in multi-source forest inventory. Remote sensing of Environment, 94(2), 256-268.

Wallis, C. I., Paulsch, D., Zeilinger, J., Silva, B., Fernández, G. F. C., Brandl, R., ... \& Bendix, J. (2016). Contrasting performance of Lidar and optical texture models in predicting avian diversity in a tropical mountain forest. Remote Sensing of Environment, 174, 223-232. 
Wulder, M. A., Bater, C. W., Coops, N. C., Hilker, T., \& White, J. C. (2008). The role of LiDAR in sustainable forest management. The Forestry Chronicle, 84(6), 807826.

Wunderle, A. L., Franklin, S. E., \& Guo, X. G. (2007). Regenerating boreal forest structure estimation using SPOT-5 pan-sharpened imagery. International Journal of Remote Sensing, 28(19), 4351-4364. doi:10.1080/01431160701244849 


\section{Appendix A.}

Table 13. Forest inventory using all remote sensing instruments for oak species

\begin{tabular}{|c|c|c|c|c|}
\hline All_Oak & $\mathbf{r F}$ & Multiple_R $\mathbf{R}^{2}$ & Adjusted $R^{2}$ & yai \\
\hline E.Tree & 62.72 & 0.91 & 0.90 & 32.97 \\
\hline T.Tree & 59.51 & 0.91 & 0.89 & 30.46 \\
\hline T.tpha & 60.82 & 0.90 & 0.88 & 32.72 \\
\hline E.tpha & 64.50 & 0.86 & 0.84 & 33.06 \\
\hline E.av.above.pha & 57.78 & 0.77 & 0.74 & 20.08 \\
\hline E.av.litter.pha & 57.18 & 0.77 & 0.74 & 22.41 \\
\hline E.av.above & 57.50 & 0.76 & 0.73 & 22.05 \\
\hline All.av.vol & 55.80 & 0.75 & 0.72 & 31.58 \\
\hline T.av.gen.pha & 57.98 & 0.75 & 0.71 & 22.96 \\
\hline E.sum.dbh & 53.65 & 0.75 & 0.71 & 23.18 \\
\hline E.Increment.pha & 21.91 & 0.75 & 0.71 & 12.12 \\
\hline E.av.car.pha & 57.28 & 0.75 & 0.71 & 21.53 \\
\hline T.sum.dbh & 39.06 & 0.75 & 0.71 & 22.36 \\
\hline All.Tree & 67.15 & 0.75 & 0.71 & 30.31 \\
\hline All.tpha & 56.25 & 0.75 & 0.71 & 29.79 \\
\hline T.av.litter.pha & 58.67 & 0.74 & 0.70 & 25.03 \\
\hline T.av.car.pha & 58.08 & 0.74 & 0.70 & 22.51 \\
\hline T.av.car.soil.pha & 58.45 & 0.74 & 0.70 & 22.64 \\
\hline All.av.car.soil.pha & 53.18 & 0.73 & 0.69 & 17.64 \\
\hline T.av.ba.ha & 55.42 & 0.73 & 0.69 & 23.52 \\
\hline T.av.above.pha & 57.95 & 0.73 & 0.69 & 21.53 \\
\hline T.av.litter & 57.43 & 0.73 & 0.69 & 23.66 \\
\hline T.av.car & 58.60 & 0.73 & 0.69 & 22.37 \\
\hline T.av.car.soil & 58.51 & 0.73 & 0.69 & 22.49 \\
\hline T.av.under & 58.18 & 0.73 & 0.68 & 22.39 \\
\hline
\end{tabular}




\begin{tabular}{|c|c|c|c|c|}
\hline T.av.under.pha & 57.20 & 0.73 & 0.68 & 21.94 \\
\hline E.av.car.soil.pha & 57.16 & 0.73 & 0.68 & 22.44 \\
\hline T.av.dbh & 51.82 & 0.73 & 0.68 & 25.97 \\
\hline E.av.vol & 58.38 & 0.72 & 0.68 & 21.80 \\
\hline E.av.ba.ha & 53.41 & 0.72 & 0.68 & 23.24 \\
\hline T.av.above & 57.65 & 0.71 & 0.67 & 23.62 \\
\hline T.av.gen & 57.68 & 0.71 & 0.67 & 23.74 \\
\hline E.av.car.soil & 57.78 & 0.71 & 0.66 & 21.42 \\
\hline T.av.vol.pha & 55.75 & 0.71 & 0.66 & 24.58 \\
\hline E.Av.BA & 53.61 & 0.71 & 0.66 & 24.83 \\
\hline T.sum.vol & 57.18 & 0.71 & 0.66 & 22.42 \\
\hline E.av.under & 57.57 & 0.71 & 0.66 & 22.28 \\
\hline E.av.litter & 57.83 & 0.71 & 0.66 & 21.64 \\
\hline T.Av.BA & 53.11 & 0.71 & 0.66 & 23.70 \\
\hline E.av.vol.pha & 56.92 & 0.71 & 0.66 & 22.69 \\
\hline E.av.gen.pha & 57.30 & 0.70 & 0.66 & 23.21 \\
\hline E.av.gen & 57.63 & 0.70 & 0.66 & 20.94 \\
\hline All.av.above & 53.02 & 0.70 & 0.65 & 19.24 \\
\hline All.av.above.pha & 56.32 & 0.70 & 0.65 & 17.63 \\
\hline E.av.car & 57.16 & 0.69 & 0.64 & 20.75 \\
\hline All.Sum.DBH & 53.75 & 0.69 & 0.64 & 26.46 \\
\hline E.av.under.pha & 57.33 & 0.69 & 0.64 & 21.71 \\
\hline All.Av.DBH & 37.82 & 0.67 & 0.62 & 13.48 \\
\hline All.av.car.soil & 53.83 & 0.66 & 0.61 & 18.68 \\
\hline All.av.ba.ha & 48.23 & 0.66 & 0.60 & 19.05 \\
\hline All.av.car & 54.15 & 0.65 & 0.60 & 19.62 \\
\hline All.av.litter.pha & 52.99 & 0.65 & 0.60 & 19.35 \\
\hline All.av.gen.pha & 52.45 & 0.65 & 0.60 & 18.64 \\
\hline All.av.car.pha & 53.73 & 0.65 & 0.60 & 18.27 \\
\hline
\end{tabular}




\begin{tabular}{|c|c|c|c|c|}
\hline T.sum.car.pha & 48.09 & 0.65 & 0.60 & 13.05 \\
\hline All.av.under.pha & 54.06 & 0.64 & 0.59 & 19.63 \\
\hline All.av.litter & 53.42 & 0.63 & 0.58 & 18.48 \\
\hline All.av.gen & 54.27 & 0.63 & 0.58 & 17.96 \\
\hline All.av.under & 53.64 & 0.63 & 0.57 & 18.77 \\
\hline All.av.vol.pha & 53.79 & 0.63 & 0.57 & 17.89 \\
\hline E.sum.car.soil.pha & 46.49 & 0.63 & 0.57 & 11.20 \\
\hline All.av.inc.pha & 6.42 & 0.62 & 0.56 & 4.96 \\
\hline All.Av.BA & 48.67 & 0.61 & 0.55 & 18.46 \\
\hline T.sum.above & 46.50 & 0.61 & 0.55 & 12.77 \\
\hline T.sum.car.soil & 46.56 & 0.61 & 0.55 & 12.25 \\
\hline T.sum.litter.pha & 46.76 & 0.61 & 0.55 & 13.09 \\
\hline T.sum.gen.pha & 46.56 & 0.61 & 0.55 & 13.20 \\
\hline T.sum.car.soil.pha & 45.89 & 0.61 & 0.55 & 11.85 \\
\hline E.sum.under.pha & 43.18 & 0.60 & 0.54 & 10.42 \\
\hline E.av.inc & 4.25 & 0.60 & 0.54 & 8.44 \\
\hline E.av.dbh & 53.13 & 0.60 & 0.54 & 23.35 \\
\hline T.sum.vol.pha & 42.33 & 0.60 & 0.54 & 10.65 \\
\hline T.sum.under & 43.16 & 0.58 & 0.51 & 11.33 \\
\hline T.sum.under.pha & 53.82 & 0.58 & 0.51 & 10.87 \\
\hline T.av.vol & 41.87 & 0.57 & 0.50 & 11.18 \\
\hline E.sum.vol & 41.92 & 0.56 & 0.48 & 10.99 \\
\hline E.Volume & 40.48 & 0.55 & 0.48 & 9.48 \\
\hline All.sum.above & 45.97 & 0.55 & 0.48 & 12.40 \\
\hline All.sum.car.soil.pha & 46.14 & 0.54 & 0.47 & 11.18 \\
\hline E.sum.above & 45.68 & 0.54 & 0.47 & 13.74 \\
\hline All.sum.gen & 45.58 & 0.54 & 0.47 & 13.62 \\
\hline All.sum.gen.pha & 46.48 & 0.54 & 0.47 & 12.38 \\
\hline E.sum.above.pha & 46.05 & 0.54 & 0.47 & 13.00 \\
\hline
\end{tabular}




\begin{tabular}{|c|c|c|c|c|}
\hline E.sum.car.soil & 46.13 & 0.54 & 0.47 & 12.26 \\
\hline E.Increment & 21.39 & 0.54 & 0.47 & 11.43 \\
\hline T.sum.above.pha & 47.88 & 0.54 & 0.47 & 13.16 \\
\hline E.sum.litter & 46.32 & 0.54 & 0.47 & 11.65 \\
\hline All.sum.vol & 56.76 & 0.54 & 0.46 & 15.79 \\
\hline T.sum.gen & 46.26 & 0.54 & 0.46 & 11.93 \\
\hline T.sum.car & 46.74 & 0.54 & 0.46 & 12.28 \\
\hline All.sum.car.pha & 46.17 & 0.54 & 0.46 & 12.03 \\
\hline E.sum.gen & 45.63 & 0.54 & 0.46 & 12.56 \\
\hline E.sum.car.pha & 46.61 & 0.53 & 0.45 & 11.51 \\
\hline T.av.inc.pha & 7.99 & 0.52 & 0.44 & 10.55 \\
\hline All.sum.under.pha & 42.83 & 0.51 & 0.43 & 11.75 \\
\hline E.sum.under & 43.49 & 0.51 & 0.43 & 9.71 \\
\hline T.av.inc & 7.67 & 0.50 & 0.42 & 9.23 \\
\hline All.sum.vol.pha & 40.56 & 0.50 & 0.42 & 9.22 \\
\hline E.Volume.pha & 41.74 & 0.49 & 0.41 & 11.30 \\
\hline T.sum.litter & 45.87 & 0.49 & 0.41 & 13.16 \\
\hline T.sum.inc & 18.38 & 0.48 & 0.40 & 12.07 \\
\hline E.sum.car & 47.31 & 0.48 & 0.39 & 12.95 \\
\hline E.sum.vol.pha & 41.41 & 0.47 & 0.39 & 7.98 \\
\hline E.sum.inc.pha & 22.14 & 0.47 & 0.39 & 11.68 \\
\hline All.sum.above.pha & 46.41 & 0.47 & 0.38 & 11.81 \\
\hline E.sum.litter.pha & 46.29 & 0.46 & 0.38 & 12.28 \\
\hline All.sum.litter & 46.17 & 0.46 & 0.38 & 11.84 \\
\hline All.sum.car & 46.35 & 0.46 & 0.38 & 11.05 \\
\hline All.sum.car.soil & 46.47 & 0.46 & 0.38 & 12.08 \\
\hline All.sum.litter.pha & 46.56 & 0.46 & 0.38 & 12.56 \\
\hline E.sum.inc & 20.19 & 0.46 & 0.37 & 12.02 \\
\hline E.av.inc.pha & 6.76 & 0.46 & 0.37 & 8.26 \\
\hline
\end{tabular}




\begin{tabular}{|c|c|c|c|c|}
\hline All.sum.under & 43.15 & 0.41 & 0.37 & 11.10 \\
\hline E.sum.gen.pha & 46.21 & 0.45 & 0.37 & 12.91 \\
\hline All.av.inc & 16.06 & 0.45 & 0.36 & 16.79 \\
\hline T.sum.ba.ha & 8.75 & 0.42 & 0.33 & -1.67 \\
\hline All.Sum.Ba.ha & 6.76 & 0.41 & 0.32 & -1.97 \\
\hline E.sum.ba.ha & 9.57 & 0.41 & 0.31 & -1.43 \\
\hline T.Sum.BA & 9.97 & 0.36 & 0.25 & -2.84 \\
\hline T.sum.inc.pha & 20.19 & 0.36 & 0.25 & 10.29 \\
\hline All.sum.inc.pha & -19.84 & 0.30 & 0.18 & -8.86 \\
\hline E.Sum.BA & 9.13 & 0.29 & 0.18 & -1.25 \\
\hline All.Sum.BA & 7.32 & 0.24 & 0.12 & -1.66 \\
\hline All.sum.inc & -15.26 & 0.08 & 0.01 & -8.94 \\
\hline
\end{tabular}


Table 14. Forest Inventory using all remote sensing instrument for maritime species

\begin{tabular}{|c|c|c|c|c|}
\hline All_Pine & $\mathbf{r F}$ & Multiple_R $^{2}$ & Adjusted R $^{2}$ & yai \\
\hline E.av.under & 37.57 & 0.79 & 0.75 & 9.86 \\
\hline E.sum.dbh & 52.46 & 0.78 & 0.74 & 32.45 \\
\hline E.av.car.soil.pha & 36.21 & 0.77 & 0.73 & 13.23 \\
\hline E.av.gen & 36.62 & 0.77 & 0.73 & 11.31 \\
\hline All.av.car.pha & 22.70 & 0.77 & 0.73 & 4.28 \\
\hline E.av.gen.pha & 33.48 & 0.77 & 0.73 & 11.44 \\
\hline All.Sum.DBH & 46.61 & 0.76 & 0.72 & 30.70 \\
\hline T.av.above.pha & 40.87 & 0.76 & 0.72 & 11.59 \\
\hline T.av.vol & 38.51 & 0.76 & 0.71 & 10.45 \\
\hline T.av.car & 39.32 & 0.76 & 0.71 & 13.18 \\
\hline T.av.litter.pha & 40.06 & 0.76 & 0.71 & 12.16 \\
\hline T.av.vol.pha & 39.65 & 0.76 & 0.71 & 9.97 \\
\hline T.av.car.pha & 41.51 & 0.76 & 0.71 & 45.99 \\
\hline E.av.under.pha & 36.86 & 0.75 & 0.71 & 10.11 \\
\hline T.av.car.soil.pha & 39.76 & 0.75 & 0.71 & 12.79 \\
\hline T.av.car.soil & 41.38 & 0.75 & 0.71 & 11.93 \\
\hline T.av.gen.pha & 40.75 & 0.75 & 0.71 & 13.20 \\
\hline E.av.above.pha & 36.85 & 0.75 & 0.71 & 12.83 \\
\hline T.av.above & 40.68 & 0.75 & 0.71 & 13.94 \\
\hline All.av.above.pha & 22.60 & 0.75 & 0.71 & 2.90 \\
\hline E.sum.above & 43.55 & 0.75 & 0.70 & 5.01 \\
\hline T.sum.litter.pha & 44.22 & 0.75 & 0.70 & 5.47 \\
\hline E.av.litter.pha & 36.35 & 0.75 & 0.70 & 12.69 \\
\hline E.av.car.pha & 36.70 & 0.75 & 0.70 & 11.62 \\
\hline E.av.litter & 37.68 & 0.75 & 0.70 & 12.08 \\
\hline T.sum.above & 45.82 & 0.75 & 0.70 & 4.44 \\
\hline
\end{tabular}




\begin{tabular}{|c|c|c|c|c|}
\hline T.av.under.pha & 39.06 & 0.74 & 0.70 & 12.70 \\
\hline T.av.under & 40.22 & 0.74 & 0.70 & 12.24 \\
\hline All.sum.above.pha & 43.50 & 0.74 & 0.70 & 4.70 \\
\hline E.av.above & 35.33 & 0.74 & 0.70 & 10.36 \\
\hline T.sum.gen.pha & 45.99 & 0.74 & 0.70 & 4.54 \\
\hline T.av.gen & 40.36 & 0.74 & 0.70 & 12.69 \\
\hline E.av.car & 35.67 & 0.74 & 0.70 & 11.08 \\
\hline E.av.car.soil & 37.12 & 0.74 & 0.69 & 11.48 \\
\hline T.sum.car & 46.04 & 0.74 & 0.69 & 6.02 \\
\hline T.Tree & 41.11 & 0.74 & 0.69 & 27.06 \\
\hline E.Volume & 41.63 & 0.74 & 0.69 & 7.89 \\
\hline E.sum.inc & 50.30 & 0.73 & 0.69 & 31.68 \\
\hline E.Av.BA & 35.26 & 0.73 & 0.68 & 8.37 \\
\hline T.Av.BA & 36.57 & 0.73 & 0.68 & 11.01 \\
\hline All.av.car.soil.pha & 24.91 & 0.73 & 0.68 & 4.76 \\
\hline E.Volume.pha & 0.97 & 0.73 & 0.68 & 8.09 \\
\hline T.av.litter & 43.18 & 0.73 & 0.68 & 12.39 \\
\hline T.sum.car.pha & 44.46 & 0.72 & 0.68 & 6.40 \\
\hline T.sum.inc & 50.83 & 0.72 & 0.67 & 32.40 \\
\hline All.sum.car.soil.pha & 45.13 & 0.72 & 0.67 & 5.75 \\
\hline All.av.litter & 45.20 & 0.72 & 0.67 & 5.35 \\
\hline T.tpha & 41.34 & 0.72 & 0.67 & 26.75 \\
\hline T.sum.dbh & 52.28 & 0.72 & 0.67 & 32.88 \\
\hline E.sum.car.soil & 34.48 & 0.72 & 0.67 & 11.67 \\
\hline E.Tree & 40.01 & 0.72 & 0.67 & 24.59 \\
\hline T.sum.under & 45.14 & 0.72 & 0.67 & 7.72 \\
\hline All.sum.car.pha & 44.70 & 0.72 & 0.66 & 4.37 \\
\hline E.av.vol.pha & 37.71 & 0.71 & 0.66 & 9.73 \\
\hline All.sum.litter.pha & 43.86 & 0.71 & 0.66 & 5.18 \\
\hline
\end{tabular}




\begin{tabular}{|c|c|c|c|c|}
\hline E.av.vol & 37.81 & 0.71 & 0.66 & 11.50 \\
\hline All.sum.under.pha & 43.72 & 0.71 & 0.66 & 8.50 \\
\hline E.tpha & 39.99 & 0.71 & 0.66 & 23.97 \\
\hline All.sum.inc & 48.91 & 0.71 & 0.66 & 31.26 \\
\hline All.sum.inc.pha & 47.66 & 0.71 & 0.66 & 30.08 \\
\hline E.sum.under.pha & 45.41 & 0.71 & 0.66 & 7.86 \\
\hline T.sum.above.pha & 44.94 & 0.71 & 0.66 & 6.00 \\
\hline All.Sum.BA & 48.29 & 0.71 & 0.65 & 16.66 \\
\hline T.sum.litter & 44.07 & 0.70 & 0.65 & 4.62 \\
\hline T.sum.gen & 48.98 & 0.70 & 0.65 & 6.86 \\
\hline T.sum.inc.pha & 48.48 & 0.70 & 0.65 & 29.76 \\
\hline E.sum.inc.pha & 49.51 & 0.70 & 0.65 & 30.62 \\
\hline All.av.car & 24.69 & 0.70 & 0.64 & 3.83 \\
\hline T.av.ba.ha & 38.65 & 0.70 & 0.64 & 11.79 \\
\hline All.Sum.Ba.ha & 47.11 & 0.70 & 0.64 & 17.50 \\
\hline E.sum.litter & 44.79 & 0.69 & 0.64 & 4.59 \\
\hline All.av.above & 26.79 & 0.69 & 0.64 & 3.84 \\
\hline E.sum.litter.pha & 42.48 & 0.69 & 0.64 & 5.25 \\
\hline All.av.car.soil & 22.23 & 0.69 & 0.64 & 4.72 \\
\hline All.av.gen.pha & 26.22 & 0.69 & 0.64 & 3.29 \\
\hline E.sum.gen & 44.38 & 0.69 & 0.64 & 5.47 \\
\hline E.sum.car.pha & 45.45 & 0.69 & 0.63 & 5.91 \\
\hline E.sum.under & 46.68 & 0.69 & 0.63 & 8.75 \\
\hline All.sum.above & 43.79 & 0.68 & 0.63 & 6.09 \\
\hline E.av.ba.ha & 36.68 & 0.68 & 0.63 & 9.93 \\
\hline All.sum.gen & 45.19 & 0.68 & 0.62 & 7.02 \\
\hline T.av.dbh & 37.42 & 0.68 & 0.62 & 5.95 \\
\hline E.sum.vol & 45.82 & 0.68 & 0.62 & 8.25 \\
\hline All.av.under & 22.16 & 0.68 & 0.62 & 1.99 \\
\hline
\end{tabular}




\begin{tabular}{|c|c|c|c|c|}
\hline T.sum.under.pha & 45.44 & 0.68 & 0.62 & 7.38 \\
\hline All.sum.under & 45.17 & 0.68 & 0.62 & 7.81 \\
\hline T.Sum.BA & 48.97 & 0.67 & 0.62 & 18.02 \\
\hline T.av.inc & 31.16 & 0.67 & 0.62 & 3.71 \\
\hline E.sum.above.pha & 44.36 & 0.67 & 0.62 & 6.27 \\
\hline All.av.vol & 18.42 & 0.67 & 0.62 & 1.54 \\
\hline All.av.vol.pha & 20.63 & 0.67 & 0.62 & 0.73 \\
\hline All.sum.gen.pha & 44.00 & 0.67 & 0.61 & 5.51 \\
\hline All.sum.car & 44.38 & 0.67 & 0.61 & 6.24 \\
\hline All.av.litter.pha & 23.04 & 0.67 & 0.61 & 2.67 \\
\hline T.sum.vol.pha & 43.91 & 0.66 & 0.60 & 8.51 \\
\hline All.sum.vol & 44.40 & 0.66 & 0.60 & 8.43 \\
\hline T.sum.car.soil.pha & 44.58 & 0.66 & 0.60 & 7.01 \\
\hline All.av.gen & 22.46 & 0.66 & 0.60 & 4.17 \\
\hline E.Increment & 48.27 & 0.66 & 0.60 & 19.47 \\
\hline T.sum.car.soil & 44.52 & 0.65 & 0.59 & 7.98 \\
\hline E.sum.ba.ha & 47.88 & 0.65 & 0.59 & 17.27 \\
\hline T.sum.ba.ha & 48.81 & 0.65 & 0.59 & 19.70 \\
\hline E.av.inc.pha & 29.24 & 0.65 & 0.59 & 3.63 \\
\hline E.av.inc & 30.72 & 0.65 & 0.59 & 6.31 \\
\hline All.av.under.pha & 21.55 & 0.65 & 0.59 & 2.36 \\
\hline E.Increment.pha & 47.19 & 0.65 & 0.58 & 19.93 \\
\hline E.sum.vol.pha & 45.10 & 0.64 & 0.57 & 9.46 \\
\hline E.sum.gen.pha & 44.99 & 0.63 & 0.57 & 6.98 \\
\hline All.sum.car.soil & 46.07 & 0.62 & 0.56 & 4.87 \\
\hline E.sum.car.soil.pha & 45.82 & 0.62 & 0.56 & 5.47 \\
\hline E.sum.car & 45.93 & 0.62 & 0.56 & 5.87 \\
\hline E.Sum.BA & 47.83 & 0.62 & 0.55 & 17.60 \\
\hline T.sum.vol & 9.41 & 0.61 & 0.54 & 9.41 \\
\hline
\end{tabular}




\begin{tabular}{|c|c|c|c|c|}
\hline E.av.dbh & 36.90 & 0.58 & 0.51 & 6.69 \\
\hline All.Av.BA & 9.76 & 0.57 & 0.49 & -2.97 \\
\hline All.sum.litter & 43.61 & 0.56 & 0.49 & 6.56 \\
\hline All.av.inc.pha & 6.74 & 0.49 & 0.40 & 1.12 \\
\hline All.av.ba.ha & 8.87 & 0.46 & 0.37 & -4.03 \\
\hline All.tpha & 0.40 & 0.44 & 0.34 & 3.94 \\
\hline T.av.inc.pha & 30.27 & 0.43 & 0.33 & 3.45 \\
\hline All.Av.DBH & 12.35 & 0.41 & 0.31 & 1.40 \\
\hline All.av.inc & 3.95 & 0.39 & 0.29 & 1.61 \\
\hline All.Tree & -0.55 & 0.39 & 0.28 & 5.19 \\
\hline All.sum.vol.pha & 6.16 & 0.37 & 0.26 & 0.58 \\
\hline
\end{tabular}


Table 15. Forest inventory using LiDAR for pine

\begin{tabular}{|c|c|c|c|c|}
\hline lidar_Pine & $\mathbf{r F}$ & Multiple_R $\mathbf{R}^{\mathbf{2}}$ & $\begin{array}{c}\text { Adjusted } \\
\mathbf{R}^{\mathbf{2}}\end{array}$ & yai \\
\hline T.av.under & 47.64 & 0.83 & 0.80 & 44.46 \\
\hline T.av.car.soil & 46.49 & 0.81 & 0.78 & 45.17 \\
\hline E.av.car.soil & 42.10 & 0.81 & 0.77 & 43.17 \\
\hline E.av.under.pha & 43.92 & 0.80 & 0.77 & 32.47 \\
\hline E.av.vol & 45.43 & 0.80 & 0.76 & 43.27 \\
\hline All.av.litter & 51.00 & 0.78 & 0.74 & 33.45 \\
\hline E.av.above.pha & 42.83 & 0.78 & 0.74 & 42.04 \\
\hline E.av.litter & 42.07 & 0.78 & 0.74 & 40.15 \\
\hline E.av.gen & 41.58 & 0.78 & 0.74 & 40.15 \\
\hline E.av.car & 42.29 & 0.78 & 0.74 & 42.73 \\
\hline E.av.car.pha & 41.11 & 0.76 & 0.72 & 41.06 \\
\hline E.av.gen.pha & 37.98 & 0.76 & 0.72 & 41.43 \\
\hline E.av.car.soil.pha & 41.26 & 0.75 & 0.71 & 40.31 \\
\hline T.av.litter & 46.52 & 0.75 & 0.71 & 43.05 \\
\hline T.av.gen & 43.95 & 0.75 & 0.71 & 44.72 \\
\hline T.av.car & 46.33 & 0.75 & 0.71 & 42.91 \\
\hline T.sum.vol & 51.29 & 0.75 & 0.70 & 31.94 \\
\hline T.av.above & 43.19 & 0.73 & 0.70 & 42.24 \\
\hline T.av.car.soil.pha & 44.75 & 0.74 & 0.70 & 42.58 \\
\hline E.av.above & 41.19 & 0.74 & 0.69 & 39.67 \\
\hline T.av.litter.pha & 46.85 & 0.74 & 0.69 & 43.63 \\
\hline T.av.car.pha & 45.50 & 0.74 & 0.69 & 43.28 \\
\hline T.sum.gen & 53.67 & 0.71 & 0.69 & 30.59 \\
\hline E.sum.above & 50.47 & 0.74 & 0.69 & 33.05 \\
\hline E.sum.above.pha & 51.53 & 0.74 & 0.69 & 31.59 \\
\hline & & & & \\
\hline
\end{tabular}




\begin{tabular}{|c|c|c|c|c|}
\hline T.av.gen.pha & 44.49 & 0.73 & 0.69 & 41.46 \\
\hline E.sum.car.soil & 50.70 & 0.73 & 0.69 & 32.49 \\
\hline E.sum.car.pha & 51.05 & 0.73 & 0.69 & 32.69 \\
\hline All.sum.above.pha & 51.23 & 0.73 & 0.69 & 31.95 \\
\hline All.sum.car.soil & 51.63 & 0.73 & 0.68 & 31.11 \\
\hline All.sum.car.soil.pha & 51.68 & 0.73 & 0.68 & 31.18 \\
\hline E.av.vol.pha & 45.50 & 0.73 & 0.68 & 41.79 \\
\hline E.sum.gen & 50.96 & 0.73 & 0.68 & 32.66 \\
\hline T.av.above.pha & 44.54 & 0.70 & 0.68 & 43.50 \\
\hline E.Volume.pha & 46.74 & 0.72 & 0.67 & 38.91 \\
\hline E.Volume & 46.40 & 0.72 & 0.67 & 37.41 \\
\hline T.av.vol.pha & 47.21 & 0.70 & 0.67 & 45.35 \\
\hline All.sum.vol.pha & 50.96 & 0.72 & 0.67 & 33.46 \\
\hline E.av.litter.pha & 41.29 & 0.72 & 0.67 & 40.86 \\
\hline T.sum.under.pha & 51.83 & 0.69 & 0.66 & 34.01 \\
\hline All.sum.above & 50.89 & 0.71 & 0.66 & 30.30 \\
\hline All.sum.gen & 51.70 & 0.71 & 0.66 & 32.03 \\
\hline All.sum.litter.pha & 51.03 & 0.71 & 0.66 & 30.65 \\
\hline All.Sum.Ba.ha & 49.55 & 0.71 & 0.66 & 35.37 \\
\hline T.sum.litter & 51.64 & 0.71 & 0.66 & 32.26 \\
\hline All.Sum.BA & 48.44 & 0.71 & 0.66 & 35.20 \\
\hline E.sum.gen.pha & 51.44 & 0.71 & 0.66 & 32.50 \\
\hline E.sum.vol.pha & 51.64 & 0.71 & 0.66 & 33.54 \\
\hline E.sum.car & 52.23 & 0.71 & 0.65 & 33.36 \\
\hline All.sum.under.pha & 51.12 & 0.71 & 0.65 & 32.20 \\
\hline T.sum.under & 51.76 & 0.71 & 0.65 & 32.60 \\
\hline E.sum.litter.pha & 31.27 & 0.70 & 0.65 & 51.05 \\
\hline E.sum.car.soil.pha & 51.29 & 0.70 & 0.65 & 30.89 \\
\hline E.sum.ba.ha & 48.07 & 0.70 & 0.65 & 36.72 \\
\hline
\end{tabular}




\begin{tabular}{|c|c|c|c|c|}
\hline T.av.under.pha & 47.31 & 0.70 & 0.65 & 43.35 \\
\hline All.sum.litter & 49.74 & 0.70 & 0.65 & 31.89 \\
\hline All.sum.car & 51.09 & 0.70 & 0.65 & 30.15 \\
\hline All.sum.gen.pha & 50.37 & 70.32 & 0.65 & 30.54 \\
\hline All.sum.car.pha & 51.62 & 0.70 & 0.65 & 31.17 \\
\hline T.sum.car & 52.60 & 0.70 & 0.65 & 32.25 \\
\hline T.sum.car.soil & 52.76 & 0.70 & 0.65 & 31.35 \\
\hline T.sum.litter.pha & 52.80 & 0.70 & 0.65 & 30.95 \\
\hline T.sum.gen.pha & 53.47 & 0.70 & 0.65 & 31.70 \\
\hline T.sum.car.pha & 51.77 & 0.70 & 0.65 & 31.35 \\
\hline T.sum.above & 51.83 & 0.70 & 0.65 & 31.11 \\
\hline T.sum.above.pha & 51.56 & 0.70 & 0.65 & 30.00 \\
\hline All.av.litter.pha & 31.55 & 0.70 & 0.65 & 24.23 \\
\hline E.sum.under & 52.26 & 0.70 & 0.65 & 32.73 \\
\hline All.av.above.pha & 33.43 & 0.70 & 0.64 & 22.21 \\
\hline E.sum.litter & 51.67 & 0.69 & 0.64 & 31.44 \\
\hline E.Sum.BA & 48.40 & 0.69 & 0.63 & 35.15 \\
\hline E.sum.under.pha & 51.93 & 0.68 & 0.63 & 43.92 \\
\hline T.sum.vol.pha & 51.78 & 0.68 & 0.63 & 34.93 \\
\hline All.sum.vol & 51.74 & 0.68 & 0.62 & 30.41 \\
\hline T.Tree & 38.49 & 0.68 & 0.62 & 31.40 \\
\hline T.Sum.BA & 49.00 & 0.68 & 0.62 & 34.41 \\
\hline All.Sum.DBH & 36.38 & 0.68 & 0.62 & 33.36 \\
\hline T.av.ba.ha & 47.67 & 0.67 & 0.62 & 45.46 \\
\hline All.sum.under & 51.45 & 0.67 & 0.62 & 31.43 \\
\hline E.Tree & 38.66 & 0.67 & 0.61 & 31.96 \\
\hline T.sum.car.soil.pha & 52.04 & 0.64 & 0.61 & 33.10 \\
\hline E.sum.vol & 51.39 & 0.66 & 0.60 & 32.32 \\
\hline T.tpha & 39.31 & 0.66 & 0.60 & 32.62 \\
\hline
\end{tabular}




\begin{tabular}{|c|c|c|c|c|}
\hline T.Av.BA & 48.39 & 0.65 & 0.59 & 45.51 \\
\hline All.av.under.pha & 33.73 & 0.65 & 0.59 & 23.41 \\
\hline All.av.vol.pha & 34.38 & 0.65 & 0.59 & 20.15 \\
\hline E.sum.inc & 43.22 & 0.65 & 0.59 & 36.95 \\
\hline E.sum.inc.pha & 43.06 & 0.65 & 0.59 & 34.41 \\
\hline E.tpha & 34.99 & 0.65 & 0.59 & 31.33 \\
\hline E.av.ba.ha & 47.48 & 0.65 & 0.58 & 45.18 \\
\hline T.sum.dbh & 41.23 & 0.64 & 0.58 & 35.19 \\
\hline E.sum.dbh & 40.11 & 0.64 & 0.58 & 37.99 \\
\hline E.Av.BA & 49.04 & 0.64 & 0.57 & 44.38 \\
\hline E.av.under & 44.38 & 0.64 & 0.57 & 42.69 \\
\hline T.sum.inc & 42.77 & 0.62 & 0.56 & 34.85 \\
\hline T.sum.inc.pha & 43.94 & 0.62 & 0.56 & 37.31 \\
\hline All.sum.inc & 40.75 & 0.62 & 0.55 & 33.81 \\
\hline All.sum.inc.pha & 40.91 & 0.62 & 0.55 & 34.73 \\
\hline All.av.car.pha & 34.50 & 0.61 & 0.54 & 23.38 \\
\hline All.av.car & 31.01 & 0.60 & 0.53 & 21.48 \\
\hline T.av.vol & 48.26 & 0.60 & 0.53 & 43.87 \\
\hline T.av.inc.pha & 43.99 & 0.55 & 0.51 & 30.97 \\
\hline All.av.gen & 32.68 & 0.58 & 0.51 & 20.96 \\
\hline T.av.dbh & 48.04 & 0.58 & 0.50 & 38.85 \\
\hline T.av.inc & 43.53 & 0.58 & 0.50 & 32.45 \\
\hline E.Increment.pha & 42.51 & 0.58 & 0.50 & 34.05 \\
\hline All.av.gen.pha & 32.26 & 0.56 & 0.48 & 20.71 \\
\hline E.Increment & 42.31 & 0.56 & 0.48 & 31.60 \\
\hline E.av.inc & 42.09 & 0.55 & 0.47 & 34.96 \\
\hline All.av.under & 33.22 & 0.55 & 0.47 & 21.32 \\
\hline E.av.dbh & 48.02 & 0.52 & 0.44 & 41.11 \\
\hline E.av.inc.pha & 43.65 & 0.52 & 0.43 & 32.47 \\
\hline & & & & \\
\hline
\end{tabular}




\begin{tabular}{|c|c|c|c|c|}
\hline All.av.car.soil & 32.79 & 0.51 & 0.43 & 22.93 \\
\hline All.av.inc.pha & 32.89 & 0.50 & 0.41 & 14.43 \\
\hline T.sum.ba.ha & 48.39 & 0.50 & 0.41 & 34.45 \\
\hline All.av.car.soil.pha & 34.40 & 0.45 & 0.35 & 20.28 \\
\hline All.Av.BA & 23.40 & 0.45 & 0.35 & 16.35 \\
\hline All.av.ba.ha & 19.92 & 0.43 & 0.33 & 16.72 \\
\hline All.av.above & 32.17 & 0.41 & 0.31 & 20.60 \\
\hline All.av.inc & 32.40 & 0.40 & 0.30 & 16.44 \\
\hline All.Av.DBH & 23.18 & 0.39 & 0.28 & 19.65 \\
\hline All.tpha & -9.85 & 0.30 & 0.18 & -2.33 \\
\hline All.Tree & -10.48 & 0.28 & 0.16 & -2.28 \\
\hline All.av.vol & 29.49 & 0.12 & -0.03 & 18.25 \\
\hline
\end{tabular}


Table 16. Forest inventory using LiDAR for oak

\begin{tabular}{|c|c|c|c|c|}
\hline lidar_oak & $\mathbf{r F}$ & Multiple $\mathbf{R}^{\mathbf{2}}$ & $\begin{array}{c}\text { Adjusted } \\
\mathbf{R}^{2}\end{array}$ & yai \\
\hline E.tpha & 64.64 & 0.82 & 0.80 & 55.37 \\
\hline E.Tree & 59.87 & 0.80 & 0.77 & 55.85 \\
\hline All.av.vol & 57.60 & 0.80 & 0.77 & 53.36 \\
\hline T.Tree & 57.79 & 0.79 & 0.76 & 54.54 \\
\hline T.tpha & 61.28 & 0.79 & 0.76 & 53.49 \\
\hline All.Tree & 64.78 & 0.79 & 0.75 & 50.37 \\
\hline All.tpha & 57.66 & 0.77 & 0.73 & 50.78 \\
\hline T.av.gen.pha & 57.67 & 0.76 & 0.72 & 46.27 \\
\hline T.av.car & 57.25 & 0.76 & 0.72 & 45.73 \\
\hline T.av.litter.pha & 57.14 & 0.76 & 0.72 & 45.41 \\
\hline T.av.gen & 57.58 & 0.76 & 0.72 & 46.41 \\
\hline T.av.car.pha & 58.32 & 0.76 & 0.72 & 46.83 \\
\hline T.av.car.soil.pha & 58.01 & 0.76 & 0.72 & 45.93 \\
\hline T.av.above & 57.04 & 0.76 & 0.72 & 46.36 \\
\hline T.av.above.pha & 59.03 & 0.76 & 0.72 & 46.19 \\
\hline T.av.litter & 56.79 & 0.76 & 0.72 & 46.79 \\
\hline T.av.car.soil & 57.50 & 0.76 & 0.72 & 46.12 \\
\hline T.av.under.pha & 56.75 & 0.76 & 0.72 & 45.92 \\
\hline T.av.under & 56.69 & 0.75 & 0.71 & 44.37 \\
\hline T.sum.vol & 58.26 & 0.75 & 0.71 & 46.39 \\
\hline E.av.gen.pha & 58.21 & 0.74 & 0.70 & 42.49 \\
\hline E.av.car.soil & 57.54 & 0.74 & 0.69 & 45.42 \\
\hline E.av.car.soil.pha & 56.82 & 0.74 & 0.69 & 45.18 \\
\hline T.av.dbh & 58.73 & 0.74 & 0.69 & 49.34 \\
\hline E.av.vol & 56.96 & 0.73 & 0.69 & 46.15 \\
\hline & & & & \\
\hline
\end{tabular}




\begin{tabular}{|c|c|c|c|c|}
\hline All.av.gen & 59.23 & 0.71 & 0.66 & 36.68 \\
\hline E.av.above & 57.22 & 0.68 & 0.65 & 45.74 \\
\hline E.av.above.pha & 58.54 & 0.68 & 0.65 & 42.13 \\
\hline E.av.litter & 57.15 & 0.68 & 0.65 & 44.62 \\
\hline E.av.gen & 56.09 & 0.68 & 0.65 & 43.94 \\
\hline E.av.car & 57.15 & 0.68 & 0.65 & 44.26 \\
\hline E.av.litter.pha & 57.19 & 0.68 & 0.65 & 44.11 \\
\hline E.av.car.pha & 56.55 & 0.68 & 0.65 & 44.19 \\
\hline T.av.ba.ha & 57.46 & 0.67 & 0.65 & 46.90 \\
\hline T.Av.BA & 56.17 & 0.67 & 0.65 & 48.09 \\
\hline T.av.vol.pha & 57.41 & 0.67 & 0.65 & 45.62 \\
\hline E.av.under & 57.22 & 0.67 & 0.65 & 42.46 \\
\hline E.av.under.pha & 56.66 & 0.67 & 0.65 & 43.94 \\
\hline E.av.vol.pha & 56.87 & 0.67 & 0.65 & 43.91 \\
\hline E.av.dbh & 56.14 & 0.69 & 0.64 & 42.87 \\
\hline All.av.litter.pha & 57.34 & 0.69 & 0.64 & 41.28 \\
\hline E.av.ba.ha & 56.52 & 0.66 & 0.64 & 50.78 \\
\hline All.av.car & 57.22 & 0.69 & 0.64 & 42.39 \\
\hline All.av.gen.pha & 57.11 & 0.69 & 0.64 & 42.49 \\
\hline All.av.above & 58.26 & 0.66 & 0.63 & 40.72 \\
\hline All.av.litter & 57.95 & 0.66 & 0.63 & 39.71 \\
\hline All.av.car.soil & 58.55 & 0.66 & 0.63 & 41.99 \\
\hline All.av.car.soil.pha & 57.97 & 0.66 & 0.63 & 39.77 \\
\hline All.av.vol.pha & 56.69 & 0.68 & 0.63 & 41.98 \\
\hline All.av.above.pha & 59.05 & 0.68 & 0.63 & 41.06 \\
\hline E.Av.BA & 55.66 & 0.65 & 0.63 & 44.12 \\
\hline All.av.under & 57.72 & 0.65 & 0.63 & 39.09 \\
\hline All.av.under.pha & 57.27 & 0.67 & 0.62 & 40.76 \\
\hline All.sum.vol & 59.61 & 0.65 & 0.62 & 50.25 \\
\hline
\end{tabular}




\begin{tabular}{|c|c|c|c|c|}
\hline All.av.car.pha & 58.06 & 0.67 & 0.61 & 41.46 \\
\hline All.av.ba.ha & 50.21 & 0.63 & 0.61 & 38.77 \\
\hline All.Av.BA & 52.59 & 0.63 & 0.61 & 40.00 \\
\hline All.av.inc & 26.50 & 0.62 & 0.59 & 26.51 \\
\hline All.sum.above & 47.20 & 0.64 & 0.59 & 41.96 \\
\hline T.sum.above & 48.01 & 0.64 & 0.58 & 43.32 \\
\hline T.sum.above.pha & 47.99 & 0.64 & 0.58 & 42.39 \\
\hline T.sum.litter & 47.39 & 0.64 & 0.58 & 42.26 \\
\hline T.sum.gen & 47.82 & 0.64 & 0.58 & 41.20 \\
\hline T.sum.car & 47.57 & 0.64 & 0.58 & 42.30 \\
\hline T.sum.litter.pha & 48.01 & 0.64 & 0.58 & 43.35 \\
\hline T.sum.gen.pha & 48.50 & 0.64 & 0.58 & 42.29 \\
\hline T.sum.car.pha & 48.09 & 0.64 & 0.58 & 43.41 \\
\hline T.sum.car.soil.pha & 47.06 & 0.64 & 0.58 & 40.97 \\
\hline E.sum.above & 47.53 & 0.63 & 0.58 & 40.61 \\
\hline E.sum.above.pha & 47.85 & 0.63 & 0.58 & 43.16 \\
\hline All.sum.above.pha & 46.90 & 0.63 & 0.57 & 40.88 \\
\hline E.sum.litter & 47.15 & 0.63 & 0.57 & 41.51 \\
\hline E.sum.gen & 47.01 & 0.63 & 0.57 & 41.70 \\
\hline E.sum.car.soil & 47.10 & 0.63 & 0.57 & 42.22 \\
\hline E.sum.gen.pha & 47.85 & 0.63 & 0.57 & 42.40 \\
\hline E.sum.car.soil.pha & 47.28 & 0.63 & 0.57 & 41.28 \\
\hline All.sum.litter & 47.12 & 0.63 & 0.57 & 43.60 \\
\hline All.sum.gen & 47.26 & 0.63 & 0.57 & 41.45 \\
\hline All.sum.car & 47.69 & 0.63 & 0.57 & 41.80 \\
\hline All.sum.car.soil & 46.57 & 0.63 & 0.57 & 40.53 \\
\hline All.sum.litter.pha & 46.60 & 0.63 & 0.57 & 43.18 \\
\hline All.sum.car.pha & 47.05 & 0.63 & 0.57 & 41.99 \\
\hline All.sum.car.soil.pha & 47.83 & 0.63 & 0.57 & 40.21 \\
\hline
\end{tabular}




\begin{tabular}{|c|c|c|c|c|}
\hline T.sum.under & 44.74 & 0.63 & 0.57 & 41.51 \\
\hline All.sum.gen.pha & 47.10 & 0.62 & 0.56 & 40.26 \\
\hline T.sum.under.pha & 44.14 & 0.62 & 0.55 & 40.76 \\
\hline E.sum.under & 43.84 & 0.61 & 0.55 & 39.54 \\
\hline All.sum.under & 43.15 & 0.61 & 0.55 & 40.30 \\
\hline All.sum.under.pha & 43.85 & 0.61 & 0.55 & 40.68 \\
\hline T.sum.vol.pha & 44.00 & 0.61 & 0.55 & 39.09 \\
\hline E.sum.vol & 43.20 & 0.60 & 0.54 & 39.64 \\
\hline E.sum.vol.pha & 42.85 & 0.60 & 0.54 & 40.31 \\
\hline E.Volume & 42.57 & 0.60 & 0.54 & 42.25 \\
\hline E.Volume.pha & 42.18 & 0.60 & 0.54 & 41.58 \\
\hline All.sum.vol.pha & 42.76 & 0.60 & 0.54 & 41.05 \\
\hline T.av.inc & 16.55 & 0.57 & 0.51 & 12.22 \\
\hline All.Sum.DBH & 32.33 & 0.54 & 0.51 & 36.15 \\
\hline E.Increment.pha & 17.74 & 0.57 & 0.50 & 23.00 \\
\hline T.sum.car.soil & 47.27 & 0.57 & 0.50 & 42.32 \\
\hline All.Av.DBH & 39.20 & 0.53 & 0.50 & 26.39 \\
\hline E.sum.car & 46.80 & 0.56 & 0.49 & 40.32 \\
\hline E.sum.litter.pha & 47.46 & 0.56 & 0.49 & 43.29 \\
\hline E.sum.car.pha & 46.98 & 0.56 & 0.49 & 43.08 \\
\hline E.av.inc & 12.44 & 0.56 & 0.49 & 9.53 \\
\hline E.sum.dbh & 29.57 & 0.56 & 0.49 & 34.02 \\
\hline T.av.inc.pha & 15.61 & 0.55 & 0.48 & 12.91 \\
\hline T.sum.dbh & 23.60 & 0.51 & 0.47 & 33.46 \\
\hline E.av.inc.pha & 12.61 & 0.53 & 0.46 & 8.45 \\
\hline E.sum.inc.pha & 19.48 & 0.53 & 0.46 & 22.15 \\
\hline E.sum.under.pha & 44.17 & 0.53 & 0.45 & 39.66 \\
\hline T.av.vol & 42.73 & 0.53 & 0.45 & 40.10 \\
\hline E.Sum.BA & 17.01 & 0.49 & 0.41 & 14.25 \\
\hline
\end{tabular}




\begin{tabular}{|c|c|c|c|c|}
\hline All.Sum.BA & 14.78 & 0.48 & 0.40 & 15.02 \\
\hline E.sum.inc & 13.89 & 0.47 & 0.39 & 21.10 \\
\hline E.Increment & 12.75 & 0.47 & 0.39 & 23.23 \\
\hline T.sum.inc & 14.12 & 0.47 & 0.38 & 22.17 \\
\hline E.sum.ba.ha & 15.71 & 0.46 & 0.38 & 15.81 \\
\hline T.sum.inc.pha & 13.55 & 0.43 & 0.35 & 19.59 \\
\hline T.sum.ba.ha & 17.90 & 0.41 & 0.32 & 17.26 \\
\hline T.Sum.BA & 16.56 & 0.39 & 0.29 & 15.15 \\
\hline All.Sum.Ba.ha & 16.58 & 0.34 & 0.23 & 17.30 \\
\hline All.av.inc.pha & 7.68 & 0.23 & 0.17 & 6.42 \\
\hline All.sum.inc & -16.04 & 0.13 & 0.07 & -11.22 \\
\hline All.sum.inc.pha & -15.16 & 0.14 & 0.01 & -8.75 \\
\hline
\end{tabular}


Table 17. Forest inventory using Pleiades for oak

\begin{tabular}{|c|c|c|c|c|}
\hline Pleiades_oak & $\mathbf{r F}$ & $\begin{array}{c}\text { Multiple } \\
\mathbf{R}^{\mathbf{2}}\end{array}$ & $\begin{array}{c}\text { Adjusted } \\
\mathbf{R}^{\mathbf{2}}\end{array}$ & yai \\
\hline E.tpha & 50.10 & 0.85 & 0.83 & 27.86 \\
\hline T.tpha & 47.52 & 0.83 & 0.80 & 30.46 \\
\hline E.Tree & 48.85 & 0.80 & 0.77 & 27.56 \\
\hline T.Tree & 47.05 & 0.79 & 0.76 & 27.16 \\
\hline All.av.vol & 45.95 & 0.77 & 0.74 & 29.05 \\
\hline All.Sum.DBH & 43.24 & 0.75 & 0.71 & 26.62 \\
\hline E.sum.dbh & 43.18 & 0.73 & 0.69 & 25.54 \\
\hline T.sum.dbh & 34.19 & 0.73 & 0.68 & 25.86 \\
\hline All.tpha & 39.39 & 0.71 & 0.66 & 24.86 \\
\hline E.Increment.pha & 19.82 & 0.62 & 0.55 & 10.29 \\
\hline All.Tree & 46.01 & 0.60 & 0.54 & 24.84 \\
\hline T.av.dbh & 23.45 & 0.55 & 0.48 & 18.59 \\
\hline T.av.above & 29.99 & 0.54 & 0.47 & 14.99 \\
\hline T.av.gen.pha & 29.00 & 0.54 & 0.47 & 13.59 \\
\hline T.av.car.pha & 28.19 & 0.54 & 0.47 & 14.37 \\
\hline T.sum.vol & 29.81 & 0.54 & 0.46 & 13.83 \\
\hline T.av.car.soil & 29.32 & 0.53 & 0.46 & 14.67 \\
\hline E.sum.inc.pha & 19.14 & 0.53 & 0.46 & 9.19 \\
\hline E.av.inc & 4.54 & 0.53 & 0.45 & 4.72 \\
\hline T.av.car & 30.18 & 0.52 & 0.45 & 13.25 \\
\hline T.av.under & 29.02 & 0.52 & 0.44 & 14.06 \\
\hline E.av.car.soil.pha & 27.43 & 0.51 & 0.43 & 13.47 \\
\hline E.av.litter & 28.08 & 0.51 & 0.43 & 12.45 \\
\hline T.Av.BA & 24.74 & 0.51 & 0.43 & 16.80 \\
\hline E.av.vol.pha & 26.18 & 0.51 & 0.43 & 12.24 \\
\hline & & & & \\
\hline & & & \\
\hline
\end{tabular}




\begin{tabular}{|c|c|c|c|c|}
\hline T.av.under.pha & 28.12 & 0.50 & 0.43 & 13.33 \\
\hline E.av.gen.pha & 26.33 & 0.50 & 0.42 & 12.86 \\
\hline T.av.litter.pha & 30.09 & 0.50 & 0.42 & 14.80 \\
\hline T.av.inc & 6.09 & 0.50 & 0.42 & 3.13 \\
\hline E.av.above.pha & 28.15 & 0.50 & 0.42 & 11.43 \\
\hline T.av.litter & 29.68 & 0.50 & 0.42 & 16.28 \\
\hline E.Av.BA & 24.44 & 0.49 & 0.41 & 13.48 \\
\hline E.av.car.pha & 26.89 & 0.49 & 0.41 & 12.62 \\
\hline E.av.under.pha & 27.28 & 0.49 & 0.40 & 12.63 \\
\hline T.av.vol.pha & 29.26 & 0.48 & 0.39 & 13.96 \\
\hline T.av.above.pha & 29.29 & 0.47 & 0.39 & 16.18 \\
\hline T.av.gen & 29.24 & 0.47 & 0.39 & 14.55 \\
\hline T.av.car.soil.pha & 28.49 & 0.47 & 0.39 & 13.81 \\
\hline T.av.ba.ha & 25.16 & 0.46 & 0.37 & 18.10 \\
\hline All.Av.DBH & 10.46 & 0.45 & 0.37 & 1.47 \\
\hline E.av.above & 27.84 & 0.45 & 0.36 & 12.28 \\
\hline E.av.inc.pha & 4.81 & 0.45 & 0.36 & 6.17 \\
\hline E.av.gen & 27.50 & 0.45 & 0.36 & 12.52 \\
\hline E.av.car & 28.41 & 0.45 & 0.36 & 12.53 \\
\hline E.av.litter.pha & 27.24 & 0.45 & 0.36 & 13.80 \\
\hline E.av.vol & 26.86 & 0.45 & 0.36 & 14.77 \\
\hline E.av.ba.ha & 23.96 & 0.45 & 0.36 & 15.64 \\
\hline E.av.under & 26.21 & 0.45 & 0.36 & 11.98 \\
\hline E.Volume & 1.95 & 0.43 & 0.34 & -4.14 \\
\hline E.av.car.soil & 27.88 & 0.43 & 0.34 & 10.80 \\
\hline All.av.gen & 17.23 & 0.43 & 0.34 & 7.73 \\
\hline All.av.car & 17.15 & 0.43 & 0.34 & 8.92 \\
\hline All.sum.above.pha & 4.71 & 0.42 & 0.33 & -2.51 \\
\hline All.av.vol.pha & 17.07 & 0.42 & 0.33 & 7.56 \\
\hline & & & & \\
\hline
\end{tabular}




\begin{tabular}{|c|c|c|c|c|}
\hline All.av.inc & 11.16 & 0.41 & 0.32 & 9.02 \\
\hline T.sum.inc & 19.06 & 0.41 & 0.31 & 9.46 \\
\hline All.av.ba.ha & 12.37 & 0.38 & 0.28 & 8.26 \\
\hline E.av.dbh & 28.25 & 0.38 & 0.28 & 16.08 \\
\hline T.av.inc.pha & 6.49 & 0.33 & 0.26 & 8.24 \\
\hline All.av.inc.pha & 3.17 & 0.36 & 0.26 & 0.69 \\
\hline All.Av.BA & 12.39 & 0.36 & 0.26 & 6.48 \\
\hline E.sum.gen & 4.85 & 0.36 & 0.26 & -3.63 \\
\hline All.av.above & 18.46 & 0.36 & 0.25 & 9.37 \\
\hline All.av.car.pha & 18.09 & 0.36 & 0.25 & 9.15 \\
\hline T.sum.under.pha & 3.54 & 0.35 & 0.25 & -8.11 \\
\hline E.sum.inc & 20.02 & 0.35 & 0.25 & 8.49 \\
\hline E.Increment & 20.46 & 0.35 & 0.25 & 11.47 \\
\hline All.sum.vol.pha & 2.20 & 0.35 & 0.25 & -9.23 \\
\hline All.sum.vol & 9.16 & 0.34 & 0.24 & -3.23 \\
\hline All.av.under & 16.37 & 0.34 & 0.24 & 8.79 \\
\hline T.sum.vol.pha & 2.35 & 0.33 & 0.23 & -6.43 \\
\hline All.sum.gen & 4.27 & 0.31 & 0.22 & -4.24 \\
\hline All.sum.gen.pha & 4.12 & 0.33 & 0.22 & -0.48 \\
\hline E.sum.under.pha & 2.32 & 0.31 & 0.20 & -7.57 \\
\hline All.av.litter & 16.89 & 0.31 & 0.20 & 8.40 \\
\hline All.av.litter.pha & 18.24 & 0.31 & 0.20 & 10.42 \\
\hline T.sum.car.pha & 4.13 & 0.31 & 0.20 & -2.76 \\
\hline All.sum.litter.pha & 4.20 & 0.31 & 0.20 & -6.50 \\
\hline All.sum.car.pha & 5.62 & 0.31 & 0.20 & -3.78 \\
\hline T.sum.gen & 3.68 & 0.31 & 0.20 & -5.93 \\
\hline T.sum.above.pha & 5.18 & 0.25 & 0.20 & -1.24 \\
\hline E.sum.above.pha & 5.55 & 0.31 & 0.20 & -4.24 \\
\hline T.sum.above & 5.43 & 0.30 & 0.19 & -4.37 \\
\hline & & & & \\
\hline & & & \\
\hline
\end{tabular}




\begin{tabular}{|c|c|c|c|c|}
\hline All.av.under.pha & 14.02 & 0.30 & 0.19 & 7.80 \\
\hline E.sum.car & 5.20 & 0.30 & 0.19 & -2.77 \\
\hline E.sum.vol & 1.71 & 0.30 & 0.19 & -5.23 \\
\hline All.sum.car.soil.pha & 4.77 & 0.30 & 0.18 & -3.31 \\
\hline All.sum.litter & 4.34 & 0.29 & 0.18 & -4.29 \\
\hline All.sum.above & 3.83 & 0.29 & 0.18 & -5.68 \\
\hline All.av.above.pha & 18.89 & 0.29 & 0.18 & 8.29 \\
\hline All.av.car.soil & 18.79 & 0.29 & 0.17 & 9.47 \\
\hline All.av.car.soil.pha & 18.16 & 0.29 & 0.17 & 7.05 \\
\hline E.sum.car.pha & 4.37 & 0.29 & 0.17 & -2.42 \\
\hline E.sum.litter & 5.44 & 0.28 & 0.17 & -3.76 \\
\hline All.sum.car & 4.18 & 0.28 & 0.17 & -6.47 \\
\hline T.sum.litter & 4.07 & 0.28 & 0.17 & -3.82 \\
\hline T.sum.car & 5.16 & 0.28 & 0.17 & -5.21 \\
\hline E.sum.car.soil.pha & 3.64 & 0.28 & 0.17 & -4.22 \\
\hline E.sum.litter.pha & 4.23 & 0.23 & 0.16 & -5.90 \\
\hline All.av.gen.pha & 17.72 & 0.27 & 0.16 & 8.51 \\
\hline E.sum.vol.pha & 1.96 & 0.27 & 0.16 & -8.17 \\
\hline All.sum.under & 2.58 & 0.27 & 0.15 & -4.60 \\
\hline E.Volume.pha & 2.53 & 0.27 & 0.15 & -2.86 \\
\hline T.sum.litter.pha & 3.91 & 0.26 & 0.14 & -6.45 \\
\hline E.sum.under & 2.51 & 0.26 & 0.14 & -5.83 \\
\hline E.sum.gen.pha & 4.46 & 0.26 & 0.14 & -3.06 \\
\hline T.sum.car.soil & 5.51 & 0.26 & 0.14 & -2.74 \\
\hline T.sum.gen.pha & 3.58 & 0.26 & 0.14 & -2.15 \\
\hline E.sum.above & 4.59 & 0.26 & 0.14 & -2.52 \\
\hline T.sum.car.soil.pha & 5.48 & 0.26 & 0.14 & -3.43 \\
\hline E.sum.car.soil & 4.51 & 0.25 & 0.13 & -4.60 \\
\hline All.sum.car.soil & 4.58 & 0.25 & 0.13 & -2.93 \\
\hline
\end{tabular}




\begin{tabular}{|c|c|c|c|c|}
\hline T.sum.ba.ha & -9.94 & 0.25 & 0.13 & -12.25 \\
\hline T.sum.inc.pha & 19.17 & 0.25 & 0.13 & 8.95 \\
\hline T.sum.under & 2.48 & 0.24 & 0.12 & -6.90 \\
\hline All.sum.under.pha & 1.76 & 0.23 & 0.10 & -7.12 \\
\hline T.av.vol & 2.30 & 0.22 & 0.10 & -5.44 \\
\hline E.sum.ba.ha & -9.68 & 0.22 & 0.10 & -15.07 \\
\hline E.Sum.BA & -10.03 & 0.22 & 0.09 & -13.35 \\
\hline All.Sum.Ba.ha & -8.14 & 0.19 & 0.06 & -15.05 \\
\hline All.Sum.BA & -9.90 & 0.17 & 0.04 & -12.64 \\
\hline All.sum.inc.pha & -15.72 & 0.16 & 0.03 & -13.11 \\
\hline T.Sum.BA & -9.26 & 0.12 & -0.02 & -12.45 \\
\hline All.sum.inc & -15.95 & 0.08 & -0.06 & -12.23 \\
\hline
\end{tabular}


Table 18. Forest inventory using Pleiades for pine

\begin{tabular}{|c|c|c|c|c|}
\hline Plei_Pine & $\mathbf{r F}$ & Multiple $\mathbf{R}^{\mathbf{2}}$ & $\begin{array}{c}\text { Adjusted } \\
\mathbf{R}^{\mathbf{2}}\end{array}$ & yai \\
\hline All.av.car.soil & 6.52 & 0.70 & 0.65 & -12.24 \\
\hline All.av.gen.pha & 7.57 & 0.70 & 0.65 & -13.46 \\
\hline All.av.car.pha & 5.60 & 0.70 & 0.65 & -15.36 \\
\hline All.av.car.soil.pha & 6.92 & 0.70 & 0.65 & -13.29 \\
\hline E.sum.dbh & 38.18 & 0.69 & 0.64 & 29.94 \\
\hline T.sum.inc.pha & 31.04 & 0.64 & 0.59 & 14.15 \\
\hline All.sum.inc & 29.11 & 0.64 & 0.58 & 29.63 \\
\hline All.Sum.DBH & 34.56 & 0.64 & 0.57 & 29.53 \\
\hline T.sum.inc & 29.88 & 0.64 & 0.57 & 32.85 \\
\hline E.sum.inc.pha & 30.38 & 0.63 & 0.57 & 31.65 \\
\hline All.sum.inc.pha & 27.72 & 0.63 & 0.57 & 32.87 \\
\hline E.sum.inc & 31.58 & 0.62 & 0.55 & 31.49 \\
\hline All.av.vol & -1.13 & 0.61 & 0.54 & -15.97 \\
\hline All.av.vol.pha & 0.93 & 0.61 & 0.54 & -15.11 \\
\hline E.av.litter & 7.39 & 0.59 & 0.52 & -11.84 \\
\hline E.av.gen & 6.05 & 0.59 & 0.52 & -12.73 \\
\hline E.av.car.soil & 5.39 & 0.59 & 0.52 & -10.96 \\
\hline T.Tree & 27.95 & 0.58 & 0.51 & 19.45 \\
\hline T.tpha & 30.05 & 0.58 & 0.51 & 19.39 \\
\hline All.av.above.pha & 9.36 & 0.57 & 0.50 & -11.98 \\
\hline E.Tree & 30.19 & 0.57 & 0.49 & 17.07 \\
\hline E.tpha & 27.59 & 0.57 & 0.49 & 16.14 \\
\hline All.av.litter.pha & 6.07 & 0.53 & 0.45 & -10.42 \\
\hline E.Increment & 13.48 & 0.51 & 0.42 & 14.33 \\
\hline All.tpha & 3.16 & 0.50 & 0.41 & 0.99 \\
\hline & & & & \\
\hline & & & & \\
\hline
\end{tabular}




\begin{tabular}{|c|c|c|c|c|}
\hline All.av.gen & 7.87 & 0.50 & 0.41 & -13.02 \\
\hline All.av.car & 7.49 & 0.50 & 0.41 & -12.57 \\
\hline E.Increment.pha & 13.12 & 0.48 & 0.39 & 15.08 \\
\hline E.av.above.pha & 6.30 & 0.46 & 0.36 & -12.77 \\
\hline All.Sum.Ba.ha & 7.84 & 0.45 & 0.35 & 7.06 \\
\hline E.av.litter.pha & 6.98 & 0.45 & 0.35 & -11.88 \\
\hline T.av.vol.pha & 3.28 & 0.44 & 0.34 & -12.56 \\
\hline E.av.car.soil.pha & 7.22 & 0.43 & 0.33 & -11.54 \\
\hline All.av.under & 2.91 & 0.43 & 0.32 & -7.51 \\
\hline E.av.car.pha & 6.78 & 0.42 & 0.32 & -13.00 \\
\hline E.av.inc & -5.62 & 0.42 & 0.32 & -11.61 \\
\hline T.sum.dbh & 39.56 & 0.42 & 0.32 & 31.89 \\
\hline E.av.above & 8.64 & 0.42 & 0.32 & -10.87 \\
\hline E.sum.under.pha & 0.23 & 0.42 & 0.31 & -6.13 \\
\hline T.Sum.BA & 6.90 & 0.41 & 0.31 & 8.40 \\
\hline E.av.car & 5.93 & 0.41 & 0.30 & -15.20 \\
\hline T.sum.vol & 0.82 & 0.41 & 0.30 & -5.51 \\
\hline T.av.vol & 3.49 & 0.41 & 0.30 & -12.10 \\
\hline T.sum.vol.pha & 2.11 & 0.40 & 0.29 & -4.80 \\
\hline All.av.under.pha & 0.78 & 0.40 & 0.29 & -15.85 \\
\hline All.Tree & 3.05 & 0.39 & 0.28 & 1.38 \\
\hline E.av.under.pha & 1.66 & 0.37 & 0.26 & -14.61 \\
\hline E.av.under & 2.60 & 0.36 & 0.25 & -12.41 \\
\hline E.sum.under & 0.51 & 0.36 & 0.25 & -8.62 \\
\hline T.av.inc & -4.25 & 0.35 & 0.24 & -6.28 \\
\hline E.sum.car.soil.pha & 0.17 & 0.35 & 0.23 & -11.39 \\
\hline T.sum.gen.pha & -12.40 & 0.34 & 0.23 & -7.35 \\
\hline E.sum.gen.pha & 1.24 & 0.34 & 0.23 & -14.54 \\
\hline All.sum.under.pha & 1.21 & 0.33 & 0.22 & -7.19 \\
\hline & & & & \\
\hline
\end{tabular}




\begin{tabular}{|c|c|c|c|c|}
\hline T.sum.ba.ha & 8.02 & 0.33 & 0.22 & 6.50 \\
\hline E.sum.vol.pha & -5.15 & 0.27 & 0.21 & -11.16 \\
\hline E.sum.vol & 0.73 & 0.32 & 0.20 & -8.34 \\
\hline E.av.gen.pha & 6.66 & 0.32 & 0.20 & -10.58 \\
\hline T.sum.litter & -11.60 & 0.32 & 0.20 & -7.47 \\
\hline T.sum.car.pha & -10.98 & 0.32 & 0.20 & -8.03 \\
\hline E.Volume & 2.22 & 0.27 & 0.19 & -13.04 \\
\hline T.sum.above & -13.60 & 0.25 & 0.19 & -7.82 \\
\hline T.sum.car & -9.45 & 0.25 & 0.19 & -6.56 \\
\hline E.sum.gen & 0.04 & 0.31 & 0.19 & -13.06 \\
\hline All.av.inc & -9.74 & 0.31 & 0.18 & -3.14 \\
\hline E.av.inc.pha & -4.44 & 0.31 & 0.18 & -7.98 \\
\hline All.Sum.BA & 8.54 & 0.30 & 0.18 & 8.50 \\
\hline All.sum.car.soil.pha & 1.21 & 0.30 & 0.18 & -12.87 \\
\hline E.sum.above & 0.59 & 0.30 & 0.17 & -11.32 \\
\hline All.sum.under & -1.22 & 0.29 & 0.16 & -8.44 \\
\hline All.sum.vol & 0.63 & 0.28 & 0.16 & -8.33 \\
\hline All.sum.vol.pha & -0.46 & 0.28 & 0.16 & -8.98 \\
\hline E.sum.litter & -0.16 & 0.22 & 0.16 & -14.06 \\
\hline E.sum.car.soil & 1.23 & 0.22 & 0.16 & -11.75 \\
\hline E.sum.litter.pha & 0.72 & 0.22 & 0.16 & -10.50 \\
\hline E.sum.car.pha & 0.13 & 0.22 & 0.16 & -12.44 \\
\hline T.sum.car.soil.pha & -12.22 & 0.28 & 0.15 & -8.40 \\
\hline E.Sum.BA & 8.25 & 0.27 & 0.14 & 4.42 \\
\hline T.sum.above.pha & -12.30 & 0.27 & 0.14 & -8.47 \\
\hline T.sum.gen & -13.89 & 0.20 & 0.14 & -7.42 \\
\hline E.Volume.pha & 1.43 & 0.19 & 0.13 & -12.22 \\
\hline E.sum.above.pha & 0.97 & 0.25 & 0.12 & -13.38 \\
\hline All.sum.above.pha & 0.10 & 0.25 & 0.12 & -13.36 \\
\hline & & & & \\
\hline
\end{tabular}




\begin{tabular}{|c|c|c|c|c|}
\hline All.sum.litter & 0.33 & 0.25 & 0.12 & -12.93 \\
\hline All.sum.gen & 0.41 & 0.25 & 0.12 & -13.45 \\
\hline All.sum.car.soil & 0.60 & 0.25 & 0.12 & -8.98 \\
\hline All.sum.car.pha & 1.25 & 0.25 & 0.12 & -12.32 \\
\hline All.sum.litter.pha & 0.35 & 0.25 & 0.12 & -11.59 \\
\hline All.sum.above & 0.23 & 0.25 & 0.12 & -13.34 \\
\hline All.av.litter & 0.99 & 0.25 & 0.11 & -10.68 \\
\hline All.sum.car & 1.24 & 0.24 & 0.11 & -11.19 \\
\hline T.av.ba.ha & -7.85 & 0.18 & 0.11 & -18.30 \\
\hline T.sum.car.soil & -9.65 & 0.24 & 0.10 & -6.22 \\
\hline All.sum.gen.pha & 1.36 & 0.24 & 0.10 & -12.20 \\
\hline E.av.vol.pha & 1.78 & 0.17 & 0.10 & -16.84 \\
\hline T.sum.litter.pha & -13.04 & 0.23 & 0.10 & -7.13 \\
\hline T.av.above & 16.10 & 0.22 & 0.09 & -4.97 \\
\hline T.av.above.pha & 13.15 & 0.22 & 0.09 & -5.93 \\
\hline T.sum.under & -3.95 & 0.15 & 0.08 & -6.61 \\
\hline T.av.dbh & -3.94 & 0.22 & 0.08 & -15.45 \\
\hline T.av.gen & 13.07 & 0.22 & 0.08 & -5.69 \\
\hline T.av.litter.pha & 13.61 & 0.22 & 0.08 & -6.55 \\
\hline T.Av.BA & -5.40 & 0.15 & 0.08 & -16.16 \\
\hline T.av.inc.pha & -5.54 & 0.22 & 0.08 & -12.85 \\
\hline T.av.gen.pha & 11.81 & 0.21 & 0.07 & -6.48 \\
\hline T.av.car.pha & 13.49 & 0.21 & 0.07 & -6.06 \\
\hline All.Av.DBH & -9.92 & 0.21 & 0.07 & -7.29 \\
\hline T.av.under & 8.98 & 0.20 & 0.06 & -7.07 \\
\hline E.sum.ba.ha & 8.24 & 0.20 & 0.06 & 5.56 \\
\hline T.av.litter & 12.91 & 0.20 & 0.06 & -5.16 \\
\hline T.av.car.soil & 13.01 & 0.20 & 0.06 & -3.38 \\
\hline T.av.car & 11.06 & 0.20 & 0.06 & -5.49 \\
\hline & & & & \\
\hline
\end{tabular}




\begin{tabular}{|c|c|c|c|c|}
\hline E.sum.car & 1.40 & 0.20 & 0.06 & -11.58 \\
\hline E.Av.BA & -6.36 & 0.20 & 0.06 & -14.05 \\
\hline T.av.under.pha & 11.29 & 0.19 & 0.05 & -7.35 \\
\hline T.av.car.soil.pha & 11.97 & 0.19 & 0.04 & -5.85 \\
\hline T.sum.under.pha & -6.13 & 0.19 & 0.04 & -4.52 \\
\hline E.av.dbh & -4.62 & 0.11 & 0.03 & -16.84 \\
\hline All.av.ba.ha & -8.11 & 0.17 & 0.02 & -16.86 \\
\hline All.av.above & 5.43 & 0.17 & 0.02 & -9.95 \\
\hline All.Av.BA & -7.52 & 0.17 & 0.02 & -17.33 \\
\hline All.av.inc.pha & -9.57 & 0.16 & 0.01 & -0.34 \\
\hline E.av.vol & 0.57 & 0.15 & 0.01 & -13.33 \\
\hline E.av.ba.ha & -8.41 & 0.02 & -0.06 & -11.62 \\
\hline
\end{tabular}


Table 19. Forest Inventory using Göktürk-2 for pine

\begin{tabular}{|c|c|c|c|c|}
\hline Göktürk_Pine & rF & Multiple R & Adjusted $\mathbf{R}^{\mathbf{2}}$ & yai \\
\hline All.av.gen & 4.56 & 0.68 & 0.63 & -5.22 \\
\hline All.av.gen.pha & 5.10 & 0.68 & 0.63 & -4.87 \\
\hline All.av.above.pha & 6.18 & 0.64 & 0.58 & -6.33 \\
\hline All.Sum.DBH & 20.09 & 0.64 & 0.57 & 19.39 \\
\hline All.av.car & 7.32 & 0.63 & 0.57 & -7.30 \\
\hline All.av.car.soil & 2.24 & 0.63 & 0.57 & -7.60 \\
\hline All.av.under.pha & 5.18 & 0.61 & 0.54 & -5.38 \\
\hline All.av.vol & 3.24 & 0.59 & 0.52 & -10.24 \\
\hline All.av.vol.pha & 1.17 & 0.59 & 0.52 & -8.14 \\
\hline E.av.above.pha & 11.32 & 0.58 & 0.51 & -6.36 \\
\hline E.av.gen & 10.73 & 0.58 & 0.50 & -7.04 \\
\hline E.av.car.soil & 10.07 & 0.58 & 0.50 & -7.62 \\
\hline E.av.litter.pha & 9.96 & 0.58 & 0.50 & -7.04 \\
\hline All.av.litter.pha & 4.67 & 0.57 & 0.49 & -4.96 \\
\hline All.av.car.soil.pha & 4.82 & 0.57 & 0.49 & -5.55 \\
\hline T.av.above & 13.00 & 0.56 & 0.49 & -7.15 \\
\hline T.av.car.soil & 10.95 & 0.56 & 0.48 & -8.30 \\
\hline T.av.gen.pha & 10.54 & 0.56 & 0.48 & -5.77 \\
\hline T.av.car.pha & 11.02 & 0.56 & 0.48 & -6.11 \\
\hline All.av.under & 3.62 & 0.56 & 0.48 & -6.67 \\
\hline E.av.under & 10.15 & 0.54 & 0.46 & -9.25 \\
\hline E.av.under.pha & 8.72 & 0.54 & 0.46 & -7.91 \\
\hline E.av.car & 10.37 & 0.53 & 0.45 & -8.30 \\
\hline E.av.gen.pha & 10.45 & 0.53 & 0.45 & -7.78 \\
\hline E.av.car.soil.pha & 11.10 & 0.53 & 0.45 & -7.43 \\
\hline E.av.vol & 9.00 & 0.53 & 0.44 & -9.52 \\
\hline & & & & \\
\hline
\end{tabular}




\begin{tabular}{|c|c|c|c|c|}
\hline E.av.vol.pha & 9.69 & 0.53 & 0.44 & -8.48 \\
\hline All.sum.inc.pha & 21.93 & 0.52 & 0.44 & 13.88 \\
\hline E.sum.dbh & 24.42 & 0.52 & 0.44 & 17.76 \\
\hline T.sum.dbh & 24.63 & 0.52 & 0.43 & 21.63 \\
\hline T.av.under & 9.86 & 0.52 & 0.43 & -7.52 \\
\hline T.av.under.pha & 9.92 & 0.52 & 0.43 & -8.40 \\
\hline T.av.above.pha & 11.09 & 0.51 & 0.43 & -6.83 \\
\hline T.av.litter & 10.16 & 0.51 & 0.43 & -6.43 \\
\hline T.av.car.soil.pha & 11.11 & 0.51 & 0.43 & -7.67 \\
\hline T.Tree & 29.56 & 0.51 & 0.42 & 19.16 \\
\hline T.tpha & 29.05 & 0.51 & 0.42 & 19.86 \\
\hline T.av.vol & 10.07 & 0.50 & 0.42 & -8.13 \\
\hline T.av.vol.pha & 8.98 & 0.50 & 0.42 & -9.24 \\
\hline All.sum.under & 0.45 & 0.49 & 0.41 & -7.59 \\
\hline E.av.car.pha & 10.80 & 0.49 & 0.40 & -7.40 \\
\hline All.av.above & 4.19 & 0.49 & 0.40 & -5.54 \\
\hline T.av.gen & 10.80 & 0.48 & 0.39 & -7.68 \\
\hline T.av.litter.pha & 10.12 & 0.44 & 0.39 & -6.89 \\
\hline E.Tree & 29.28 & 0.48 & 0.39 & 14.87 \\
\hline E.tpha & 27.92 & 0.48 & 0.39 & 17.51 \\
\hline E.sum.inc & 21.16 & 0.48 & 0.38 & 15.86 \\
\hline T.sum.under & 2.20 & 0.48 & 0.38 & -6.92 \\
\hline E.av.above & 10.88 & 0.47 & 0.38 & -6.81 \\
\hline T.sum.inc.pha & 21.68 & 0.47 & 0.38 & 16.46 \\
\hline T.sum.inc & 22.09 & 0.47 & 0.37 & 16.06 \\
\hline All.sum.litter.pha & -3.91 & 0.47 & 0.37 & -9.33 \\
\hline T.sum.car.pha & -5.13 & 0.46 & 0.37 & -6.69 \\
\hline T.sum.vol.pha & 1.08 & 0.46 & 0.36 & -7.00 \\
\hline T.av.car & 11.82 & 0.46 & 0.36 & -5.69 \\
\hline
\end{tabular}




\begin{tabular}{|c|c|c|c|c|}
\hline E.av.ba.ha & 5.93 & 0.46 & 0.36 & -12.96 \\
\hline All.Sum.BA & 9.49 & 0.46 & 0.36 & 2.27 \\
\hline All.Sum.Ba.ha & 9.33 & 0.45 & 0.35 & 3.78 \\
\hline E.Increment & 20.43 & 0.45 & 0.35 & 5.45 \\
\hline E.av.inc.pha & 0.09 & 0.45 & 0.35 & -13.97 \\
\hline E.Increment.pha & 20.11 & 0.45 & 0.35 & 3.45 \\
\hline E.sum.under.pha & 0.45 & 0.44 & 0.34 & -5.47 \\
\hline T.sum.under.pha & 2.08 & 0.44 & 0.34 & -8.01 \\
\hline E.sum.ba.ha & 10.08 & 0.44 & 0.34 & 2.09 \\
\hline All.sum.inc & 21.99 & 0.43 & 0.33 & 14.47 \\
\hline E.Sum.BA & 9.49 & 0.43 & 0.32 & 2.92 \\
\hline E.Av.BA & 6.98 & 0.42 & 0.32 & -12.58 \\
\hline All.av.ba.ha & 9.54 & 0.42 & 0.32 & -9.37 \\
\hline All.Av.BA & 6.31 & 0.42 & 0.32 & -11.47 \\
\hline T.sum.gen & -2.48 & 0.41 & 0.31 & -6.84 \\
\hline T.sum.vol & 2.45 & 0.41 & 0.31 & -6.76 \\
\hline All.sum.car.pha & -2.87 & 0.41 & 0.30 & -9.09 \\
\hline E.sum.vol & 2.08 & 0.39 & 0.30 & -6.77 \\
\hline T.Av.BA & 4.99 & 0.40 & 0.29 & -13.07 \\
\hline E.sum.litter.pha & -4.17 & 0.38 & 0.29 & -10.56 \\
\hline E.sum.above.pha & -3.31 & 0.39 & 0.29 & -8.47 \\
\hline E.sum.gen & -5.15 & 0.39 & 0.28 & -7.17 \\
\hline All.sum.gen.pha & -2.33 & 0.37 & 0.28 & -10.33 \\
\hline T.Sum.BA & 9.18 & 0.38 & 0.27 & 3.95 \\
\hline All.av.inc.pha & 0.62 & 0.38 & 0.27 & -15.81 \\
\hline All.av.car.pha & 4.34 & 0.38 & 0.27 & -2.64 \\
\hline E.sum.vol.pha & 1.29 & 0.36 & 0.27 & -6.41 \\
\hline E.av.dbh & 3.35 & 0.37 & 0.26 & -13.69 \\
\hline T.sum.ba.ha & 9.46 & 0.37 & 0.25 & 5.72 \\
\hline
\end{tabular}




\begin{tabular}{|c|c|c|c|c|}
\hline All.sum.car.soil.pha & -2.63 & 0.35 & 0.24 & -8.74 \\
\hline All.sum.vol.pha & 2.36 & 0.35 & 0.23 & -6.61 \\
\hline T.av.ba.ha & 4.18 & 0.34 & 0.22 & -10.70 \\
\hline E.Volume.pha & 4.51 & 0.34 & 0.22 & -7.67 \\
\hline E.sum.car.soil & -5.42 & 0.34 & 0.22 & -8.93 \\
\hline E.sum.litter & -3.91 & 0.33 & 0.22 & -10.69 \\
\hline E.sum.under & -0.28 & 0.33 & 0.21 & -6.40 \\
\hline All.sum.under.pha & 0.95 & 0.33 & 0.21 & -6.77 \\
\hline E.av.litter & 10.24 & 0.32 & 0.20 & -7.30 \\
\hline T.av.dbh & 2.45 & 0.32 & 0.20 & -16.88 \\
\hline E.Volume & 5.03 & 0.32 & 0.20 & -8.70 \\
\hline All.av.inc & 0.38 & 0.31 & 0.19 & -15.08 \\
\hline T.sum.above.pha & -4.80 & 0.31 & 0.19 & -9.19 \\
\hline T.sum.litter & -3.53 & 0.31 & 0.19 & -9.64 \\
\hline T.sum.car.soil & -3.76 & 0.31 & 0.19 & -7.80 \\
\hline All.tpha & 14.80 & 0.31 & 0.19 & 4.43 \\
\hline E.sum.car.pha & -4.74 & 0.31 & 0.19 & -9.62 \\
\hline All.Tree & 13.30 & 0.31 & 0.18 & 4.38 \\
\hline E.sum.gen.pha & -4.09 & 0.31 & 0.18 & -8.95 \\
\hline T.sum.car.soil.pha & -4.63 & 0.30 & 0.18 & -9.33 \\
\hline All.sum.car & -3.80 & 0.30 & 0.18 & -9.49 \\
\hline T.sum.above & -5.00 & 0.30 & 0.18 & -9.01 \\
\hline E.sum.above & -3.21 & 0.30 & 0.18 & -10.08 \\
\hline All.sum.vol & 1.18 & 0.30 & 0.18 & -8.95 \\
\hline T.sum.litter.pha & -5.04 & 0.30 & 0.17 & -12.13 \\
\hline All.av.litter & -4.07 & 0.30 & 0.17 & -8.92 \\
\hline All.sum.car.soil & -3.22 & 0.29 & 0.16 & -9.46 \\
\hline All.sum.litter & -2.69 & 0.28 & 0.15 & -9.57 \\
\hline T.sum.gen.pha & -4.40 & 0.28 & 0.15 & -10.58 \\
\hline
\end{tabular}




\begin{tabular}{|c|c|c|c|c|}
\hline T.sum.car & -3.50 & 0.28 & 0.15 & -6.99 \\
\hline All.sum.above & -5.38 & 0.28 & 0.15 & -11.12 \\
\hline E.sum.car.soil.pha & -3.15 & 0.27 & 0.14 & -8.06 \\
\hline T.av.inc.pha & 0.79 & 0.25 & 0.12 & -14.69 \\
\hline All.sum.gen & -4.40 & 0.25 & 0.12 & -9.54 \\
\hline E.sum.inc.pha & 20.14 & 0.23 & 0.10 & 16.19 \\
\hline T.av.inc & 1.38 & 0.22 & 0.09 & -15.03 \\
\hline All.sum.above.pha & -3.42 & 0.22 & 0.08 & -10.29 \\
\hline E.av.inc & -0.74 & 0.21 & 0.08 & -12.84 \\
\hline All.Av.DBH & 1.12 & 0.17 & 0.03 & -7.10 \\
\hline E.sum.car & -5.01 & 0.13 & -0.02 & -11.07 \\
\hline
\end{tabular}


Table 20. Forest inventory using Göktürk-2 for oak

\begin{tabular}{|c|c|c|c|c|}
\hline Göktürk_Oak & $\mathbf{r F}$ & Multiple $\mathbf{R}^{2}$ & Adjusted $\mathbf{R}^{2}$ & yai \\
\hline E.Increment.pha & -4.18 & 0.70 & 0.65 & -0.65 \\
\hline T.sum.inc & -2.82 & 0.59 & 0.52 & -2.19 \\
\hline E.Increment & -2.90 & 0.52 & 0.44 & -1.67 \\
\hline T.Tree & 12.54 & 0.51 & 0.43 & -0.93 \\
\hline E.sum.inc & -3.74 & 0.44 & 0.35 & -4.63 \\
\hline T.sum.inc.pha & 0.15 & 0.42 & 0.33 & -3.17 \\
\hline E.av.inc.pha & 2.82 & 0.42 & 0.33 & -6.65 \\
\hline All.av.inc & 7.60 & 0.41 & 0.32 & 0.64 \\
\hline E.sum.inc.pha & -0.59 & 0.38 & 0.29 & -2.62 \\
\hline E.av.dbh & 14.37 & 0.38 & 0.28 & 1.75 \\
\hline E.Av.BA & 12.04 & 0.37 & 0.27 & 2.85 \\
\hline All.Av.BA & 6.46 & 0.37 & 0.27 & 1.76 \\
\hline T.tpha & 11.12 & 0.37 & 0.27 & 0.20 \\
\hline All.sum.vol & 8.75 & 0.35 & 0.25 & -3.51 \\
\hline E.Tree & 15.35 & 0.34 & 0.24 & -2.55 \\
\hline E.tpha & 15.22 & 0.34 & 0.24 & -0.12 \\
\hline E.av.under.pha & 14.10 & 0.34 & 0.24 & 1.18 \\
\hline All.sum.inc.pha & -29.98 & 0.34 & 0.23 & -14.05 \\
\hline All.av.inc.pha & 2.94 & 0.33 & 0.23 & -8.82 \\
\hline E.av.gen & 13.75 & 0.28 & 0.22 & 3.22 \\
\hline E.av.litter.pha & 13.77 & 0.28 & 0.22 & 2.29 \\
\hline All.av.car & 6.28 & 0.33 & 0.22 & 1.61 \\
\hline All.av.car.pha & 6.43 & 0.33 & 0.22 & 3.44 \\
\hline All.av.above & 5.21 & 0.33 & 0.22 & 0.14 \\
\hline All.Sum.DBH & 8.75 & 0.33 & 0.22 & -1.23 \\
\hline All.av.litter.pha & 5.50 & 0.32 & 0.21 & 1.85 \\
\hline
\end{tabular}




\begin{tabular}{|c|c|c|c|c|}
\hline E.sum.dbh & 8.49 & 0.31 & 0.20 & -3.24 \\
\hline All.av.vol & 10.98 & 0.31 & 0.20 & -2.42 \\
\hline All.tpha & 12.21 & 0.31 & 0.20 & -1.14 \\
\hline E.av.inc & 2.73 & 0.25 & 0.19 & -5.88 \\
\hline T.av.above & 17.08 & 0.30 & 0.18 & 4.71 \\
\hline T.av.car & 18.19 & 0.29 & 0.18 & 4.77 \\
\hline T.av.gen.pha & 17.80 & 0.29 & 0.18 & 4.47 \\
\hline T.av.under.pha & 18.10 & 0.29 & 0.18 & 3.34 \\
\hline All.av.ba.ha & 6.77 & 0.29 & 0.18 & 2.37 \\
\hline All.Tree & 9.71 & 0.29 & 0.18 & -1.07 \\
\hline All.Av.DBH & 3.14 & 0.29 & 0.18 & -2.59 \\
\hline E.av.litter & 14.82 & 0.29 & 0.17 & 1.84 \\
\hline T.av.inc & 0.13 & 0.23 & 0.17 & -4.64 \\
\hline E.av.vol.pha & 14.37 & 0.28 & 0.16 & 2.60 \\
\hline T.av.car.soil & 18.94 & 0.27 & 0.15 & 6.61 \\
\hline All.sum.above.pha & 7.82 & 0.21 & 0.15 & -7.75 \\
\hline T.sum.gen.pha & 6.96 & 0.21 & 0.15 & -8.95 \\
\hline T.sum.car.pha & 6.91 & 0.21 & 0.15 & -6.29 \\
\hline T.sum.car.soil.pha & 5.63 & 0.21 & 0.15 & -9.06 \\
\hline E.sum.above & 7.02 & 0.21 & 0.15 & -6.04 \\
\hline E.sum.above.pha & 6.60 & 0.21 & 0.15 & -7.03 \\
\hline All.sum.litter.pha & 7.08 & 0.21 & 0.15 & -7.67 \\
\hline All.sum.gen.pha & 7.18 & 0.21 & 0.15 & -7.38 \\
\hline E.sum.litter & 8.99 & 0.21 & 0.15 & -6.74 \\
\hline E.sum.gen & 6.58 & 0.21 & 0.15 & -6.71 \\
\hline E.sum.car & 6.56 & 0.21 & 0.15 & -8.61 \\
\hline E.sum.car.soil & 8.87 & 0.21 & 0.15 & -10.89 \\
\hline E.sum.litter.pha & 7.89 & 0.21 & 0.15 & -6.47 \\
\hline T.av.under & 19.30 & 0.26 & 0.15 & 4.56 \\
\hline
\end{tabular}




\begin{tabular}{|c|c|c|c|c|}
\hline T.av.dbh & 13.62 & 0.20 & 0.15 & 5.03 \\
\hline T.sum.ba.ha & -6.01 & 0.26 & 0.14 & -17.31 \\
\hline All.av.car.soil & 7.06 & 0.26 & 0.14 & 0.98 \\
\hline All.av.gen.pha & 7.16 & 0.26 & 0.14 & 1.79 \\
\hline All.av.under & 8.16 & 0.26 & 0.14 & 2.55 \\
\hline T.sum.dbh & 8.69 & 0.20 & 0.14 & -4.50 \\
\hline E.sum.ba.ha & -4.84 & 0.26 & 0.14 & -14.94 \\
\hline T.sum.under & 7.01 & 0.25 & 0.14 & -10.66 \\
\hline All.sum.under & 4.95 & 0.19 & 0.13 & -7.54 \\
\hline All.sum.under.pha & 6.02 & 0.19 & 0.13 & -8.71 \\
\hline E.sum.under.pha & 6.68 & 0.19 & 0.13 & -9.39 \\
\hline T.av.car.pha & 16.28 & 0.25 & 0.13 & 1.58 \\
\hline All.sum.vol.pha & 5.15 & 0.18 & 0.12 & -9.76 \\
\hline All.Sum.BA & -5.07 & 0.18 & 0.12 & -13.80 \\
\hline T.sum.above & 7.08 & 0.18 & 0.12 & -8.74 \\
\hline T.sum.above.pha & 7.23 & 0.18 & 0.12 & -7.30 \\
\hline All.sum.above & 6.51 & 0.18 & 0.12 & -7.45 \\
\hline T.sum.litter & 6.59 & 0.18 & 0.12 & -7.37 \\
\hline T.sum.gen & 6.24 & 0.18 & 0.12 & -8.01 \\
\hline T.sum.car & 7.40 & 0.18 & 0.12 & -7.81 \\
\hline T.sum.car.soil & 7.58 & 0.18 & 0.12 & -8.47 \\
\hline T.sum.litter.pha & 6.92 & 0.18 & 0.12 & -6.98 \\
\hline All.sum.litter & 8.14 & 0.18 & 0.12 & -8.02 \\
\hline All.sum.gen & 7.40 & 0.18 & 0.12 & -8.35 \\
\hline All.sum.car & 7.95 & 0.18 & 0.12 & -6.64 \\
\hline All.sum.car.soil & 7.23 & 0.18 & 0.12 & -10.90 \\
\hline All.sum.car.pha & 6.34 & 0.18 & 0.12 & -8.27 \\
\hline All.sum.car.soil.pha & 7.62 & 0.18 & 0.12 & -5.10 \\
\hline E.sum.gen.pha & 7.51 & 0.17 & 0.11 & -9.63 \\
\hline
\end{tabular}




\begin{tabular}{|c|c|c|c|c|}
\hline E.sum.car.pha & 7.44 & 0.17 & 0.11 & -8.48 \\
\hline E.sum.car.soil.pha & 6.35 & 0.17 & 0.11 & -7.53 \\
\hline E.av.under & 12.46 & 0.23 & 0.11 & 3.87 \\
\hline T.sum.under.pha & 6.26 & 0.17 & 0.11 & -9.57 \\
\hline E.sum.under & 5.05 & 0.17 & 0.10 & -11.66 \\
\hline T.av.vol & 6.58 & 0.16 & 0.10 & -10.13 \\
\hline T.sum.vol.pha & 6.20 & 0.16 & 0.10 & -9.61 \\
\hline E.sum.vol & 6.08 & 0.16 & 0.10 & -8.74 \\
\hline T.Sum.BA & -4.08 & 0.16 & 0.10 & -15.06 \\
\hline T.Av.BA & 16.51 & 0.22 & 0.10 & 6.23 \\
\hline All.Sum.Ba.ha & -4.64 & 0.15 & 0.09 & -15.55 \\
\hline T.av.litter & 17.72 & 0.15 & 0.09 & 2.35 \\
\hline T.av.gen & 19.70 & 0.15 & 0.09 & 3.22 \\
\hline E.av.above & 13.13 & 0.15 & 0.08 & 4.26 \\
\hline E.av.car & 13.61 & 0.15 & 0.08 & 2.92 \\
\hline E.av.car.soil & 13.27 & 0.15 & 0.08 & 0.03 \\
\hline E.av.gen.pha & 14.93 & 0.15 & 0.08 & 1.61 \\
\hline E.av.car.pha & 13.01 & 0.15 & 0.08 & 1.81 \\
\hline E.av.ba.ha & 13.61 & 0.15 & 0.08 & 3.68 \\
\hline E.Volume & 5.54 & 0.21 & 0.08 & -7.76 \\
\hline E.av.car.soil.pha & 14.29 & 0.15 & 0.08 & 1.52 \\
\hline T.sum.vol & 17.03 & 0.14 & 0.08 & 3.54 \\
\hline T.av.vol.pha & 18.97 & 0.14 & 0.08 & 1.77 \\
\hline T.av.inc.pha & 0.32 & 0.21 & 0.08 & -4.38 \\
\hline E.av.vol & 9.72 & 0.14 & 0.08 & 3.29 \\
\hline E.Sum.BA & -4.02 & 0.14 & 0.08 & -13.97 \\
\hline T.av.litter.pha & 18.42 & 0.13 & 0.07 & 3.79 \\
\hline T.av.car.soil.pha & 18.28 & 0.13 & 0.07 & 1.98 \\
\hline All.av.gen & 7.68 & 0.13 & 0.07 & 1.55 \\
\hline
\end{tabular}




\begin{tabular}{|c|c|c|c|c|}
\hline All.av.car.soil.pha & 6.98 & 0.13 & 0.07 & 0.21 \\
\hline All.sum.inc & -28.17 & 0.20 & 0.07 & -11.95 \\
\hline E.av.above.pha & 14.38 & 0.13 & 0.07 & 1.41 \\
\hline T.av.ba.ha & 17.10 & 0.19 & 0.07 & 6.86 \\
\hline E.sum.vol.pha & 5.90 & 0.19 & 0.07 & -9.49 \\
\hline E.Volume.pha & 6.15 & 0.19 & 0.07 & -6.39 \\
\hline T.av.above.pha & 18.32 & 0.15 & 0.06 & 4.45 \\
\hline All.av.above.pha & 5.71 & 0.10 & 0.04 & 1.82 \\
\hline All.av.litter & 6.48 & 0.10 & 0.04 & 0.98 \\
\hline All.av.under.pha & 6.14 & 0.10 & 0.03 & 1.83 \\
\hline All.av.vol.pha & 5.39 & 0.10 & 0.03 & 0.70 \\
\hline
\end{tabular}

